\title{
jen
}

INSTITUTO DE PESQUISAS ENERGÉTICAS E NUCLEARES

Autarquia Associada à Universidade de São Paulo

Caracterização radioisotópica dos filtros de purificação da água do circuito primário do reator IEA-R1, e efluentes líquidos eventualmente liberados, por meio de técnicas radioanalíticas de separação para a determinação dos radionuclídeos de difícil medição e fatores de escala

\section{BIANCA GERALDO}

Tese apresentada como parte dos requisitos para obtenção do Grau de Doutor em Ciências na Área de Tecnologia Nuclear - Aplicações

Orientador:

Prof. Dr. Júlio Takehiro Marumo

Coorientador:

Prof. Dr. Roberto Vicente 


\section{INSTITUTO DE PESQUISAS ENERGÉTICAS E NUCLEARES \\ Autarquia Associada à Universidade de São Paulo}

Caracterização radioisotópica dos filtros de purificação da água do circuito primário do reator IEA-R1, e efluentes líquidos eventualmente liberados, por meio de técnicas radioanalíticas de separação para a determinação dos radionuclídeos de difícil medição e fatores de escala

Versão Corrigida

Versão Original disponível no IPEN

BIANCA GERALDO

Tese apresentada como parte dos requisitos para obtenção do Grau de Doutor em Ciências na Área de Tecnologia Nuclear - Aplicações

Orientador:

Prof. Dr. Júlio Takehiro Marumo Coorientador:

Prof. Dr. Roberto Vicente 
Fonte de Financiamento: Bolsa Institucional - Quota IPEN

Autorizo a reprodução e divulgação total ou parcial deste trabalho, para fins de estudo e pesquisa, desde que citada a fonte

Como citar:

GERALDO, B. Caracterização radioisotópica dos filtros de purificação da água do circuito primário do reator IEA-R1, e efluentes líquidos eventualmente liberados, por meio de técnicas radioanalíticas de separação para a determinação dos radionuclídeos de difícil medição e fatores de escala. 2018. 80 p. Tese (Doutorado em Tecnologia Nuclear), Instituto de Pesquisas Energéticas e Nucleares, IPEN-CNEN/SP, São Paulo. Disponível em: (data de consulta no formato: $\mathrm{dd} / \mathrm{mm} / \mathrm{aaaa}$ )

Ficha catalográfica elaborada pelo Sistema de geração automática da Biblioteca IPEN/USP, com os dados fornecidos pelo(a) autor(a)

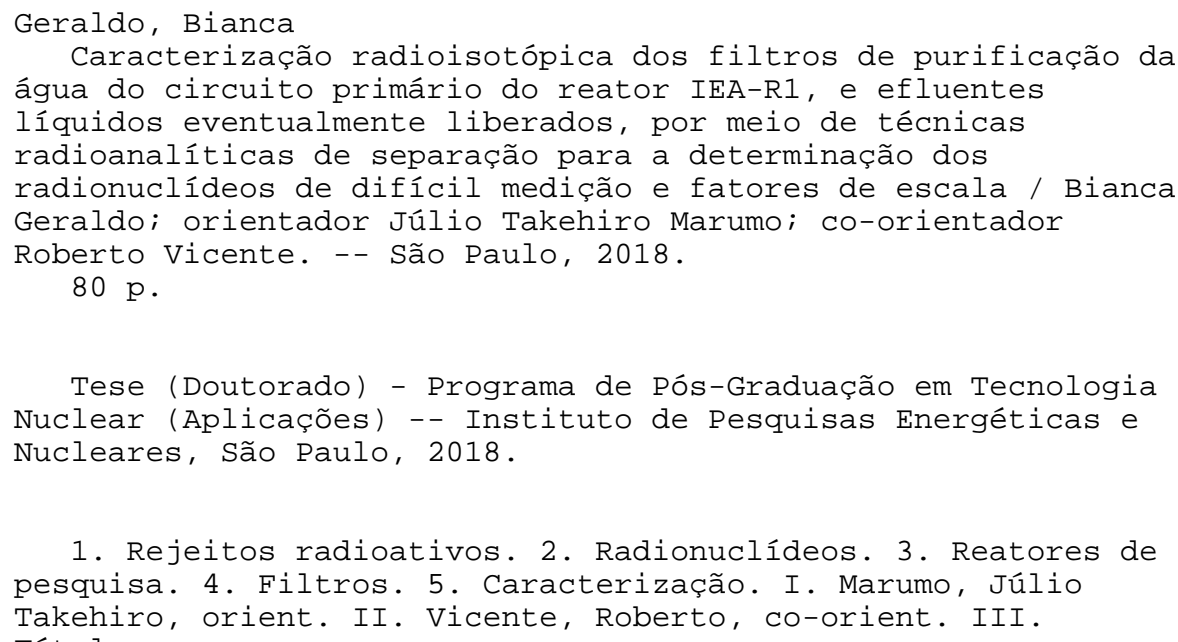


A Deus,

Aos meus pais, Claudemir e Elizabeti. 


\section{AGRADECIMENTOS}

A Deus pela realização deste trabalho, pois sem o seu consentimento este não teria sido realizado;

Ao Dr. Júlio Takehiro Marumo, meu orientador, pela constante dedicação, confiança, paciência e pelo apoio e orientação ao longo do desenvolvimento deste trabalho;

Ao Dr. Roberto Vicente, meu coorientador, pela imensurável ajuda com o entendimento da teoria e dos cálculos, e pelas incansáveis discussões sobre o trabalho;

À Maria Helena T. Taddei, a quem eu admiro pelo seu conhecimento, sua postura e portadora de uma grande capacidade de ensinar, pelas discussões e conselhos sempre pertinentes e importantes no desenvolvimento deste trabalho, por sempre abrir as portas do seu laboratório para mim, meus experimentos e minhas dúvidas. A ela agradeço por ter-me aceito e mostrado um novo caminho, acreditando sempre que pudesse trilhá-lo com sucesso;

Aos meus pais, por acreditarem sempre em mim, pelo incentivo constante, compreensão e por estarem sempre presentes em todos os momentos da minha vida;

Aos meus irmãos Paloma e Guilherme, pela amizade, confiança, amor e incentivo;

Ao Jonas, que sempre esteve do meu lado, acreditando em mim, me apoiando e incentivando, foi meu maior motivador, minha referência, pessoa na qual eu me espelho quando penso em ser melhor;

Aos membros da banca examinadora: Dra. Adir Janete Godoy, Dra. Clédola Cássia de Tello, Dra. Sandra Damatto, Dr. Paulo Cardoso;

Aos membros suplentes da banca examinadora: Dra. Carolina Freire, Dra. Luciana Farias, Dr. José Cláudio Dellamano e Dr. Marcelo Máduar;

Aos amigos e colegas da Gerência de Rejeitos Radioativos pelo auxílio, apoio e incentivo: Hissae, Sílvia, Ademar, Cláudio, Juscelino, Marcos, Ricardo, Robson, Valmir e em especial o Dr. Goro pela inestimável ajuda, amizade e incansáveis discussões sobre o trabalho;

A amiga leda, pela amizade e prontidão para me ajudar em tudo que fosse necessário; 
Aos amigos e colegas do Laboratório de Poços de Caldas pelo auxílio, apoio, incentivo e por sempre me receberem de braços abertos, sempre dispostos a ensinar e ajudar, e em especial à Sandra, Marcelo e Mychelle pela ajuda incomensurável, amizade e dedicação no decorrer deste trabalho;

Aos amigos Ana Paula, Leandro, Ludmila, Natalie, Patrícia e Priscila pela amizade, disposição em ajudar sempre e pela agradável companhia nas horas de descontração;

Aos amigos Daiane e Eduardo pela amizade e pela dedicação ao trabalho, colaboraram de forma preciosa, lendo, revisando, sugerindo e discutindo sobre o trabalho;

Aos colegas Sandra Damatto, Felipe Lourenço Borges, Marcelo Bessa e Marcelo Máduar pela amizade, colaboração no desenvolvimento do trabalho e por serem sempre tão solícitos em todas as vezes que eu precisei de ajuda;

À Dra. Marina Koskinas pela amizade e pela inestimável ajuda com o preparo dos padrões;

À equipe do Laboratório de Análises Químicas e Ambiental (LAQA) do departamento Centro de Química e Meio Ambiente (CQMA) do IPEN, pela realização das análises de $\mathrm{Ni}$ estável;

À USP, IPEN, Gerência de Rejeitos Radioativos e LAPOC pela oportunidade de realização deste curso;

Ao IPEN pela bolsa de estudos concedida e por todos auxílios para apresentação de trabalho em congresso;

Enfim, a todos que de alguma maneira contribuíram para a realização deste trabalho. 
"Nem tudo que conta pode ser contado, e nem tudo que é contado, verdadeiramente conta." (Albert Einstein) 


\section{RESUMO}

GERALDO, B. Caracterização radioisotópica dos filtros de purificação da água do circuito primário do reator IEA-R1, e efluentes líquidos eventualmente liberados, por meio de técnicas radioanalíticas de separação para a determinação dos radionuclídeos de difícil medição e fatores de escala. 2018. 81 p. Tese (Doutorado em Tecnologia Nuclear) - Instituto de Pesquisas Energéticas e Nucleares - IPEN-CNEN/SP. São Paulo.

Técnicas radioquímicas de separação têm sido comumente utilizadas para a caracterização de rejeitos radioativos. No entanto, a determinação de radionuclídeos emissores alfa, beta e gama por análise radioquímica, em amostras de filtro cartucho utilizado no processo de retratamento da água de um reator do tipo piscina, não foi abordada anteriormente na literatura. Este trabalho tem como objetivo estabelecer um método de solubilização para os filtros, identificar e quantificar os radionuclídeos presentes nestes rejeitos, sendo eles os Radionuclídeos Chaves (RC) $\left({ }^{60} \mathrm{Co},{ }^{108 \mathrm{~m}} \mathrm{Ag},{ }^{110 \mathrm{~m}} \mathrm{Ag}\right)$ e principalmente os Radionuclídeos de Difícil Medição (RDM) $\left({ }^{63} \mathrm{Ni},{ }^{90} \mathrm{Sr},{ }^{234} \mathrm{U},{ }^{235} \mathrm{U},{ }^{238} \mathrm{U},{ }^{238} \mathrm{Pu}\right.$, ${ }^{239+240} \mathrm{Pu},{ }^{241} \mathrm{Pu},{ }^{241} \mathrm{Am},{ }^{242} \mathrm{Cm}$ e ${ }^{243+244} \mathrm{Cm}$ ), para posterior aplicação do método de Fator de Escala $(\mathrm{FE})$ no trabalho rotineiro de caracterização de rejeitos radioativos. A distribuição dos radionuclídeos no filtro cartucho foi investigada pela determinação dos radionuclídeos emissores gama e os resultados obtidos foram utilizados para calcular o escore-Z. Os resultados indicaram que todos os filtros podem ser considerados homogêneos, atendendo aos critérios de homogeneidade recomendados pela Agência Internacional de Energia Atômica (AIEA), e com isso foi possível definir a quantidade de amostras representativas a serem analisadas. Foram determinados, a partir de dados analíticos, a correlação existente entre os RDMs e RCs selecionados e foram obtidos FEs para todos os RDMs, com exceção do ${ }^{241} \mathrm{Pu}$.

Palavras-chave: Rejeitos radioativos; Radionuclídeos; Reatores de pesquisa, Filtros e Caracterização. 


\begin{abstract}
GERALDO, B. Radioisotopic characterization of the water purification filters of the primary circuit of the IEA-R1 reactor, and eventually released liquid effluents, using radioanalytical separation techniques for the determination of difficult-to-measure radionuclides and scaling factors. 2018. Tese (Doutorado em Tecnologia Nuclear) - Instituto de Pesquisas Energéticas e Nucleares - IPEN-CNEN/SP. São Paulo.
\end{abstract}

Separation radiochemical techniques have been commonly used for the characterization of radioactive waste. However, the determination of alpha, beta and gamma emitting radionuclides by radiochemical analysis in cartridge filter samples used in the water re-treatment process of a pool-type reactor was not previously discussed in the literature. This work aims to establish a method of solubilization for the filters, to identify and quantify the radionuclides present in these wastes, being the Key Nuclides $(\mathrm{KN})\left({ }^{60} \mathrm{Co},{ }^{108 \mathrm{~m}} \mathrm{Ag},{ }^{110 \mathrm{~m}} \mathrm{Ag}\right)$ and especially the Difficult To Measure radionuclides (DTM) ( ${ }^{63} \mathrm{Ni},{ }^{90} \mathrm{Sr},{ }^{234} \mathrm{U},{ }^{235} \mathrm{U},{ }^{238} \mathrm{U},{ }^{238} \mathrm{Pu},{ }^{239+240} \mathrm{Pu},{ }^{241} \mathrm{Pu},{ }^{241} \mathrm{Am}$, ${ }^{242} \mathrm{Cm}$ and ${ }^{243+244} \mathrm{Cm}$ ), for later application of the Scaling Factors (SF) method in routine radioactive waste characterization work. The distribution of the radionuclides in the cartridge filter was investigated by determination of gamma-emitting radionuclides and the results obtained were used to calculate the Z-score. The results indicated that all the filters can be considered homogeneous, according to the criteria of homogeneity recommended by the International Atomic Energy Agency (IAEA), and with this it was possible to define the quantity of representative samples to be analyzed. From the analytical data, the correlation between the DTMs and the selected KNs was determined and the SFs were obtained for all the DTMs, except for the ${ }^{241} \mathrm{Pu}$.

Key words: Radioactive waste, Radionuclides, Research reactors, Filters, Characterization. 


\section{LISTA DE TABELAS}

Página

Tabela 1-Resinas comercializadas pela Eichrom Technologies, LLC ..............................27

Tabela 2-Atividades de ${ }^{60} \mathrm{Co},{ }^{63} \mathrm{Ni},{ }^{90} \mathrm{Sr}$ e ${ }^{108 \mathrm{~m}} \mathrm{Ag}$ nas amostras de filtro ...........................6 65

Tabela 3-Atividades de ${ }^{110 \mathrm{~m}} \mathrm{Ag},{ }^{234} \mathrm{U},{ }^{235} \mathrm{U}$ e ${ }^{238} \mathrm{U}$ nas amostras de filtro ............................6 66

Tabela 4-Atividades de ${ }^{238} \mathrm{Pu},{ }^{239+240} \mathrm{Pu}$ e ${ }^{241} \mathrm{Pu}$ nas amostras de filtro .............................67

Tabela 5-Atividades de ${ }^{241} \mathrm{Am},{ }^{242} \mathrm{Cm}$ e ${ }^{243+244} \mathrm{Cm}$ nas amostras de filtro........................... 68

Tabela 6-Valores médios dos Fatores de Escala e valores da dispersão $2 \sigma$ obtidos para os filtros 


\section{LISTA DE FIGURAS}

Página

Figura 1-Plano de caracterização para inventário 19

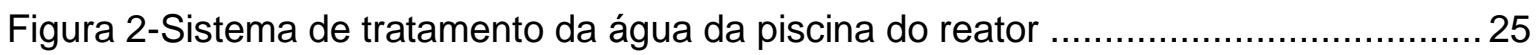

Figura 3-Esquema adotado na amostragem dos cartuchos de filtro ................................ 32

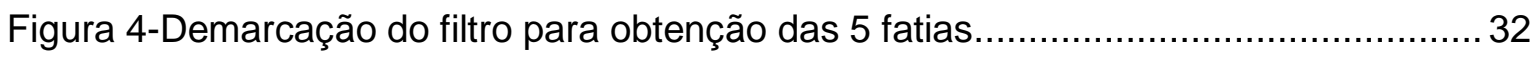

Figura 5-Amostras de filtro já cortadas e embaladas ......................................................3

Figura 6-Fluxograma de separação dos isótopos de U, Pu, Am e Cm .............................. 38

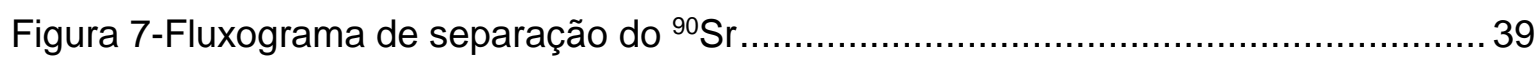

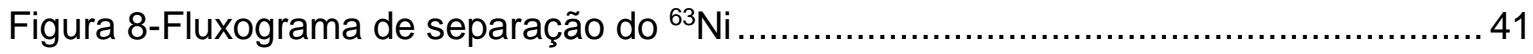

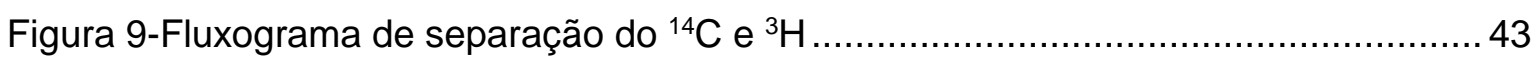

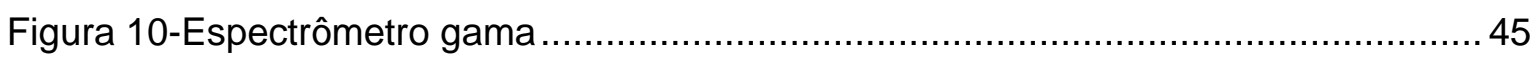

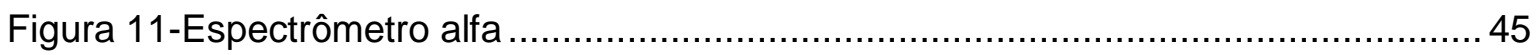

Figura 12-Espectrômetro de cintilação em meio líquido ................................................. 46

Figura 13-Espectro gama de Co e Ag obtido como resultado de medida com duração de 35000 segundos em amostra de filtro.......................................................... 53

Figura 14-Avaliação da homogeneidade do filtro 5 , utilizando valores de escore-Z.........54

Figura 15-Avaliação da homogeneidade do filtro 6, utilizando valores de escore-Z..........55

Figura 16-Avaliação da homogeneidade do filtro 7, utilizando valores de escore-Z.........55

Figura 17-Avaliação da homogeneidade do filtro 8, utilizando valores de escore-Z.........56

Figura 18-Avaliação da homogeneidade do filtro 9, utilizando valores de escore-Z.........56

Figura 19-Avaliação da homogeneidade do filtro 10, utilizando valores de escore-Z.......57

Figura 20-Avaliação da homogeneidade do filtro 12, utilizando valores de escore-Z........57

Figura 21-Avaliação da homogeneidade do filtro 15 , utilizando valores de escore-Z.......58

Figura 22-(A) fatia do filtro homogêneo, (B) fatia do filtro heterogêneo............................59

Figura 23-Espectro alfa de U obtido como resultado de medida com duração de 200040

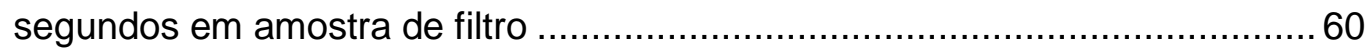

Figura 24-Espectro alfa de Pu obtido como resultado de medida com duração de 200040

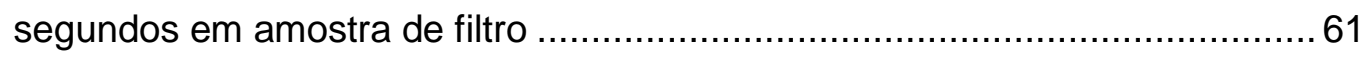

Figura 25-Espectro alfa e beta de ${ }^{241} \mathrm{Pu}$ obtido como resultado de medida com duração de



Figura 26-Espectro alfa de $\mathrm{Am}$ e $\mathrm{Cm}$ obtido como resultado de medida com duração de 200040 segundos em amostra de filtro.....

Figura 27-Espectro beta de Sr obtido como resultado de medida com duração de 14400

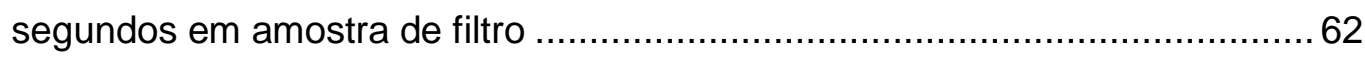

Figura 28-Espectro beta de Ni obtido como resultado de medida com duração de 3600 segundos em amostra de filtro 


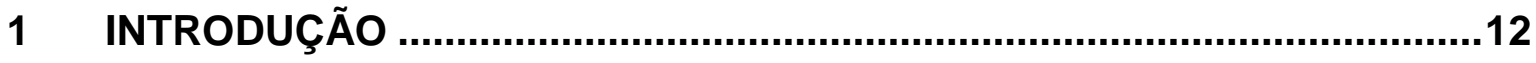

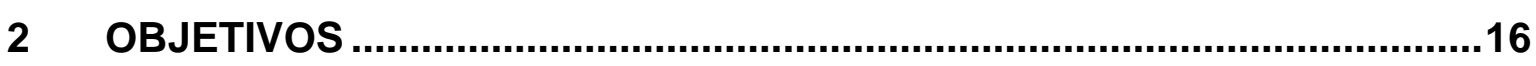

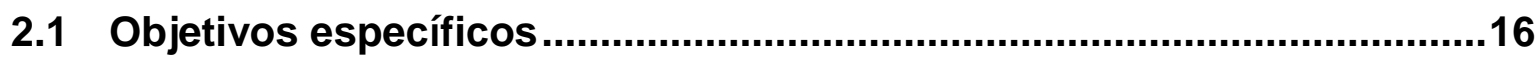

3 REVISÃO BIBLIOGRÁFICA …...........................................................17

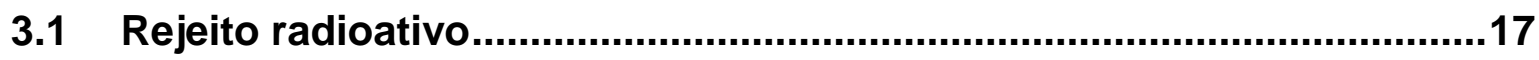

3.2 Classificação dos rejeitos radioativos...................................................17

3.3 Gerência de rejeitos radioativos .............................................................19

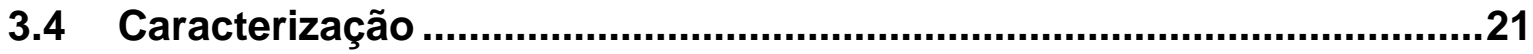

3.5 Reator nuclear de pesquisas - IEA-R1 ..................................................23

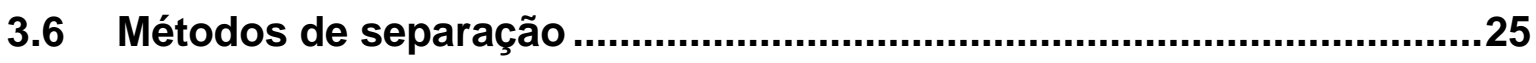

4 METODOLOGIA



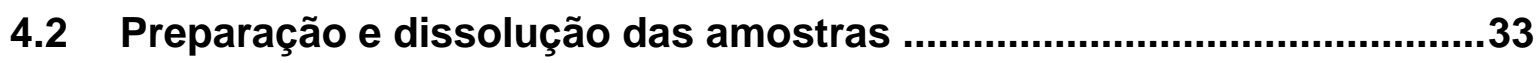

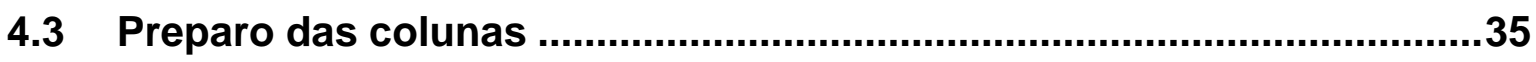

4.4 Determinação dos isótopos de U, Pu, Am e $\mathrm{Cm}$.......................................35



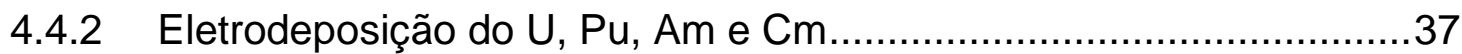

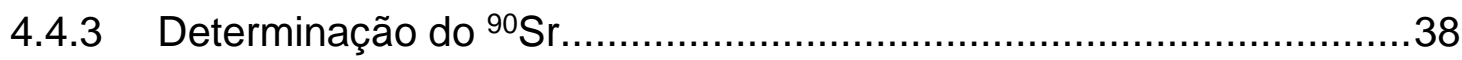

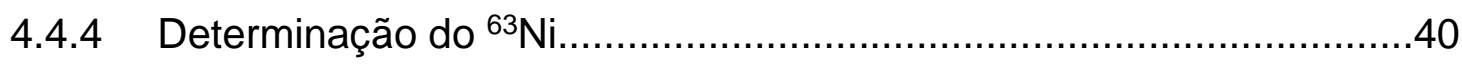

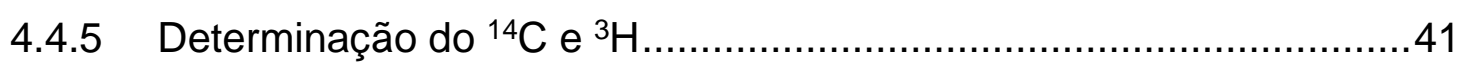

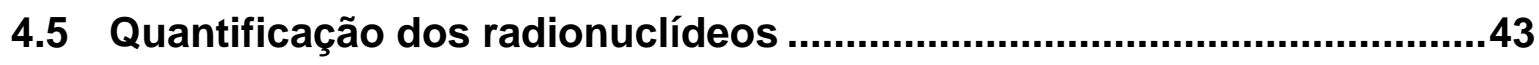

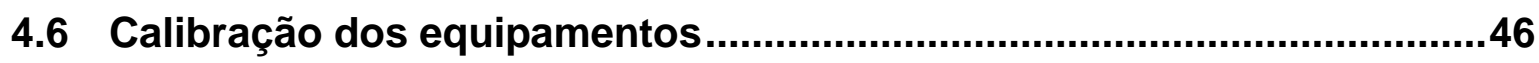

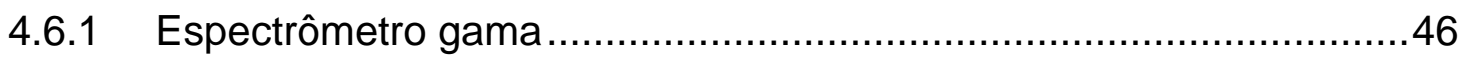

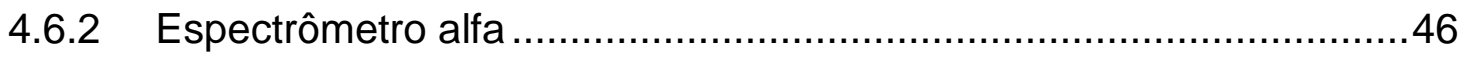

4.6.3 Espectrômetro de cintilação em meio líquido ......................................46

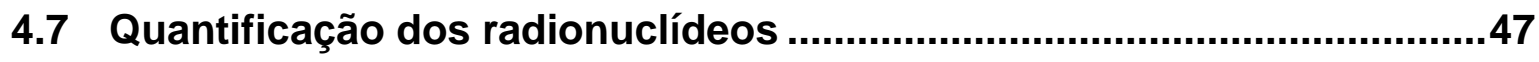

4.7.1 Radionuclídeos emissores gama .................................................. 47

4.7.2 Radionuclídeos emissores alfa ................................................4 
4.7.3 Radionuclídeos emissores beta ..............................................48

4.7.4 Cálculo da Atividade Mínima Detectável (MDA)..............................49

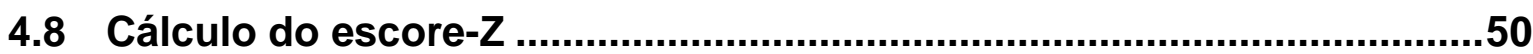

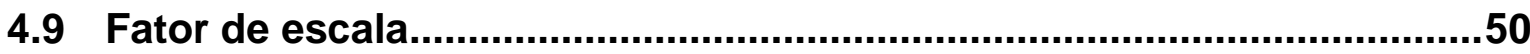

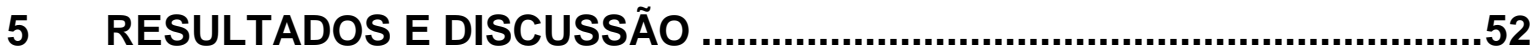

5.1 Homogeneidade dos filtros...............................................................52

5.2 Separação radioquímica dos radionuclídeos emissores alfa ..................59

5.3 Atividades dos radionuclídeos nas amostras.......................................64

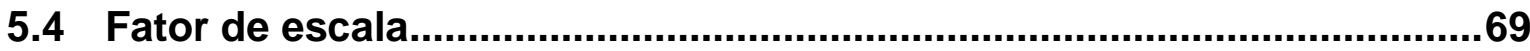

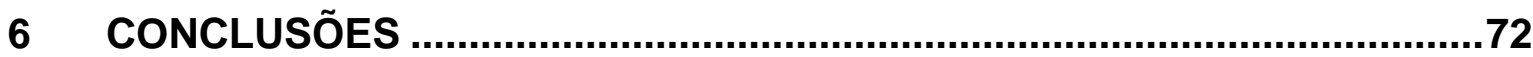

REFERÊNCIAS BIBLIOGRÁFICAS............................................................. 


\section{INTRODUÇÃO}

Durante a operação de reatores nucleares são gerados diversos tipos de rejeitos radioativos no tanque de resfriamento, que podem ser agrupados de acordo com sua forma física, em: sólidos, líquidos e gasosos. Os radionuclídeos presentes nestes rejeitos têm meias-vidas curtas e média e alta radiotoxicidade, os quais são produzidos por ativação neutrônica de elementos não radioativos, como os produtos de corrosão dos materiais estruturais ou impurezas do fluído refrigerante. Além deles, são gerados produtos de fissão que escapam das varetas combustíveis quando há falha no revestimento, ou que são provenientes da fissão do urânio presente como contaminante na superfície externa do elemento combustível.

Além disto, são gerados rejeitos radioativos sólidos, pelo re-tratamento da água de refrigeração, os quais são constituídos de materiais de proteção individual, material de limpeza, ferramentas, materiais estruturais contaminados, filtros para retenção de aerossóis e gases utilizados no sistema de ventilação do reator, filtros de carvão ativado provenientes do sistema de purificação do refrigerante, resinas de troca iônica do sistema de tratamento da água da piscina de estocagem de elementos combustíveis queimados e os concentrados de evaporador provenientes do tratamento de rejeitos líquidos. Os rejeitos radioativos líquidos são provenientes de atividades de descontaminação de componentes estruturais, pisos e roupas. Já os rejeitos radioativos gasosos, são gerados no núcleo do reator devido à formação de produtos de fissão gasosos, os quais migram do elemento combustível para a água de refrigeração, onde permanecem dissolvidos. Durante o tratamento da água, os rejeitos gasosos provenientes do sistema de exaustão do vaso de contenção do reator são coletados em tanques para tratamento, os quais são coletados conjuntamente por um sistema de exaustão, formando um único fluxo de rejeitos gasosos constituídos de vapores, partículas em suspensão, aerossóis e gases inertes que passa por um sistema de filtração para reter possíveis contaminantes (HIROMOTO et al., 1999).

Para o gerenciamento desses rejeitos no Brasil, a AIEA e a CNEN propuseram um sistema de classificação no qual os rejeitos são subdivididos considerando-se os níveis de radiação, sendo, deste modo, classificados como rejeitos de nível baixo, médio ou alto e por meias-vida curta, média e alta. A gerência de rejeitos envolve várias atividades e dentre elas a caracterização 
primária é uma que merece destaque, pois indica se o rejeito é isento e pode ser liberado para o meio ambiente ou se é rejeito radioativo e deve ser confinado e de que forma estes procedimentos devem ser conduzidos (HIROMOTO et al., 1999, IAEA, 2003, CNEN, 2014).

O Instituto de Pesquisas Energéticas e Nucleares (IPEN), localizado em São Paulo, no campus da Universidade de São Paulo (USP), possui um reator nuclear de pesquisa, o IEA-R1, que é do tipo piscina, de 5 MW de potência, moderado e refrigerado a água leve.

O objeto de estudo deste trabalho é o cartucho de filtro proveniente do processo de purificação da água do reator nuclear de pesquisas IEA-R1, uma vez que é substituído com mais frequência e em cada troca são retirados seis cartuchos. São realizadas seis trocas por ano, gerando 36 unidades (LONGO, 2014) e uma grande quantidade deste material encontra-se armazenado no depósito da Gerência de Rejeitos Radioativos (GRR) do IPEN, aguardando a caracterização radioisotópica.

Estabelecer uma metodologia de análise radioquímica para este tipo de rejeito é uma tarefa difícil, não somente pela aplicação das técnicas de separação, mas também pela quantidade de radionuclídeos que devem ser analisados. Além disso, não há na literatura muitos relatos de trabalhos de caracterização de filtro proveniente de reatores nucleares. Os trabalhos disponíveis abordam somente a caracterização de matrizes como resíduo do tanque de armazenamento, água proveniente da produção do combustível nuclear, resina de troca iônica, concentrados do evaporador, resíduo de metal proveniente do reator, lodo radioativo, entre outros.

Nos rejeitos produzidos em um reator nuclear, os radionuclídeos mais comuns são: produtos de fissão $\left({ }^{90} \mathrm{Sr},{ }^{99} \mathrm{Tc},{ }^{129} \mathrm{I},{ }^{134} \mathrm{Cs},{ }^{137} \mathrm{Cs}\right)$, produtos de ativação $\left({ }^{3} \mathrm{H},{ }^{14} \mathrm{C},{ }^{54} \mathrm{Mn},{ }^{55} \mathrm{Fe},{ }^{59} \mathrm{Ni},{ }^{60} \mathrm{Co},{ }^{63} \mathrm{Ni},{ }^{94} \mathrm{Nb}\right)$ e transurânicos $\left({ }^{241} \mathrm{Am},{ }^{242} \mathrm{Cm},{ }^{243} \mathrm{Cm}\right.$, ${ }^{244} \mathrm{Cm}$ e os isótopos de $\mathrm{U}$ e $\mathrm{Pu}$ ). Uma vez que vários desses radionuclídeos não emitem radiação gama mensurável no seu processo de decaimento e suas análises envolvem métodos complexos, eles são considerados radionuclídeos de difícil medição, mas as suas concentrações podem ser estimadas por métodos indiretos como fatores de escala (US NRC, 1982; KEKKI e TIITTA, 2000).

No geral, a abordagem é determinar empiricamente os Fatores de Escala (FE) ou Funções de Correlação (FC) que correlacionam as concentrações 
dos principais radionuclídeos, também chamados de Radionuclídeos Chave (RC), que são os emissores gama fortes, facilmente mensuráveis, como ${ }^{60} \mathrm{Co}$ e ${ }^{137} \mathrm{Cs}$, com as concentrações dos Radionuclídeos Difíceis de Medir (RDM), que são os emissores gama fracos, os emissores beta e alfa puros. Nos casos em que os métodos FE ou FC são inaplicáveis, as concentrações são determinadas por análise radioquímica de amostras de rejeitos. Alguns Radionuclídeos são de Impossível Medição (RIM), mesmo em um laboratório, com as tecnologias usuais disponíveis atualmente. A metodologia de FE pode determinar a radioatividade de RDM e RIM, utilizando correlações entre eles e os RC escolhidos entre os Radionuclídeos de Fácil Medição (RFM).

Uma vez resolvido o problema dos métodos radioquímicos usados para determinar as atividades dos RC e dos RDM nos cartuchos de filtro, resta a questão de verificar a consistência dos resultados das medições e dos cálculos de inventário, não só desse fluxo de rejeito, como também daqueles que foram objeto de estudos anteriores. Para isso, pode ser efetivo comparar as razões entre as atividades totais de todos os radionuclídeos presentes em todos os rejeitos e as razões esperadas por considerações teóricas, as probabilidades das reações de fissão, por exemplo.

É possível que efluentes líquidos liberados para o ambiente durante a operação do reator carreguem parte da atividade desses radionuclídeos e, para se fechar o balanço de massa do sistema, devem ser considerados. Os efluentes gasosos podem ser desconsiderados para essa finalidade, em razão das atividades serem, usualmente, muito baixas, tendo em vista a experiência de operação não indicar contaminação do ar em níveis detectáveis. A determinação do inventário radioisotópico dos efluentes, seja por meio de análise radioquímica de amostras, seja por meio de cálculo usando os fatores de escala, segue o mesmo processo apresentado anteriormente em um estudo (TADDEI, 2013).

Desta forma, este trabalho focou no desenvolvimento de uma metodologia para caracterização radioisotópica dos filtros utilizados em reatores de pesquisa, visando o estabelecimento de FEs, sendo o primeiro a abordar esta metodologia de caracterização para os filtros do reator IEA-R1.

Por fim, destaque deve ser dado à importância do desenvolvimento de métodos radioanalíticos para caracterização de rejeitos para consolidação do 
programa nuclear brasileiro, uma vez que auxiliará no estabelecimento de um sistema nacional de gerenciamento de rejeitos radioativos. 


\section{OBJETIVOS}

O objetivo deste trabalho foi desenvolver uma metodologia para a caracterização radioisotópica dos filtros utilizados no processo de purificação da água do circuito primário do reator IEA-R1, por meio de técnicas radioanalíticas de separação para a determinação dos RDMs e a determinação dos FEs, visando a avaliação do inventário radioisotópico do termo fonte para um repositório.

\subsection{Objetivos específicos}

$\checkmark$ Estabelecer um método de solubilização para o filtro;

$\checkmark$ Analisar a homogeneidade dos filtros após a sua solubilização;

$\checkmark$ Determinar, a partir de dados analíticos, a correlação existente entre os RDMs $\left({ }^{3} \mathrm{H},{ }^{14} \mathrm{C},{ }^{63} \mathrm{Ni},{ }^{90} \mathrm{Sr},{ }^{234} \mathrm{U},{ }^{235} \mathrm{U},{ }^{238} \mathrm{U},{ }^{238} \mathrm{Pu},{ }^{239+240} \mathrm{Pu},{ }^{241} \mathrm{Pu},{ }^{241} \mathrm{Am},{ }^{242} \mathrm{Cm} \mathrm{e}^{243+244} \mathrm{Cm}\right)$ e os RCs ( ${ }^{60} \mathrm{Co},{ }^{108 \mathrm{~m}} \mathrm{Ag},{ }^{110 \mathrm{~m}} \mathrm{Ag}$ e $\left.{ }^{137} \mathrm{Cs}\right)$ selecionados. 


\section{REVISÃo BIBLIOGRÁFICA}

\subsection{Rejeito radioativo}

De acordo com a Agência Internacional de Energia Atômica (AIEA), rejeito radioativo é definido como "qualquer material que contenha ou esteja contaminado com radionuclídeos em concentrações ou valores de atividade maiores que os limites de isenção estabelecidos pela autoridade competente" (IAEA, 2003).

No Brasil, a Comissão Nacional de Energia Nuclear (CNEN) o define como "qualquer material resultante de atividades humanas que contenha radionuclídeos em quantidades superiores aos limites de isenção estabelecidos pela CNEN, para qual a reutilização é imprópria ou não prevista" (CNEN, 2015).

O termo "limite de isenção", aplicado aos rejeitos, pode ser compreendido como sendo o nível de atividade abaixo do qual o órgão regulador considera que os riscos correspondentes são insignificantes e não requerem controle (HIROMOTO et al., 1999).

\subsection{Classificação dos rejeitos radioativos}

De acordo com CNEN (2014a; 2014b) os rejeitos radioativos são classificados segundo seus níveis e natureza da radiação, bem como suas meiasvidas:

I - Classe 0: Rejeitos Isentos (RI): são rejeitos que contêm radionuclídeos com valores de atividade ou de concentração de atividade, em massa ou volume, inferiores ou iguais aos respectivos níveis de dispensa estabelecidos na Norma;

II - Classe 1: Rejeitos de Meia-Vida Muito Curta (RVMC): são os rejeitos que têm meia-vida inferior ou da ordem de 100 dias, com níveis de atividade ou de concentração em atividade superiores aos respectivos níveis de dispensa;

III - Classe 2: Rejeitos de Baixo e Médio Níveis de Radiação (RBMN): são os rejeitos que tem meia-vida superior à dos rejeitos da Classe 1 , com níveis de atividade ou de concentração em atividade superiores aos níveis de dispensa estabelecidos na Norma, bem como com potência térmica inferior a $2 \mathrm{~kW} \mathrm{.} \mathrm{m}^{-3}$;

IV - Classe 2.1: Meia-Vida Curta (RBMN - VC): são os rejeitos de baixo e médio níveis de radiação contendo emissores beta/gama, com meia-vida inferior ou da ordem de 30 anos e com concentração de radionuclídeos emissores alfa de 
meia-vida longa limitada em $3700 \mathrm{kBq} \cdot \mathrm{kg}^{-1}$ em volumes individuais e com um valor médio de $370 \mathrm{kBq} \cdot \mathrm{kg}^{-1}$ para o conjunto de volumes;

V - Classe 2.2: Rejeitos contendo Radionuclídeos Naturais (RBMN - RNp): são os rejeitos de baixo e médio níveis de radiação, provenientes de extração e exploração de petróleo, contendo radionuclídeos das séries do urânio e tório em concentrações de atividade ou atividades acima dos níveis de dispensa estabelecidos na Norma;

VI - Classe 2.3: Rejeitos contendo Radionuclídeos Naturais (RBMN - RNm): são os rejeitos que contêm matérias-primas minerais, naturais ou industrializadas, com radionuclídeos das séries do urânio e tório em concentrações de atividade ou atividades acima dos níveis de dispensa estabelecidos na Norma;

VII - Classe 2.4: Rejeitos de Meia-Vida Longa (RBMN - VL): são os rejeitos que não estão enquadrados nas Classes 2.2 e 2.3, com concentrações de radionuclídeos de meia-vida longa que excedem as limitações para classificação como rejeitos de meia-vida curta;

VIII - Classe 3: Rejeitos de Alto Nível de Radiação (RAN): são os rejeitos que têm potência térmica superior a $2 \mathrm{~kW} \cdot \mathrm{m}^{-3}$ e com concentrações de radionuclídeos de meia-vida longa que excedam as limitações para classificação como rejeitos de meia-vida curta.

Segundo HIROMOTO et al. (1999), os rejeitos radioativos podem ser classificados de acordo com a sua origem, sendo divididos em três grupos:

I - Rejeitos Institucionais: são aqueles gerados na produção e aplicação de radioisótopos na indústria, clínicas médicas, hospitais, centros de pesquisa, agricultura, entre outros;

II - Rejeitos do Ciclo do Combustível: são gerados durante as etapas do ciclo de fabricação e utilização do combustível nuclear, desde a mineração até o reprocessamento, ciclo fechado, ou armazenamento do elemento combustível queimado, ciclo aberto;

III - Rejeitos do Descomissionamento: são os elementos combustíveis e rejeitos já existentes na instalação, rejeitos líquidos de descontaminação e principalmente, peças, partes de equipamentos, estruturas metálicas, alvenaria e material estrutural. 
Segundo definição da CNEN, descomissionamento é o conjunto de ações técnicas e administrativas destinadas à liberação de uma instalação do controle regulatório (CNEN, 2015).

\subsection{Gerência de rejeitos radioativos}

A Gerência de rejeitos radioativos é o conjunto de atividades operacionais, administrativas e de gestão que controlam os rejeitos radioativos, de modo que se possa garantir a proteção à saúde do homem e do meio ambiente, no presente e no futuro, sem impor um ônus indevido às gerações futuras. A gerência de rejeitos radioativos tem como objetivo reduzir os custos e as doses operacionais durante o manuseio destes rejeitos.

Não existe um modelo padrão de gerência, pois depende de fatores sociais, políticos, tecnológicos e também da diversidade e da quantidade gerada (AMPHLETT, 1961; IAEA, 1983a; IAEA, 1983b; IAEA, 1984; IAEA, 1992; HIROMOTO et al., 1999).

As práticas e os processos envolvidos em cada uma das etapas do sistema operacional da gerência de rejeitos radioativos estão apresentados na Figura 1. Vale ressaltar que a sequência de etapas apresentada foi atualizada por este estudo. Além disso, o fluxo de rejeitos é genérico, e as práticas e processos mostrados são aqueles comumente utilizados.

Figura 1-Plano de caracterização para inventário

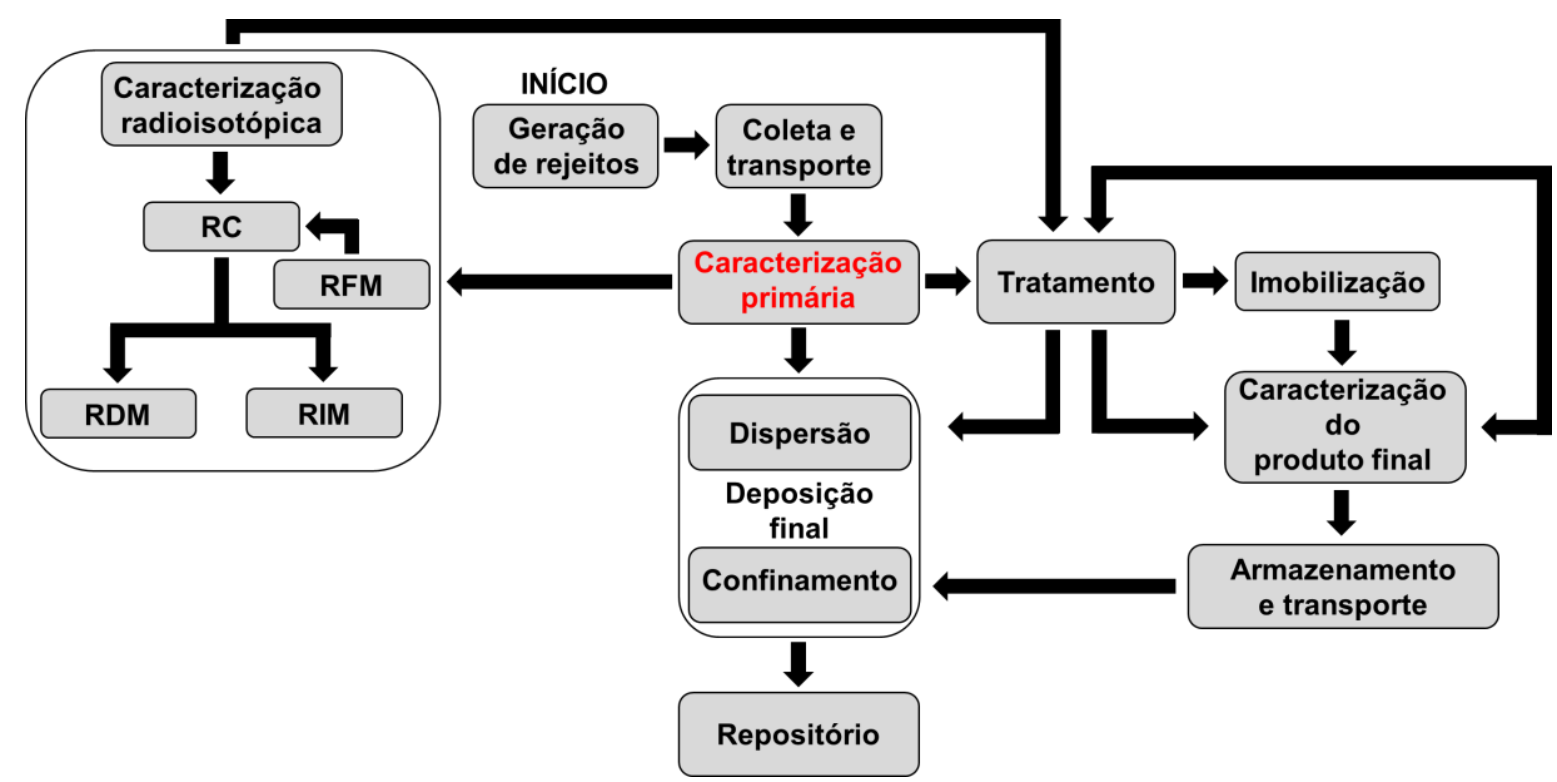

Fonte: HIROMOTO et al., 1999 (modificado). 
A coleta e o transporte fazem parte de uma etapa que compreende o acondicionamento dos rejeitos já segregados em embalagens apropriadas, sua identificação e transporte para a unidade de caracterização e tratamento. $\mathrm{Na}$ unidade de tratamento, por meio da caracterização primária, são levantadas as informações sobre as características físicas, químicas e radiológicas dos rejeitos. A caracterização primária é uma etapa muito trabalhosa, dispendiosa e também muito importante, pois é por meio dela que são definidas as etapas posteriores da gerência. Após essa etapa, os rejeitos radioativos que não atendem aos critérios de aceitação para a deposição final devem ser submetidos ao tratamento, que consiste no conjunto de ações que visam à redução de volume e a imobilização física e química do rejeito. Alguns rejeitos, como os líquidos, as lamas, precipitados, carvão ou as resinas de troca iônica, devem ser imobilizados usando matriz gerando um sólido monolítico, a fim de se criar uma barreira contra a liberação dos radionuclídeos presentes para o meio ambiente; nesse caso a cimentação é a técnica mais empregada.

Em seguida, os rejeitos tratados e imobilizados são analisados de forma a averiguar se determinadas propriedades atendem às normas de transporte, de armazenamento e de deposição final. Quando os rejeitos tratados estiverem aptos, poderão ser encaminhados para o armazenamento ou a disposição final. $O$ armazenamento é o confinamento de material radioativo ou de rejeitos radioativos por um determinado período de tempo e a disposição final é a liberação dos rejeitos para o meio ambiente de forma controlada, não recuperável e definitiva, de modo que o detrimento para o homem e seu meio ambiente seja minimizado. Há duas formas de realizar a disposição dos rejeitos controlando a dispersão dos radionuclídeos na biosfera: eliminação e confinamento em um repositório final.

Todas estas etapas estão diretamente inter-relacionadas, assim como a imobilização pode determinar o tratamento adequado do rejeito, as características de um repositório final podem determinar os processos mais adequados para o seu tratamento ou imobilização. As diferentes opções de processo para cada etapa devem ser avaliadas em conjunto, a fim de se obter um sistema capaz de cumprir com os objetivos e princípios já citados, levando-se sempre em consideração a compatibilidade entre elas. 


\subsection{Caracterização}

Um dos principais desafios técnicos da indústria nuclear é a identificação e caracterização de rejeitos radioativos. Dentre eles, o filtro cartucho, proveniente de reatores nucleares é um dos rejeitos nucleares mais problemáticos, uma vez que eles estão presentes em grandes quantidades e contêm atividades elevadas de produtos de ativação, decaimento e fissão (TAVCAR et al., 2007).

Chama-se caracterização radioisotópica de rejeitos radioativos o levantamento das informações necessárias para a certificação dos dados fornecidos pelo gerador nos documentos de identificação, qualificação e quantificação das propriedades significativas, visando a seleção do processo de tratamento e permitindo uma segregação mais efetiva. Esse levantamento inclui a determinação das propriedades físicas, químicas, biológicas e radiológicas dos rejeitos (HIROMOTO et al., 1999), assim como a identificação dos radionuclídeos contidos em um embalado e a determinação da sua concentração. Os rejeitos têm sido caracterizados visando determinar a sua classificação.

Caracterizar rejeitos não é uma tarefa fácil, pois há muitos radionuclídeos que não emitem radiação gama mensurável no seu processo de decaimento e, consequentemente, são de difícil medição, pois suas concentrações podem ser medidas somente por determinações radioquímicas, por exemplo, os radionuclídeos emissores alfa e beta puros (US NRC, 1982; KEKKI e TIITTA, 2000).

A determinação destes radionuclídeos envolve técnicas radioquímicas sofisticadas que são de difícil implementação em base rotineira. Historicamente, técnicas como precipitação, troca iônica ou extração com solventes têm sido usadas para a separação e quantificação de diversos elementos, mas estes métodos são complexos, demandam muito tempo e geram grandes quantidades de efluentes químicos (US NRC, 1982; KEKKI e TIITTA, 2000).

A técnica de precipitação, por exemplo, não é seletiva para determinados analitos se comparada com troca iônica ou extração por solventes, além de demandar um trabalho intenso no processo. A técnica de troca iônica possui maior seletividade e é menos laboriosa, mas requer grandes volumes de ácidos e de resinas nos processos de eluição e regeneração das mesmas. Extração por solventes é o mais seletivo, porém envolve um trabalho intenso e gera grandes volumes de rejeitos secundários (US NRC, 1982; KEKKI e TIITTA, 2000). 
O método de FE é uma técnica muito útil de avaliação da radioatividade, que tem potencial para uma ampla variedade de aplicações, não só para as usinas nucleares, onde este método é aplicado regularmente, mas também para outras instalações nucleares. As concentrações dos RDMs em rejeitos radioativos são inferidas por meio da multiplicação da concentração do RC pelos coeficientes e calculadas com base nos dados obtidos por amostragem e análise radioquímica, ou seja, os FEs, são as proporções de concentrações radioativas entre os RDMs e o RC.

Ao aplicar o método empírico do FE, no entanto, é necessário verificar a sua aplicabilidade na análise real do rejeito radioativo alvo. Os FEs podem ser calculados a partir de medições de radionuclídeos obtidos por meio de análise radioquímica apropriada, de modelagem ou por uma combinação de ambas as técnicas (IAEA, 2009). A metodologia de FE requer amostragem, análise destrutiva, modelagem, análise não destrutiva e cálculo (IAEA, 2007).

Análises radioquímicas consistem de cinco etapas principais: 1) prétratamento da amostra; 2) dissolução; 3) separação do analito da matriz; 4) transformação da fração separada numa fonte adequada para medida; 5) determinação da atividade da amostra. No processo de separação, é importante levar em consideração que elementos com elevado estado de valência têm grande habilidade em formar complexos aniônicos. Resinas aniônicas são bastante seletivas e adequadas para a separação desses elementos, elas removem ânions fortes e fracos, como cloretos, sulfatos, nitratos, bicarbonatos e silicatos. Resinas de troca iônica são produtos sintéticos constituídas, na sua maioria, de copolímeros de estireno, com divinilbenzeno (D.V.B), na forma de partículas esféricas de diâmetro 300 a $1.180 \mu \mathrm{m}$.

Atualmente, há resinas cromatográficas disponíveis comercialmente que facilitam e reduzem o tempo dessas determinações, pois possibilitam a separação e a análise sequencial de diversos elementos químicos. Desta forma, padronizar e implantar uma metodologia de análise sequencial, para caracterizar os filtros cartucho com essas resinas aumentaria a eficiência das determinações, além de gerar pequena quantidade de efluente radioativo, diferentemente das técnicas com resinas iônicas. Assim, o emprego dessas resinas cromatográficas já faz parte da rotina de muitos laboratórios do mundo (HORWITZ et al., 1993; HORWITZ et al., 1995), que buscam unir a alta seletividade da extração por 
solventes com a facilidade do método por troca iônica. No Brasil, poucos laboratórios adotaram essas resinas em suas análises de amostras ambientais e biológicas, dentre eles o Laboratório de Poços de Caldas em Minas Gerais (LAPOC-CNEN) (TADDEl et al., 2011).

\subsection{Reator nuclear de pesquisas - IEA-R1}

O reator nuclear de pesquisas IEA-R1 do IPEN é do tipo piscina, moderado e refrigerado a água leve (como blindagem, moderador e fluido refrigerante) e que utiliza elementos de berílio e de grafite como refletores.

O sistema de tratamento da água da piscina do reator é dividido em dois circuitos. Um não radioativo e outro radioativo, composto por filtros de polipropileno tipo cartucho, carvão ativado e trocadores iônicos.

O circuito não radioativo é responsável pelo abastecimento da piscina quando o nível estiver abaixo do limite. Recebe água proveniente da rede de abastecimento pública, sendo constituído por:

- Um conjunto contendo seis cartuchos filtrantes de polipropileno termo expandido para retenção das partículas sólidas em suspensão com dimensões maiores que $25 \mu$, no início do circuito;

- Um tanque "amolecedor", composto por trocadores iônicos para retenção de $\mathrm{Ca}^{+2}$ e $\mathrm{Mg}^{+2}$;

- Um filtro de carvão ativado para retenção de gases dissolvidos na água;

- Dois trocadores iônicos de leito misto de resinas catiônicas e aniônicas, sendo um, de reserva, para ser usado quando o outro necessitar de regeneração;

- Um conjunto contendo seis cartuchos filtrantes de polipropileno termo expandido para retenção das partículas sólidas em suspensão com dimensões maiores que $25 \mu$, no final do circuito.

O circuito radioativo é responsável pelo retratamento contínuo da água da piscina. É constituído por duas unidades, com capacidade, cada uma, de retratar $75 \mathrm{~L}$. $\mathrm{min}^{-1}$. O circuito mantém o grau de impurezas da água em torno de 2 ppm de substâncias solúveis.

A água de resfriamento desse reator é bombeada continuamente, através do núcleo do reator, para remover o calor gerado pelas reações nucleares, 
a atividade da água após sua passagem pelo núcleo do reator é resultante da ativação da própria água e de gases nela dissolvidos; da ativação de impurezas dissolvidas na água, decaimento radioativo, provenientes da rede de abastecimento ou da corrosão de materiais estruturais; de reações nucleares de recuo nos materiais que se encontram no núcleo do reator e que são submetidos a um fluxo de nêutrons rápidos; do desprendimento de radionuclídeos formados nos materiais constituintes do núcleo; decaimento radioativo; e de produtos de fissão provenientes dos elementos combustíveis por meio de difusão.

As impurezas contidas nessa água podem se tornar radioativas, como resultado da interação com as radiações no reator e devem, portanto, serem retiradas do líquido de arrefecimento para evitar um aumento de escala da radioatividade no sistema. Esse processo emprega seis cartuchos filtrantes de polipropileno, dois leitos paralelos de carvão ativado e dois leitos paralelos de resinas de troca iônica mista, que retêm os radionuclídeos por filtração, adsorção e troca iônica. Uma vez por ano, os leitos de resinas de troca iônica mistas são regenerados com ácido sulfúrico e hidróxido de sódio concentrados e os leitos de carvão ativado são lavados com água deionizada (TADDEl et al., 2013a).

O controle dessa operação é feito por meio de medidas da condutividade e da vazão que, quando estão fora dos limites estabelecidos, indicam a necessidade de regeneração dos leitos de carvão e resina e, quando isto não for mais possível, a substituição destes leitos e do conjunto de filtros, sendo estes considerados rejeitos radioativos (TADDEI, 2013).

A Figura 2 mostra um fluxograma do sistema de tratamento e retratamento da água da piscina. 
Figura 2 - Sistema de tratamento da água da piscina do reator



Fonte: autor da tese.

Cabe salientar que este trabalho caracterizou os filtros cartucho de polipropileno utilizados no retratamento da água da piscina, mostrado na Figura 2, circuito radioativo.

Desde o início da operação do IEA-R1, o sistema de retratamento de água do Reator periodicamente gera rejeitos radioativos, constituídos de resinas de troca iônica e carvão ativado, os quais foram substituídos apenas duas vezes: uma em 1993 e a outra em 2003. Uma possível explicação para o longo período de uso do primeiro lote é a operação do reator na maior parte em $2 \mathrm{MW}$, em turnos diários de 8 horas, quatro dias por semana, com cerca de duas campanhas de regeneração por ano. As resinas e o carvão ativado são regeneráveis e possuem vida útil longa. As taxas de dose de contato são da ordem de dezenas de milisieverts por hora e o volume total é de cerca de $2 \mathrm{~m}^{3}$. Estes resíduos foram recolhidos em 21 tambores com capacidade de $200 \mathrm{~L}$ cada e armazenados na Gerência de Rejeitos Radioativos (GRR). Na GRR, esses rejeitos continuam nos tambores e deverão passar por um processo de caracterização e de solidificação, antes de serem encaminhados para o depósito intermediário (IPEN, 2002; SILVA et al., 2009; TADDEl et al., 2011; IPEN, 2012).

\subsection{Métodos de separação}

A literatura apresenta diversos estudos sobre métodos de separação radioquímica para determinação dos isótopos de $\mathrm{U}, \mathrm{Np}, \mathrm{Pu}, \mathrm{Am}$ e $\mathrm{Cm}$, em matrizes 
como: solo (MORENO et al., 1997; PAYNE et al., 2008; DULANSKÁ et al., 2012b), água (PULHANI et al., 2011; HABIBI et al., 2016), solo e sedimento (MICHEL et al., 1999; MELLADO et al., 2001; MAXWELL, 2008), sedimento e peixe (LEE et al., 2005), solo e vegetação (GRAHEK e NODILO, 2012), alimentos (MAXWELL et al., 2012), rejeito radioativo líquido (lodo e concentrado do evaporador) e rejeito radioativo sólido de alto nível (CHEN et al., 2002; TOLGYESI et al., 2002; MURALI et al., 2011; ADYA et al., 2012; DULANSKÁ et al., 2012a), concentrado do evaporador e resina de troca iônica usada (GASCÓN et al., 1994; TAVCAR e BENEDIK, 2005; TAVCAR et al., 2007; KASTNER et al., 2010; REIS Jr. et al., 2010), filtro de ar e turfa (SALMINEN, 2009) e múltiplas matrizes (AGEYEV et al., 2005).

Nesses estudos foram empregadas diversas técnicas para a quantificação dos radioisótopos: espectrometria alfa, espectrometria de massa por plasma acoplado indutivamente (ICP-MS, sigla do inglês para inductively coupled plasma mass spectrometry), plasma de corrente contínua (DCP, sigla do inglês para direct current plasma spectrometry), fluorimetria por laser, espectrometria de raios $\mathrm{X} e$ espectrometria de cintilação em meio líquido (LSC, sigla do inglês para liquid scintillation spectrometry).

Visando agilizar os processos de separação e diminuir a geração de rejeitos durante 0 processo, muitos trabalhos foram publicados (SAMUELSON, 1963; KORKISCH, 1969; DORFNER, 1972; KORKISCH, 1989; LA ROSA et al., 1992) e na década de 1990 (HORWITZ et al., 1993, 1995 e 1996) desenvolveram processos de separação, utilizando diversos agentes extratores orgânicos, que mais tarde foram disponibilizados comercialmente pela Eichrom Technologies, LLC na forma de resinas cromatográficas (Tabela 1). Estas resinas constituem-se de um suporte polimérico impregnado de agentes extratantes, os quais são específicos para a separação de um radionuclídeo ou de um conjunto de radionuclídeos, elas são muito seletivas e eficientes (KORKISCH, 1969). É comum a aplicação dessas técnicas de forma isolada ou combinada, o que depende obviamente dos radionuclídeos presentes no rejeito. Isso possibilita a separação sequencial, o que reduz o tempo de determinação. 
Tabela 1-Resinas comercializadas pela Eichrom Technologies, LLC

\begin{tabular}{|c|c|c|}
\hline Resina & Extratante ativo & Aplicação \\
\hline $\mathrm{Sr}$ & $\begin{array}{l}\text { 4,4'(5')-di-t-butil ciclohexano 18-coroa-6 (éter } \\
\text { coroa) em 1-octanol }\end{array}$ & $\mathrm{Sr}, \mathrm{Pb}$ \\
\hline TRU & $\begin{array}{l}\text { óxido de N-octilfenil, N-di-isobutil carbamoilfosfina } \\
\qquad(\mathrm{CMPO})\end{array}$ & $\begin{array}{c}\mathrm{Fe}, \mathrm{Th}, \mathrm{Pa}, \mathrm{U}, \mathrm{Np} \\
\mathrm{Pu}, \mathrm{Am}, \mathrm{Cm}\end{array}$ \\
\hline UTEVA & Diamil, amil fosfonato (DAAP) & Th, U, Np, Pu \\
\hline TEVA & Nitrato (ou cloreto) de trialquil metilamônio & $\begin{array}{l}\text { Tc, Th, Np, Am, } \\
\text { lantanídeos }\end{array}$ \\
\hline $\mathrm{Ni}$ & Dimetilglioxima (DMG) & $\mathrm{Ni}$ \\
\hline RE & $\begin{array}{l}\text { Óxido de octil (fenil) -N, N-diisobutilcarbamoil } \\
\text { metilfosfina } 1 \mathrm{M}(\mathrm{CMPO}) \text { em tributil fosfato(TBP) }\end{array}$ & $\begin{array}{c}\text { Th, U, Np, Pu, Am, } \\
\text { Cm, elementos } \\
\text { terras raras }\end{array}$ \\
\hline
\end{tabular}

Fonte: https://www.eichrom.com/eichrom/products/

$\mathrm{HABIBI}$ et al. (2016) desenvolveram um procedimento que permite a separação e determinação de $\mathrm{Sr}$, Th, U, Np, Pu e Am em um lote de 16 amostras de água do rio Yvette (França) em menos de 24 horas e com excelente desempenho. O método emprega a extração cromatográfica, usando as resinas TEVA (Th, Np e Pu), TRU (U, Am e Cm) e Sr (Sr), acopladas a um espectrômetro de massa com plasma indutivamente acoplado (ICP-MS) (Th, U, Np, Pu, Am e Cm) e a um contador proporcional a gás (CPG) (Sr), cujos rendimentos químicos foram: $\mathrm{Sr}(81 \%)$, Th (93\%), U (84\%), Np (81\%), Pu (80\%) e Am (80\%).

HORWITZ et al. (1995) descreveram uma nova resina de extração cromatográfica, constituída por um trocador de ânions líquido à base de amina quaternária sorvido sobre um substrato polimérico inerte, para a sorção de actinídeos em ácido clorídrico e ácido nítrico. A aplicação desse material foi utilizada para a separação e pré-concentração de actinídeos selecionados de soluções de alto nível de resíduos nucleares para posterior determinação. No procedimento empregado para a separação dos radionuclídeos foram utilizadas as Resinas TRU (Pu e Am), UTEVA (U), TEVA (Th e Np) e Sr (Sr). As concentrações foram determinadas por espectrometria alfa (Np, Pu e Am), ICP-MS (U), DCP (Th) e LSC (Sr), a partir das quais os rendimentos químicos obtidos foram: $\mathrm{Sr}(103 \%)$, Th (106\%), U (101\%), Np (97\%), Pu (97\%) e Am (96\%). 
RODRÍGUEZ et al. (1997) desenvolveram um método rápido e preciso de análise para a determinação de ${ }^{238} \mathrm{Pu},{ }^{239+240} \mathrm{Pu},{ }^{241} \mathrm{Pu},{ }^{241} \mathrm{Am},{ }^{242} \mathrm{Cm}$ e ${ }^{244} \mathrm{Cm}$ em amostras provenientes de usinas nucleares, principalmente resinas de troca iônica gasta e concentrados do evaporador, usando a técnica de extração cromatográfica (resina TRU) para a separação dos isótopos de $\mathrm{Pu}, \mathrm{Am}$ e $\mathrm{Cm}$. Como forma de comparação dos resultados aplicou-se uma metodologia de separação que utiliza resina de troca aniônica. A determinação dos rendimentos químicos foi feita por espectrometria alfa, obtendo um rendimento químico para as análises por extração cromatográfica de $50 \%$ para $\mathrm{Pu}, 30 \%$ para $\mathrm{Am}$ e $11 \%$ para $\mathrm{Cm}$ e por troca iônica de $90 \%$ para Pu e superior a $80 \%$ para $\mathrm{Am}$ e $\mathrm{Cm}$.

IKÄHEIMONEN (2000) desenvolveu um método radioquímico para a determinação de Pu em amostras ambientais. Para testar o método foram usadas amostras de filtro de ar, deposição, grama, sedimento e materiais de referência e de intercomparação de sedimentos. A separação foi realizada utilizando-se resina de troca aniônica e a sua determinação foi feita por espectrometria alfa $\left({ }^{238} \mathrm{Pu}\right.$, ${ }^{239+240} \mathrm{Pu}$ e $\left.{ }^{242} \mathrm{Pu}\right)$ e cintilação em meio líquido $\left({ }^{241} \mathrm{Pu}\right)$, obtendo um rendimento químico entre 60 - 90\%.

PAYNE et al. (2008) determinaram as atividades de Pu em amostras de solos coletadas ao redor do perímetro da Área de Descarte de Superfície (ADS) no Laboratório Nacional de Idaho (LNI), usando uma combinação de metodologias radioanalíticas que envolve o uso de resina de troca aniônica - AG 1x4 na separação do Pu. As determinações foram feitas por espectrometria gama $\left({ }^{241} \mathrm{Am}\right)$, espectrometria alfa $\left({ }^{238} \mathrm{Pu},{ }^{239+240} \mathrm{Pu}\right.$ e $\left.{ }^{242} \mathrm{Pu}\right)$ e cintilação em meio líquido $\left({ }^{241} \mathrm{Pu}\right)$, as quais forneceram rendimentos químicos $>70 \%$.

REIS Jr. et al. (2010) desenvolveram um procedimento analítico para a determinação simultânea de radioisótopos de U, Pu e Am em amostras de concentrado do evaporador da Eletrobrás Termonuclear. A separação foi realizada utilizando resina de troca aniônica Dowex $1 \times 8(\mathrm{U}, \mathrm{Pu})$ e extração cromatográfica TRU (Am), a partir das quais o rendimento químico do Pu variou de 61 a $97 \%$ e as determinações foram feitas por espectrometria alfa.

ROSSKOPFOVÁ et al. (2011) apresentaram um método analítico radioquímico para a determinação de ${ }^{63} \mathrm{Ni}$ em amostras de concreto provenientes da Usina Nuclear Mochovce, na Eslováquia. O procedimento adotado para a separação do ${ }^{63} \mathrm{Ni}$ utilizou resinas de troca aniônica (Dowex $2 \times 8$ ) e de extração 
cromatográfica (Resina $\mathrm{Ni}$ ), a partir das quais os rendimentos químicos obtidos para o Ni estável foram de 49 - 71\%. As determinações do Ni estável e do ${ }^{63} \mathrm{Ni}$ foram feitas por espectrometria de absorção atômica com forno de grafite e cintilação em meio líquido, respectivamente.

TEMBA et al. (2011) apresentaram uma metodologia para a determinação de ${ }^{90} \mathrm{Sr}$ em diferentes tipos de rejeito radioativo gerados na Eletrobrás Termonuclear. A técnica utilizada para a separação e purificação do Sr foi a extração cromatográfica com a resina de Sr. Os rendimentos químicos para as amostras de concentrado do evaporador (81,7\%), resina de troca iônica $(64,6 \%)$ e filtro $(60,1 \%)$ foram determinados por cintilação em meio líquido.

TADDEl et al. (2013) desenvolveram um método de separação radioquímica sequencial para determinar os radionuclídeos ${ }^{90} \mathrm{Sr},{ }^{237} \mathrm{~Np},{ }^{241} \mathrm{Am}$ e ${ }^{244} \mathrm{Cm}$ e os isótopos de $\mathrm{U}$ e $\mathrm{Pu}$ em amostras de resinas de troca iônica e carvão ativado originados do sistema de retratamento do reator nuclear de pesquisas IEAR1 do IPEN. Além dos RDMs, ${ }^{60} \mathrm{Co}$ e ${ }^{137} \mathrm{Cs}$ também foram analisados. A metodologia adotada para a separação dos RDMs utilizou resina de troca aniônica (Dowex 1x8) (Pu/Np), seguida das resinas cromatográficas UTEVA (U), $\mathrm{TRU}(\mathrm{Am} / \mathrm{Cm})$ e $\mathrm{Sr}\left({ }^{90} \mathrm{Sr}\right)$, a partir das quais os rendimentos químicos foram obtidos para Sr, U, Np/Pu e Am/Cm de 62 - 85\%, 75 - 99\%, 60 - 95\% e 45 - 85\% respectivamente. As determinações foram feitas por espectrometria gama $\left({ }^{60} \mathrm{Co} \mathrm{e}\right.$ $\left.{ }^{137} \mathrm{Cs}\right)$, espectrometria alfa (U, Np, $\mathrm{Pu}, \mathrm{Am}$ e $\left.\mathrm{Cm}\right)$ e cintilação em meio líquido $\left({ }^{90} \mathrm{Sr}\right.$ $\left.\mathrm{e}^{241} \mathrm{Pu}\right)$.

TADDEl et al. (2013) adaptaram e aplicaram um método radioquímico para determinar as concentrações de atividades de ${ }^{59} \mathrm{Ni}$ e ${ }^{63} \mathrm{Ni}$ na caracterização de duas matrizes de rejeitos radioativos do reator nuclear de pesquisas nuclear IEAR1 do IPEN. No procedimento para a separação dos radionuclídeos utilizaram-se colunas contendo resina de troca aniônica (Dowex 1x4) e resina de extração cromatográfica com dimetilglioxima (DMG) como grupo funcional, foram utilizadas para separar e purificar o Ni de amostras de resina de troca iônica e carvão ativado. As concentrações de atividades dos ${ }^{59} \mathrm{Ni}$ e ${ }^{63} \mathrm{Ni}$ foram medidas por espectrometria de raios $X$ e contagens por cintilação em meio líquido, respectivamente, a partir dos quais foram obtidos rendimentos químicos de 40 - 94\% para amostras de resina e 42 - 97\% para amostras de carvão. 
COSTA (2014) desenvolveu uma metodologia para caracterizar rejeitos de baixo e médio nível de radiação do reator nuclear de pesquisas IEA-R1. O procedimento utilizou o método de Monte Carlo para a determinação dos radionuclídeos ${ }^{60} \mathrm{Co},{ }^{108 \mathrm{~m}} \mathrm{Ag}$ e ${ }^{110 \mathrm{~m}} \mathrm{Ag}$. As medidas foram feitas em um espectrômetro gama.

TADDEI et al. (2015) aplicaram a metodologia do fator de escala para estimar o inventário de radionuclídeos em resinas de troca iônica e carvão ativado, ambos com nível de atividade baixo e intermediário, gerados no reator nuclear de pesquisas IEA-R1 do IPEN. Foram selecionados para este estudo 26 radionuclídeos, sendo dois considerados RC por serem RFM e todos os outros considerados RDMs. Foram desenvolvidos ou adaptados e implementados procedimentos radioquímicos utilizados nas separações dos radionuclídeos, baseados nos processos de combustão, co-precipitação, cromatografia de extração e de troca iônica, bem como as diferentes formas de preparação das fontes para medições por espectrometria de partículas alfa, contagem por cintilação em meio líquido, espectrometria de raios gama e/ou espectrometria de raios $\mathrm{X}$. Dentre todos esses radionuclídeos, foram estabelecidos FEs ou FCs correspondentes a pares $\mathrm{RDM} / \mathrm{RC}$ em ao menos um dos rejeitos radioativos estudados, para $15 \mathrm{RDMs}$. Para os demais, não foi possível estabelecer ou adaptar procedimento para determinação de 3 RDMs e devido às concentrações de atividade muito baixas, abaixo das respectivas Atividades Mínimas Detectáveis (MDA, sigla do inglês para Minimum Detectable Activity) de 6 RDMs. 


\section{METODOLOGIA}

Neste trabalho, a sequência adotada para a caracterização dos filtros e obtenção dos Fatores de Escala foi a seguinte:

a. Coleta das amostras de filtro;

b. Preparação e solubilização das amostras;

c. Calibração dos equipamentos - eficiência de contagem;

d. Quantificação dos radionuclídeos gama;

e. Avaliação da homogeneidade;

f. Separação radioquímica dos radionuclídeos emissores alfa;

g. Quantificação dos radionuclídeos alfa;

h. Cálculo dos fatores de escala;

i. Separação radioquímica dos radionuclídeos emissores beta;

j. Quantificação dos radionuclídeos beta;

k. Determinação da correlação entre RDM e RCs;

I. Comparação das razões entre atividades de alguns radionuclídeos com as razões esperadas por considerações teóricas.

Foram selecionados 15 filtros, previamente estudados num trabalho de mestrado (TESSARO, 2015) realizado na Gerência de Rejeitos Radioativos, para avaliar a distribuição da atividade ao longo do filtro (homogeneidade), por meio da taxa de dose. Por essa técnica, demonstrou-se que os filtros eram homogêneos e assim, com o objetivo de validá-la. Optou-se, neste trabalho, por analisá-los por meio de uma técnica mais sensível. Dos 15 filtros, 8 foram separados para avaliação da homogeneidade.

\subsection{Coleta das amostras de filtro}

Os cartuchos de filtro exauridos que foram retirados do sistema de tratamento de água do reator nuclear de pesquisas IEA-R1, estão armazenados no depósito de rejeitos da Gerência de Rejeitos Radioativos (GRR) do IPEN dentro de tambores de 200 L. Para evitar a corrosão dos tambores, esses filtros são colocados em recipientes plásticos abertos para secagem logo após a retirada do porta-filtros.

É esperado que esses materiais apresentem uma variação da composição isotópica, não somente devido ao decaimento radioativo, após a 
retirada do reator, mas também às variações nas condições operacionais enquanto esses leitos estavam em uso. As variações nas condições operacionais incluem mudanças no regime de operação, potência térmica, defeitos nas placas do combustível, etc. (SILVA et al, 2009). Para a avaliação destas variações e a obtenção de amostras representativas, foram retiradas cinco fatias de cada filtro, de aproximadamente $2 \mathrm{~cm}$ cada, como ilustrado na Figura 3.

A homogeneidade dos filtros foi avaliada pela medida em espectrômetro gama da solução obtida após a calcinação e solubilização. Os resultados foram comparados ainda com os obtidos por TESSARO (2015). A avaliação da homogeneidade é importante para definir a quantidade de amostras representativas a serem analisadas.

Figura 3-Esquema adotado na amostragem dos cartuchos de filtro

\section{$50,8 \mathrm{~cm}$}



Fonte: autor da tese.

O procedimento foi realizado por um profissional habilitado para manipular este tipo de rejeito radioativo, foram utilizadas todas as precauções e Equipamentos de Proteção Individual (EPIs) necessários para esta amostragem, de forma que fosse seguro para todos os membros da equipe.

A Figura 4 ilustra o esquema utilizado para cortar as 5 fatias, e a Figura 5 mostra as amostras de filtro já cortadas, com espessura de $2 \mathrm{~cm}$ cada e embaladas em filme plástico. Para medir a taxa de dose foi utilizado um detector portátil modelo FAG FH 40F2. 
Figura 4-Demarcação do filtro para obtenção das 5 fatias

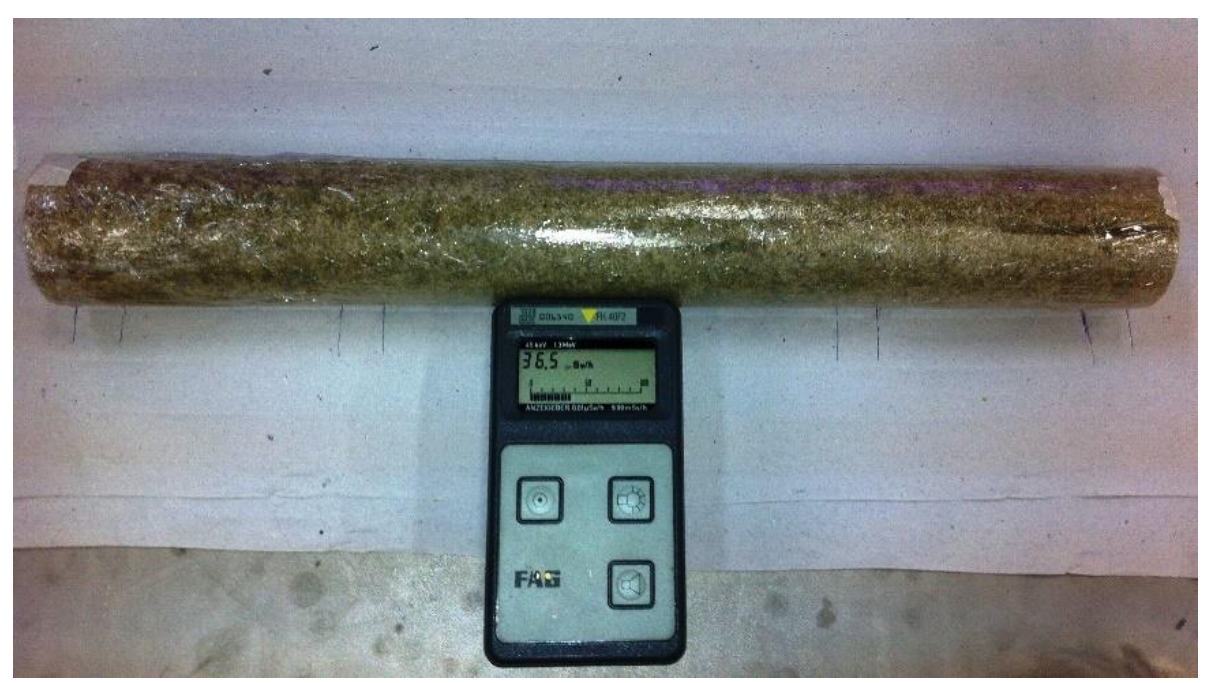

Fonte: autor da tese.

Figura 5-Amostras de filtro já cortadas e embaladas



Fonte: autor da tese.

\subsection{Preparação e solubilização das amostras}

Algumas fatias de filtro foram inicialmente medidas diretamente no espectrômetro gama, como uma primeira prospecção para identificar quais radionuclídeos emissores de raios gama estavam presentes nos filtros. Os isótopos ${ }^{60} \mathrm{Co},{ }^{108 \mathrm{~m}} \mathrm{Ag}$ e ${ }^{110 \mathrm{~m}} \mathrm{Ag}$ foram detectados, mas o ${ }^{137} \mathrm{Cs}$, um dos radioisótopos mais abundantes em rejeitos provenientes do reator, é indetectável por este método, mostrando que qualquer quantidade de césio que está na fase sólida na água de resfriamento, por exemplo, adsorvido na superfície de um sólido suspenso ou em partículas não apresenta uma concentração significativa. Portanto, os três isótopos 
${ }^{60} \mathrm{Co},{ }^{108 \mathrm{~m}} \mathrm{Ag}$ e ${ }^{110 \mathrm{~m}} \mathrm{Ag}$ foram selecionados como RC para determinação por espectrometria de raios gama, e os isótopos ${ }^{63} \mathrm{Ni},{ }^{90} \mathrm{Sr},{ }^{234,235,248} \mathrm{U},{ }^{238,239,240,241} \mathrm{Pu}$, ${ }^{241} \mathrm{Am}$ e ${ }^{242,243,244} \mathrm{Cm}$ foram selecionados como radiologicamente significativos e RDMs representativos para determinação por métodos radioquímicos.

A dificuldade em preparar uma fonte de calibração com a mesma geometria das fatias do filtro impediu a determinação direta da atividade de cada fatia da amostra por espectrometria gama. Em vez disso, após a amostragem, cada fatia de filtro foi cortada ao meio, embebida em álcool e queimada em uma cápsula de porcelana. Após a queima, o material foi calcinado em estufa por 24 horas a $350{ }^{\circ} \mathrm{C}$ para eliminar qualquer composto orgânico remanescente. Para os seis filtros restantes, apenas uma fatia foi tomada para análise radioquímica.

A amostra calcinada foi transferida para um béquer em teflon politetrafluoretileno (PTFE) com capacidade de $250 \mathrm{~mL}$, três porções contendo $20 \mathrm{~mL}$ de água régia $\left(\mathrm{HCl}_{\mathrm{HNO}} \mathrm{HN}_{3}\right.$ 3) foram adicionadas. Entre cada adição, a amostra foi aquecida em uma chapa aquecedora a $250^{\circ} \mathrm{C}$ até à secura. Como a solubilização não foi completa, adicionou-se três porções contendo $10 \mathrm{~mL}$ de ácido perclórico $\left(\mathrm{HClO}_{4} 69-72 \%\right)+10 \mathrm{~mL}$ de ácido nítrico $\left(\mathrm{HNO}_{3} 65 \%\right)$ e, numa outra etapa, mais três porções contendo $5 \mathrm{~mL}$ de ácido fluorídrico (HF 48\%) + $10 \mathrm{~mL}$ de $\mathrm{HNO}_{3} 65 \%$ para eliminação de silicatos, a amostra foi levada à secura após cada adição de ácido e quando completamente seca, foram adicionadas 3 porções contendo $2 \mathrm{~mL}$ de $\mathrm{HNO}_{3} 65 \%$, 3 gotas de peróxido de hidrogênio $\left(\mathrm{H}_{2} \mathrm{O}_{2} 30 \%\right)$ e $2 \mathrm{~mL}$ de água deionizada para a eliminação da água régia, $\mathrm{HClO}_{4}$ e HF. A amostra foi então novamente levada à secura após cada adição e quando completamente seca, foi resfriada a temperatura ambiente e os sais foram solubilizados com aproximadamente $20 \mathrm{~mL}$ de $\mathrm{HNO}_{3} 8 \mathrm{~mol}$. L-1. Após a solubilização, a amostra foi transferida para um balão volumétrico com capacidade de $100 \mathrm{~mL}$, completou-se o volume com a mesma solução, formando uma solução estoque para cada amostra de filtro.

Excetuando-se as análises de ${ }^{14} \mathrm{C}$ e ${ }^{3} \mathrm{H}$, a separação radioquímica e quantificação de todos os outros radionuclídeos foi realizada com a solução estoque.

Para a determinação das concentrações dos radionuclídeos emissores gama $\left({ }^{60} \mathrm{Co},{ }^{108 \mathrm{~m}} \mathrm{Ag}\right.$ e $\left.{ }^{110 \mathrm{~m}} \mathrm{Ag}\right)$, foi retirada uma alíquota de $10 \mathrm{~mL}$ da solução estoque e transferida para um frasco de vidro (vial) com capacidade de $20 \mathrm{~mL}$, que 
foi selado e medido em um espectrômetro de raios gama previamente calibrado com uma solução padrão na mesma geometria.

\subsection{Preparo das colunas}

Foram montadas colunas com resina de troca aniônica fortemente básica Dowex 1x2 - em coluna de vidro com $10 \mathrm{~mm}$ de diâmetro x $300 \mathrm{~mm}$ de altura, além do reservatório (40 mm de diâmetro x $130 \mathrm{~mm}$ de altura), adicionandose uma quantidade de resina previamente condicionada em $\mathrm{HNO}_{3} 8 \mathrm{~mol} . \mathrm{L}^{-1}$, suficiente para atingir $130 \mathrm{~mm}$ de altura.

E também foram montadas colunas com resina de troca aniônica fortemente básica - Dowex 1x8 - utilizando as mesmas colunas de vidro. Foram adicionados uma quantidade de resina previamente condicionada em $\mathrm{HCl} 9 \mathrm{~mol} . \mathrm{L}^{-1}$, suficiente para atingir $200 \mathrm{~mm}$ de altura.

Colunas de extração cromatográficas UTEVA, TRU, Sr e Ni produzidos pela Eichrom Technologies, LLC estão disponíveis comercialmente na forma de cartuchos, contendo $2 \mathrm{~mL}$ cada, com partículas de tamanho (100 - $150 \mu \mathrm{m}$ ).

\subsection{Determinação dos isótopos de U, Pu, Am e Cm}

\subsubsection{Separação radioquímica}

A análise sequencial envolve o uso de resinas de troca iônica e cromatográficas nas quais são percoladas soluções nítricas e clorídricas. Na resina aniônica, a afinidade e o coeficiente de distribuição dependem do estado de oxidação dos elementos e aqueles que formam nitrato-complexos ficam retidos em trocadores aniônicos. Assim os metais Th(IV), Pa(IV), Np(IV), Pu(IV), Pd(IV), Pd(II), $\mathrm{Au}(\mathrm{III}), \operatorname{Re}(\mathrm{VII})$ e Tc(VII) são facilmente separados dos elementos que não são adsorvidos, como $\mathrm{Al}(\mathrm{III}), \mathrm{Fe}$ (II e III), metais alcalinos, alcalinos terrosos, lantanídeos e actinídeos trivalentes (SEABORG e LOVELAND, 1990; RADCHEM, 2006).

Em ácido nítrico concentrado $\left(6-10 \mathrm{~mol}\right.$. $\left.\mathrm{L}^{-1}\right)$, o Pu é encontrado na forma de complexo $\left[\mathrm{Pu}\left(\mathrm{NO}_{3}\right)_{6}\right]^{-2}$, $\mathrm{Np}$ na forma de $\left[\mathrm{Np}\left(\mathrm{NO}_{3}\right)_{6}\right]^{-2}$ e o Th na forma de $\left[\mathrm{Th}\left(\mathrm{NO}_{3}\right)_{6}\right]^{-2}$, os quais serão adsorvidos pela resina aniônica. No entanto, o estado de oxidação mais estável do Pu nessas condições é o estado (IV), o complexo $\left[\mathrm{Pu}\left(\mathrm{NO}_{3}\right)_{5}\right]^{-2}$ pode, eventualmente, ser formado e ser apenas parcialmente adsorvido pela resina aniônica. Portanto, antes da percolação, é necessário ajustar 
o estado de oxidação do $\mathrm{Pu}$, o que envolve a adição de ácido nítrico contendo nitrito de sódio ( $\mathrm{NaNO}_{2}$ ) para oxidar o Pu ao estado (IV) (EICHROM, 2006).

Neste trabalho, foi retirada uma alíquota de $20 \mathrm{~mL}$ da solução estoque e levada para um béquer de $250 \mathrm{~mL}$. Em seguida, foram adicionados os traçadores para monitorar o rendimento químico do processo. Assim, foram empregados ${ }^{232} U$, ${ }^{242} \mathrm{Pu}$ e ${ }^{243} \mathrm{Am}$, e para as análises dos isótopos de $\mathrm{Cm}$ foi utilizado o traçador de ${ }^{243} \mathrm{Am}$. O estado de oxidação do Pu [+3] foi ajustado para [+4] com cerca de $0,30 \mathrm{~g}$ de nitrito de sódio para possibilitar sua retenção na resina Dowex. A amostra foi percolada em uma coluna contendo resina Dowex $1 \times 2$, previamente condicionada com $50 \mathrm{~mL}$ de $\mathrm{HNO}_{3} 8 \mathrm{~mol}$. L L-1, com uma vazão controlada de 1,5 mL . min-1. Após a percolação da amostra, foram adicionadas 3 porções de $40 \mathrm{~mL}$ de $\mathrm{HNO}_{3} 8 \mathrm{~mol} . \mathrm{L}^{-1}$, seguindo a mesma vazão, todo o efluente foi recolhido, pois continha $U$, Am e Cm. Em seguida, foram adicionadas 3 porções de $40 \mathrm{~mL}$ de ácido clorídrico ( $\mathrm{HCl} 37 \%$ ) para eliminação de possíveis interferentes e troca do meio ácido da resina. Nesta etapa não foi necessário controlar a vazão e o efluente foi descartado. O Pu que ficou retido na resina teve seu estado de oxidação reduzido com cloridrato de hidroxilamina $\left(\mathrm{NH}_{2} \mathrm{OH} . \mathrm{HCl}\right)$, de [+4] para [+3] antes da sua eluição com 3 porções de $30 \mathrm{~mL}$ de $\mathrm{HCl} 0,5 \mathrm{~mol}$. L L $\mathrm{L}^{-1}$, com uma vazão controlada de $1,5 \mathrm{~mL} \cdot \mathrm{min}^{-1}$. O eluato de Pu obtido foi seco em chapa aquecedora, dissolvido com $10 \mathrm{~mL}$ de $\mathrm{HNO}_{3} 1 \mathrm{~mol}$. L-1, transferido para um balão volumétrico de $25 \mathrm{~mL} \mathrm{e}$ avolumado, dando origem a solução estoque de Pu e esta solução foi dividida em duas alíquotas de $10 \mathrm{~mL}$ cada, a primeira foi utilizada para determinação dos isótopos de $\mathrm{Pu}$ emissores de partículas alfa e a segunda alíquota para a determinação do isótopo de ${ }^{241} \mathrm{Pu}$ que é um emissor beta.

O efluente contendo $\mathrm{U}, \mathrm{Am}$ e $\mathrm{Cm}$ foi coletado, aquecido até a secura e, em seguida, diluído com $20 \mathrm{~mL}$ de $\mathrm{HNO}_{3} 3 \mathrm{~mol}$. L $\mathrm{L}^{-1}$. Foram adicionados cerca de $0,1 \mathrm{~g}$ de ácido ascórbico $\left(\mathrm{C}_{6} \mathrm{H}_{8} \mathrm{O}_{6}\right)$ para reduzir possíveis interferentes contendo Fe (III) para Fe (II), o qual interfere na retenção do Am na coluna de extração cromatográfica (resina TRU). Um aparato contendo duas colunas, uma sobre a outra foi montado, sendo elas as colunas de extração cromatográfica (resina UTEVA e TRU, respectivamente), a solução foi percolada nas colunas, previamente condicionadas com $20 \mathrm{~mL}$ de $\mathrm{HNO}_{3} 3 \mathrm{~mol}$. L $\mathrm{L}^{-1}$. Após a percolação, 2 porções de $20 \mathrm{~mL}$ de $\mathrm{HNO}_{3} 3 \mathrm{~mol}$. L $\mathrm{L}^{-1}$ foram adicionadas nas colunas e todo o efluente foi descartado. As colunas foram separadas, para a eluição do Am e $\mathrm{Cm}$ da resina 
TRU, com $5 \mathrm{~mL}$ de HCl $9 \mathrm{~mol}$. $\mathrm{L}^{-1}$ e $30 \mathrm{~mL}$ de HCl $4 \mathrm{~mol}$. L-1. Para a eluição do $\mathrm{U}$, a resina UTEVA foi previamente condicionada com $10 \mathrm{~mL}$ de $\mathrm{HCl} 9 \mathrm{~mol}^{\text {. L-1, }}$, para troca do meio, e o efluente gerado foi descartado. $\mathrm{O} \cup$ foi então eluído com 2 porções de $15 \mathrm{~mL}$ de $\mathrm{HCl} 0,01 \mathrm{~mol}$. L-1 sem a necessidade de controle da vazão. Os eluatos de $\mathrm{U}, \mathrm{Pu}, \mathrm{Am}$ e $\mathrm{Cm}$ foram reservados para posterior eletrodeposição.

Para a determinação da eficiência e rendimento químico do ${ }^{241} \mathrm{Pu}$, uma alíquota de $10 \mathrm{~mL}$ da solução estoque de Pu foi retirada do balão volumétrico de $25 \mathrm{~mL}$, transferida para um vial e evaporada, os sais foram dissolvidos com $1 \mathrm{~mL}$ de $\mathrm{HNO}_{3}$ 0,1 mol . L-1 e em seguida adicionou-se $15 \mathrm{~mL}$ de solução cintiladora (coquetel de cintilação Ultima-Gold AB).

\subsubsection{Eletrodeposição do U, Pu, Am e Cm}

Os eluatos obtidos foram secos em chapa aquecedora e, em seguida, dissolvidos com 3 gotas de ácido sulfúrico $\left(\mathrm{H}_{2} \mathrm{SO}_{4}\right) 3 \mathrm{~mol}$. L-1 e $3 \mathrm{~mL}$ de sulfato de amônio $\left(\left(\mathrm{NH}_{4}\right)_{2} \cdot \mathrm{SO}_{4}\right)$ 0,8 $\mathrm{mol}$. $\mathrm{L}^{-1}$. As amostras foram transferidas para as células

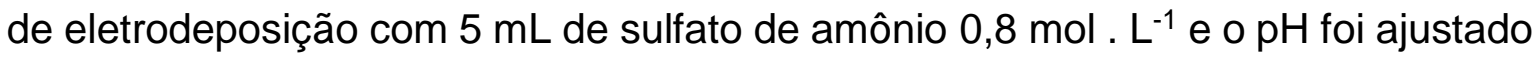
entre 2 e 3 com hidróxido de amônio $\left(\mathrm{NH}_{4} \mathrm{OH} 28 \%\right.$ ) e $\mathrm{H}_{2} \mathrm{SO}_{4} 3 \mathrm{~mol}$. L $\mathrm{L}^{-1}$, utilizando 3 gotas de azul de timol $0,1 \%$ como indicador. A cor considerada como ponto de viragem foi o salmão claro. A eletrodeposição foi conduzida sob corrente de 1,20 A por 90 minutos, sobre discos de prata previamente polidos. Após a eletrodeposição, os discos foram enxaguados com água destilada, solução de álcool etílico 70\% e secos sobre uma chapa aquecedora. As amostras eletrodepositadas foram então analisadas em um espectrômetro alfa. A Figura 6 apresenta um fluxograma de separação dos isótopos de $\mathrm{U}, \mathrm{Pu}, \mathrm{Am}$ e $\mathrm{Cm}$. 
Figura 6-Fluxograma de separação dos isótopos de U, Pu, Am e Cm



FONTE: autor da tese

\subsubsection{Determinação do ${ }^{90} \mathrm{Sr}$}

Em um béquer foram adicionados $20 \mathrm{~mL}$ da solução estoque (balão $100 \mathrm{~mL}$ ) e $1 \mathrm{~mL}$ de solução carreadora de carbonato de estrôncio $\left(\mathrm{SrCO}_{3}\right)$ 0,1 g . $\mathrm{L}^{-1}$. A amostra foi percolada em uma coluna de extração cromatográfica (resina Sr), previamente condicionada com $50 \mathrm{~mL}$ de $\mathrm{HNO}_{3} 8 \mathrm{~mol}$. L L $\mathrm{L}^{-1}$. Após a percolação da amostra, foram adicionados 3 porções de $10 \mathrm{~mL}$ de $\mathrm{HNO}_{3} 8 \mathrm{~mol} . \mathrm{L}^{-1}$ e todo o efluente foi descartado. O Sr retido na resina foi eluído com 3 porções de $10 \mathrm{~mL}$ de $\mathrm{HNO}_{3} 0,05 \mathrm{~mol}$. L $\mathrm{L}^{-1}$ e a fração eluída foi coletada para determinação da atividade por contagem de cintilação em meio líquido. Foram adicionados $0,3 \mathrm{~g}$ de ácido oxálico $\left(\mathrm{H}_{2} \mathrm{C}_{2} \mathrm{O}_{4}\right)$ à fração eluída e a solução obtida foi aquecida. O Sr foi precipitado a quente com $\mathrm{NH}_{4} \mathrm{OH}$ concentrado e o pH da solução foi elevado até 9,5 - 10 .

A amostra foi mantida em repouso durante 1 hora e o precipitado foi separado por filtração com papel faixa azul. O papel contendo o precipitado foi seco 
em estufa aquecida previamente até $100^{\circ} \mathrm{C}$ por 1 hora. Em seguida, esse papel foi colocado em um vial para análise no cintilador e foi adicionado $1 \mathrm{~mL}$ de $\mathrm{HNO}_{3} 1 \mathrm{~mol}$. L-1 para dissolver o precipitado. O vial foi fechado, aquecido levemente em chapa aquecedora e nele foram adicionados $15 \mathrm{~mL}$ de solução cintiladora (coquetel Ultima Gold AB Packard). A amostra foi, então, analisada em um espectrômetro de cintilação em meio líquido.

A Figura 7 apresenta um fluxograma de separação do ${ }^{90} \mathrm{Sr}$.

Figura 7-Fluxograma de separação do ${ }^{90} \mathrm{Sr}$

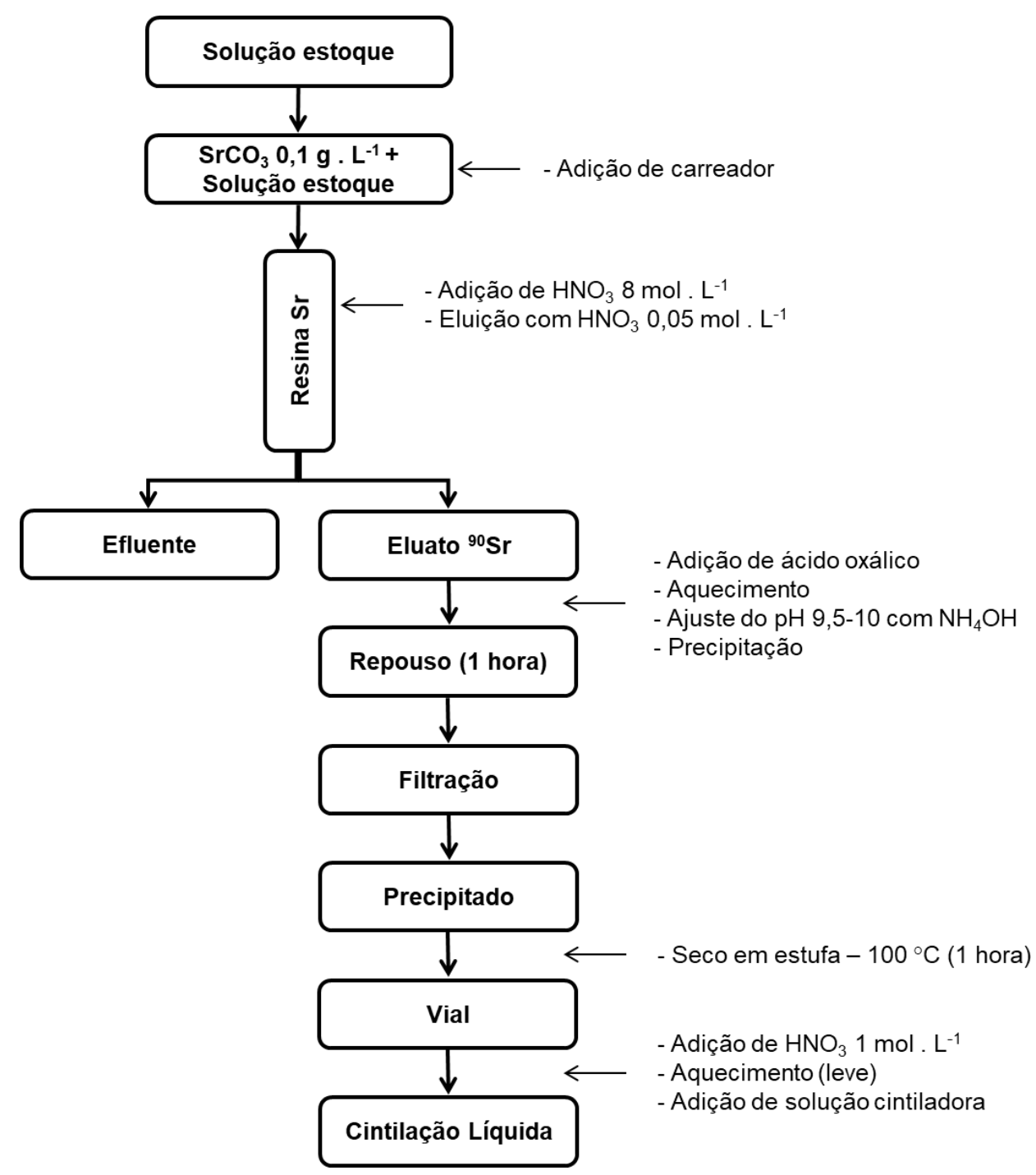

FONTE: autor da tese

\subsubsection{Determinação do ${ }^{63} \mathrm{Ni}$}

Na separação e determinação do Ni são empregadas as técnicas de quelação, cromatografia aniônica, precipitação com amônio ou com dimetilglioxima. No entanto, para uma separação eficiente dos isótopos de Ni de interferentes como 
isótopos radioativos de Cs, Sr e lantanídeos, é necessário combinar procedimentos radioquímicos (TADDEl et al., 2013). Apesar de não haver ${ }^{55} \mathrm{Fe}$ nos filtros, devido à meia-vida curta desse elemento e do tempo de estocagem dos filtros, a presença de Fe estável pode interferir na análise do Ni. Assim, empregou-se um procedimento sequencial para determinação de $\mathrm{Ni}$ e Fe, baseado na precipitação inicial com hidróxidos seguido da cromatografia aniônica para separar $\mathrm{Ni}$ de Fe e na extração cromatográfica com colunas impregnadas com DMG para purificação de Ni (TADDEl et al., 2013b; TADDEl et al., 2013c).

Em um béquer foram adicionados $15 \mathrm{~mL}$ da solução estoque (balão $100 \mathrm{~mL}$ ) e $2 \mathrm{~mL}$ de solução padrão de $1.000 \mathrm{mg}$. $\mathrm{L}^{-1}$ de Ni da marca Merck, ajustou-se o pH para 9 com hidróxido de sódio $(\mathrm{NaOH})$, onde ocorre a precipitação do hidróxido de níquel II $\left(\mathrm{Ni}(\mathrm{OH})_{2}\right)$. Após a separação por centrifugação, dissolveuse o precipitado com $5 \mathrm{~mL}$ de $\mathrm{HCl} 9 \mathrm{~mol} . \mathrm{L}^{-1}$, percolou em uma coluna de troca aniônica (Dowex 1x8), com 0,8 cm de diâmetro interno e $10 \mathrm{~cm}$ de comprimento, previamente condicionada com $20 \mathrm{~mL}$ de $\mathrm{HCl} 9 \mathrm{~mol}$. $\mathrm{L}^{-1}, 0 \mathrm{Ni}^{+3}$ passa pela resina sendo recolhido por conter os isótopos de $\mathrm{Ni}$.

Lavou-se a coluna com $40 \mathrm{~mL}$ de $\mathrm{HCl} 9 \mathrm{~mol} . \mathrm{L}^{-1}$, recolhendo, lavou-se a coluna novamente com $30 \mathrm{~mL}$ de $\mathrm{HCl} 4 \mathrm{~mol} . \mathrm{L}^{-1}$ eliminando o $\mathrm{Co}^{+2}$, essa porção foi descartada, lavou-se a coluna com $30 \mathrm{~mL}$ de $\mathrm{HCl} 0,5 \mathrm{~mol} . \mathrm{L}^{-1}$, descartando.

O efluente contendo $\mathrm{Ni}$ foi evaporado, e os sais foram solubilizados com $2 \mathrm{~mL}$ de $\mathrm{HCl} 1 \mathrm{~mol}$. $\mathrm{L}^{-1}$ e $2 \mathrm{~mL}$ de solução de citrato de amônio $\left(\left(\mathrm{NH}_{4}\right)_{2} \mathrm{HC}_{6} \mathrm{H}_{5} \mathrm{O}_{7}\right) 1 \mathrm{~mol}$. $\mathrm{L}^{-1}$. O ajuste do $\mathrm{pH}$ para 8-9 foi feito lentamente com $\mathrm{NH}_{4} \mathrm{OH}$ concentrado, a solução contendo $\mathrm{Ni}$ foi percolada em uma coluna de extração cromatográfica (resina $\mathrm{Ni}$, contendo um suporte polimérico impregnado com DMG), lavada com $20 \mathrm{~mL}$ de solução de citrato de amônio 0,2 mol . L-1 a pH 8, o efluente foi descartado. A função do citrato de amônio consiste em impedir que precipitados constituídos por hidróxidos de metais, como $\mathrm{Fe}, \mathrm{Cr}$ e Eu, se formem na coluna, bloqueiem-na e dificultem o processo de separação.

O Ni foi eluído da coluna com $10 \mathrm{~mL}$ de $\mathrm{HNO}_{3} 3 \mathrm{~mol} . \mathrm{L}^{-1}$, evaporado numa chapa aquecedora até aproximadamente $1 \mathrm{~mL}$, adicionaram-se $5 \mathrm{~mL}$ de água e evaporou-se novamente, deixando ficar aproximadamente $1 \mathrm{~mL}$, adicionou $2 \mathrm{~mL}$ de água, pipetou-se uma alíquota de $0,1 \mathrm{~mL}$ e avolumou-se para $10 \mathrm{~mL}$ com $\mathrm{HNO}_{3} 1 \%$, para a determinação do rendimento químico do Ni por ICP-OES; 
Ao restante da solução, adicionaram-se $15 \mathrm{~mL}$ de solução cintiladora (coquetel de cintilação Ultima-Gold $\mathrm{AB}$ ) para determinar a concentração de atividade do ${ }^{63} \mathrm{Ni}$ por cintilação em meio liquido, utilizando o canal 5 a 600 por 3600 segundos. A eficiência de detecção do contador foi determinada usando um padrão de ${ }^{63} \mathrm{Ni}$. A Figura 8 apresenta um fluxograma de separação do ${ }^{63} \mathrm{Ni}$.

Figura 8-Fluxograma de separação do ${ }^{63} \mathrm{Ni}$

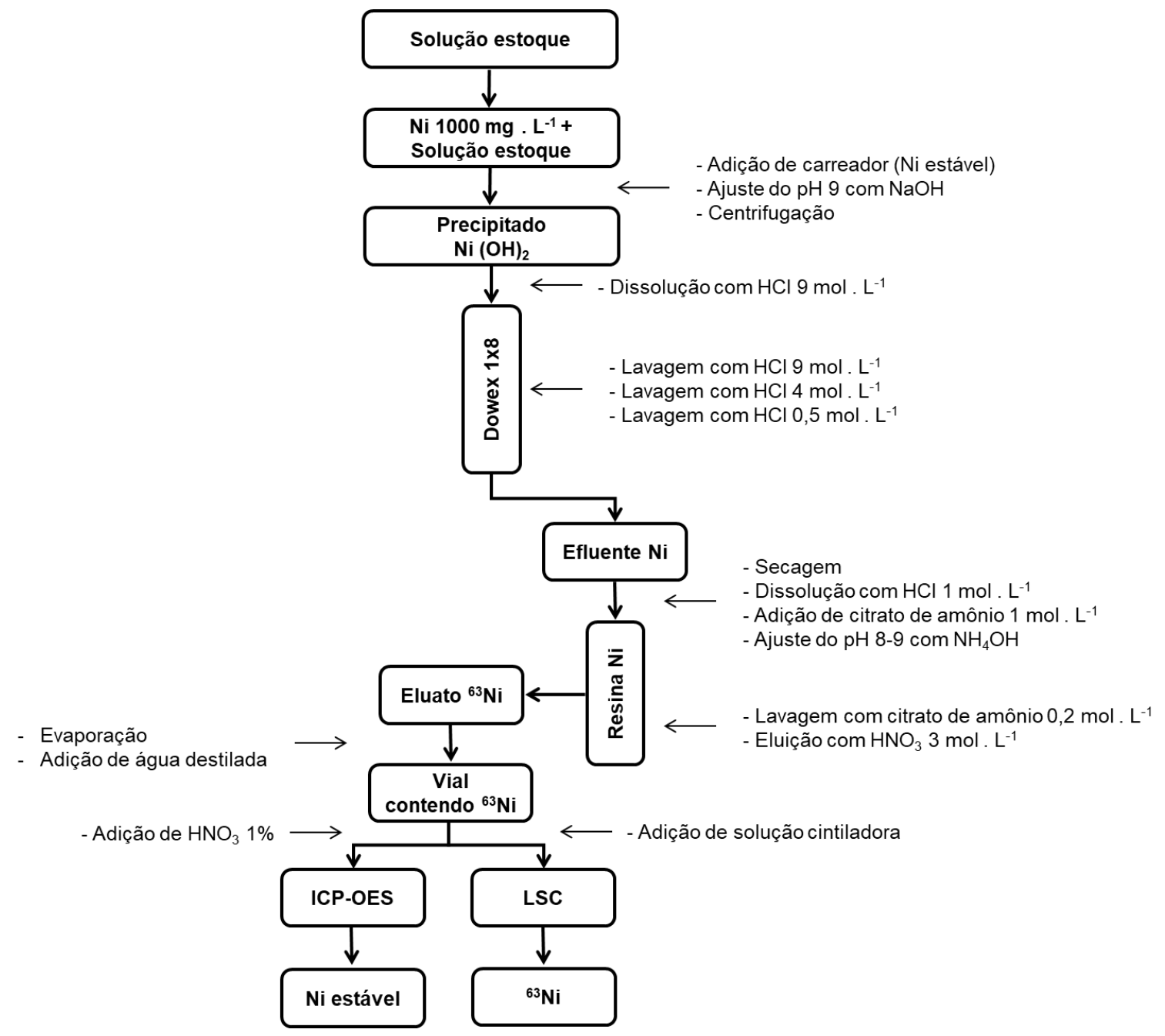

FONTE: autor da tese

\subsubsection{Determinação do ${ }^{14} \mathrm{C}$ e ${ }^{3} \mathrm{H}$}

Para determinar a atividade do ${ }^{14} \mathrm{C}$ e ${ }^{3} \mathrm{H}$ é necessário decompor a amostra que os contém, visando separar um radionuclídeo do outro, bem como separar ambos da matriz de rejeito radioativo e dos demais radionuclídeos interferentes e o procedimento por combustão é o mais utilizado para decomposição das amostras (BERG e FONNESBECK, 2001; MAGNUSSON et al., 
2008). Nesse procedimento, a amostra é misturada com oxidante e catalisador, como pentóxido de vanádio $\left(\mathrm{V}_{2} \mathrm{O}_{5}\right)$ ou óxido de cobre $(\mathrm{CuO})$, e aquecida a temperaturas entre 700 e $800{ }^{\circ} \mathrm{C}$ em forno tubular com a passagem de $\mathrm{N}_{2}$ puro através do tubo para arraste dos elementos. O processo é demorado e necessita de 4 a 6 horas para se completar (HOU, 2005).

No entanto, há equipamentos, disponíveis comercialmente, que permitem a combustão da amostra e separação do ${ }^{14} \mathrm{C}$ e do ${ }^{3} \mathrm{H}$. A maior vantagem desses equipamentos provém do fato de que o procedimento por combustão é o único que permite separar ${ }^{3} \mathrm{H}$ e ${ }^{14} \mathrm{C}$ antes das contagens, evitando assim a ocorrência de erros analíticos em amostras que contêm ambos radionuclídeos.

A proposta inicial neste trabalho era empregar 0 equipamento automático de combustão de amostra e separação de ${ }^{3} \mathrm{H}$ e ${ }^{14} \mathrm{C}$ adquirido pela GRR, da PerkinElmer Life and Analytical Sciences, modelo Sample Oxidizer 307, que oxida a amostra e separa esses radionuclídeos em frascos (vials) de contagem distintos (PERKIN ELMER, 2003). Nesse equipamento, aproximadamente 0,2 gramas das amostras são misturadas com pó de celulose e queimadas a temperaturas entre 1000 e $1200^{\circ} \mathrm{C}$. A combustão da amostra é realizada num fluxo contínuo de $\mathrm{O}_{2}$ puro, formando água e dióxido de carbono $\left(\mathrm{CO}_{2}\right)$. A água triciada transforma-se em vapor que passa pelo condensador e, depois de condensada, é coletada em um frasco (vial) de contagem específico, no qual o reagente Monophase $®$ S é automaticamente adicionado e está pronta para contagem em um equipamento de cintilação em meio líquido. Já o carbono é oxidado a dióxido de carbono, que passa através do sistema coletor de ${ }^{3} \mathrm{H}$ e depois pelo sistema coletor de ${ }^{14} \mathrm{C}$. O dióxido de carbono é retido em uma coluna com o absorvente Carbosorb® E (2- metoxi- etilamina), formando carbamatos. Os carbamatos assim formados são encaminhados para o frasco (vial) de contagem específico de ${ }^{14} \mathrm{C}$, no qual $15 \mathrm{~mL}$ do coquetel Permafluor® E, que atua também como reagente de lavagem, são adicionados. Da mesma forma que $0{ }^{3} \mathrm{H}$, a amostra já está pronta para a contagem.

No entanto, o equipamento que seria empregado neste trabalho, apresentou problemas desde sua instalação, não sendo possível sua utilização. De qualquer forma, seria empregado apenas para a determinação do ${ }^{14} \mathrm{C}$, uma vez que, o ${ }^{3} \mathrm{H}$ foi evaporado no período em que os filtros estavam escoando a água, 
antes do acondicionamento. A Figura 9 apresenta um fluxograma do funcionamento do equipamento Oxidizer 307 da PerkinElmer (PERKIN ELMER, 2003).

Figura 9-Fluxograma de separação do ${ }^{14} \mathrm{C}$ e ${ }^{3} \mathrm{H}$

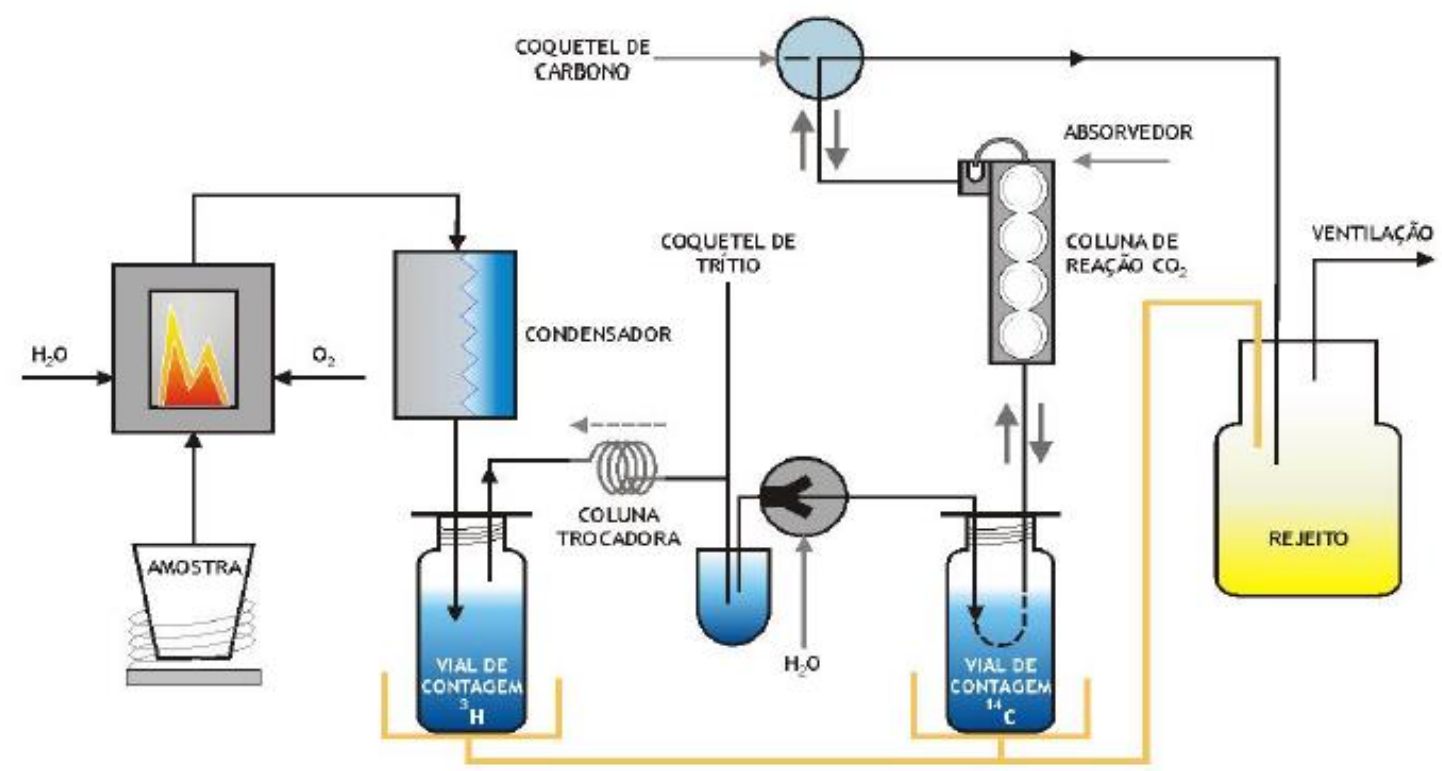

FONTE: Taddei, 2013.

\subsection{Quantificação dos radionuclídeos}

A atividade dos radionuclídeos emissores gama foi determinada por um espectrômetro gama, constituído por um detector de germânio hiperpuro (HPGe) (Modelo GX 2518 da Canberra Industries), com eficiência relativa de 25\%, resolução de Largura à Meia Altura (FWHM, sigla do inglês para Full Width at Half Maximum) a $1332 \mathrm{keV}: 1,8 \mathrm{keV}$, acoplado a um analisador multicanal com 8186 canais e um computador. Na Figura 10 é mostrado o espectrômetro gama utilizado. Para a aquisição e tratamento dos dados foi utilizado o software Genie 2000. O tempo de contagem foi de 35000,0 segundos para cada amostra.

O sistema de espectrometria alfa (modelo Alpha Analyst) da Canberra Industries, empregado neste trabalho é constituído de detectores semicondutores de barreira de superfície - Passivated Implanted Planar Silicon (PIPS), com $450 \mathrm{~mm}^{2}$ de área ativa. Cada detector possui uma resolução de aproximadamente $20 \mathrm{keV}$ (FWHM), eficiência de contagem de 17 - 19\% para uma distância fontedetector de $0,5 \mathrm{~cm}$, previamente calibrado para energia de 3000 a $10000 \mathrm{keV}$, acoplado a um computador. Na Figura 11 é mostrado o espectrômetro alfa utilizado. Para a aquisição e tratamento dos dados foi utilizado o software Genie 2000. O 
tempo de contagem foi de $200.000,0$ segundos para cada radionuclídeo (CANBERRA, 2016).

Para a determinação das atividades dos radionuclídeos emissores beta utilizou-se um espectrômetro de cintilação em meio líquido (modelo $300 \mathrm{SL}$ ) da Hidex Oy, com Triple to Double Coincidence Ratio (TDCR) automático, composto de três fotomultiplicadoras acopladas com os pulsos de coincidência, nível de discriminação e acoplado a um computador. Na Figura 12 é mostrado o espectrômetro de cintilação em meio líquido utilizado. Para a aquisição e tratamento dos dados foi utilizado o software mikroWin 2000. O tempo de contagem variou de 3600 - 18000 segundos de acordo com cada radionuclídeo.

As análises envolvendo a técnica de espectrometria de emissão óptica com plasma de argônio (ICP-OES, sigla do inglês para inductively coupled plasma optical emission spectrometry) foram realizadas no Laboratório de Análises Químicas e Ambiental (LAQA) do departamento Centro de Química e Meio Ambiente (CQMA) do IPEN. 
Figura 10-Espectrômetro gama

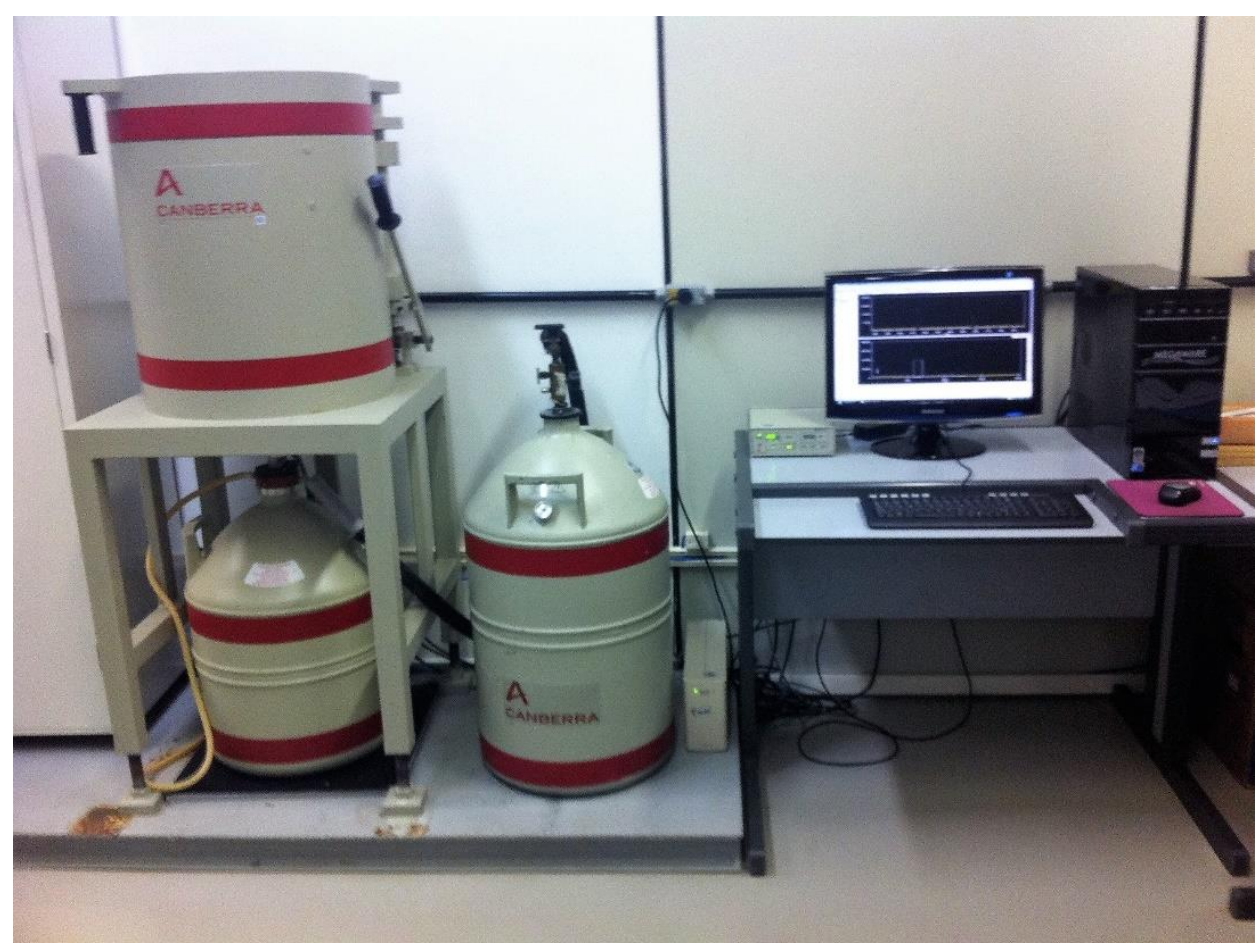

Fonte: autor da tese.

Figura 11-Espectrômetro alfa

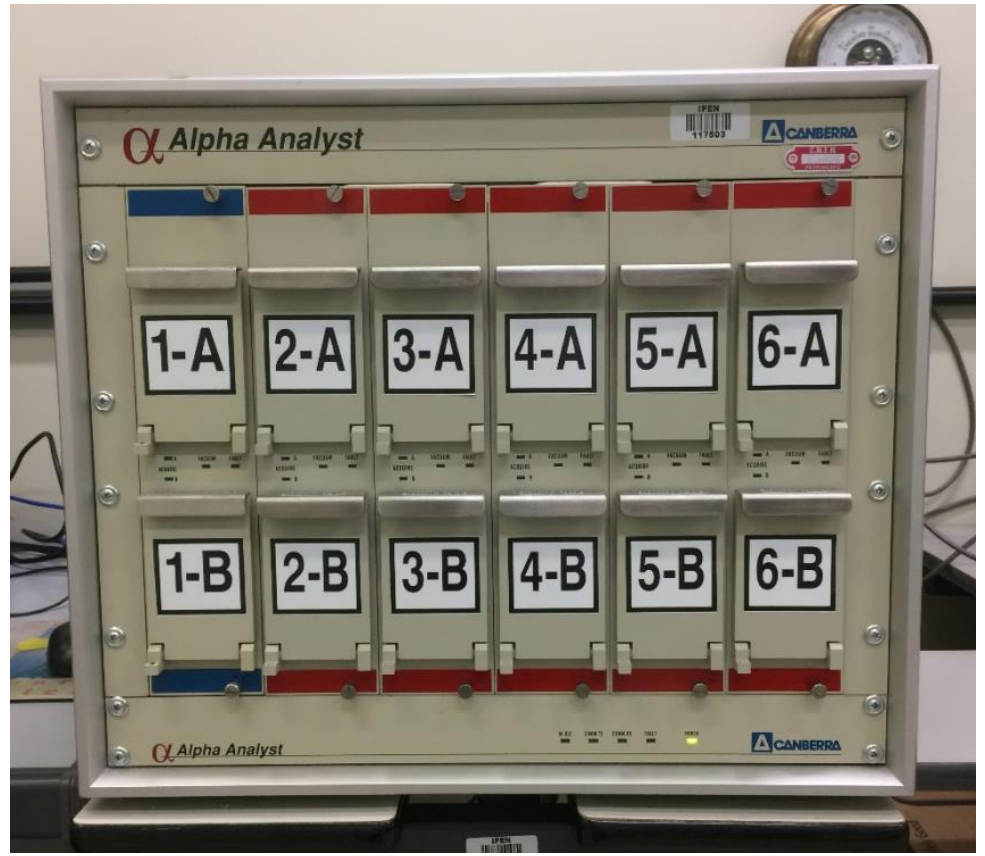

Fonte: autor da tese. 
Figura 12-Espectrômetro de cintilação em meio líquido

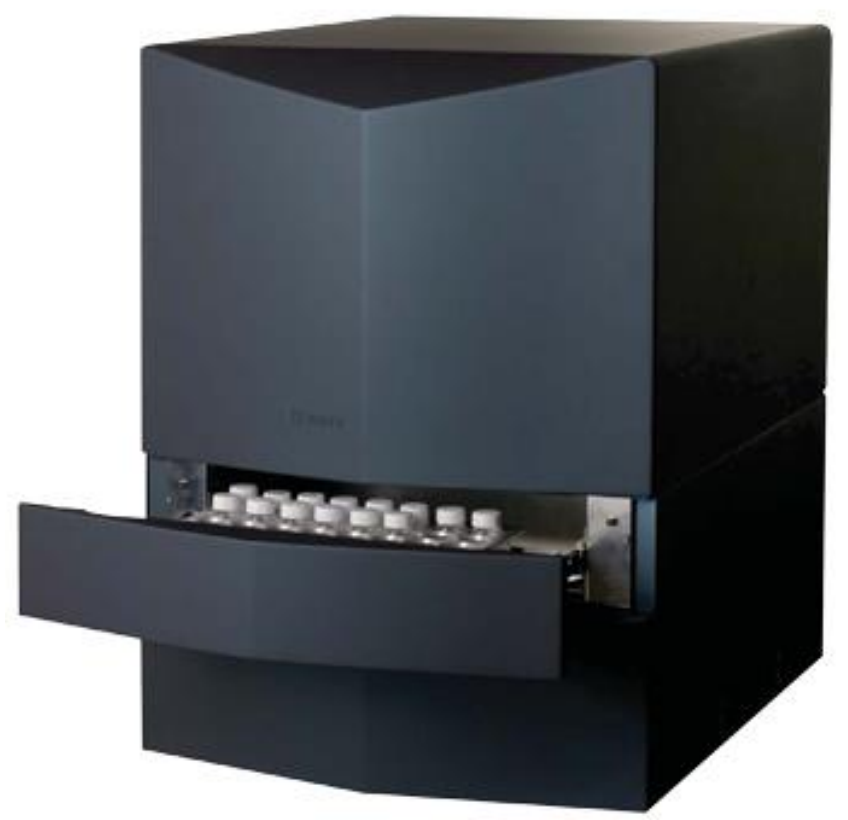

Fonte: autor da tese.

\subsection{Calibração dos equipamentos}

\subsubsection{Espectrômetro gama}

Para garantir a correta identificação e quantificação dos radionuclídeos, o sistema foi calibrado em energia, resolução e eficiência de contagem, utilizandose de uma fonte padrão mista líquida contendo ${ }^{60} \mathrm{Co},{ }^{137} \mathrm{Cs}$ e ${ }^{241} \mathrm{Am}$, com picos de energia em: $1332,49,661,66$ e 59,54 keV, respectivamente.

\subsubsection{Espectrômetro alfa}

No espectrômetro alfa, o sistema foi calibrado em energia, resolução e eficiência de contagem, para garantir a correta identificação e quantificação dos radionuclídeos, e para isto, foi utilizada uma fonte padrão mista eletrodepositada contendo 1,301 Bq de ${ }^{234} \mathrm{U}, 1,317 \mathrm{~Bq}$ de ${ }^{238} \mathrm{U}, 1,573 \mathrm{~Bq}{ }^{239} \mathrm{Pu}$ e 1,695 Bq de ${ }^{241} \mathrm{Am}$, certificada pela Analytics Inc. e rastreável pelo NIST, modelo SRS 63997-121.

\subsubsection{Espectrômetro de cintilação em meio líquido}

A calibração em eficiência de contagem foi realizada para cada radionuclídeo, utilizando um padrão do mesmo isótopo a ser determinado $\left({ }^{90} \mathrm{Sr}\right.$, 
${ }^{63} \mathrm{Ni},{ }^{241} \mathrm{Pu}$ ), com atividade aproximada de $20 \mathrm{~Bq}$, adicionado diretamente no vial seguido de $15 \mathrm{~mL}$ de solução cintiladora e o tempo de contagem foi o mesmo utilizado para as amostras.

\subsection{Quantificação dos radionuclídeos}

\subsubsection{Radionuclídeos emissores de raios gama}

Para calcular as atividades dos radionuclídeos emissores de raios gama presentes nos filtros, foi aplicada a Equação (1). A amostra de fundo, conhecida como background (BG) foi preparada e analisada nas mesmas condições das amostras, ou seja, foram adicionados $10 \mathrm{~mL}$ de solução de $\mathrm{HNO}_{3} 8 \mathrm{~mol}$. L-1 em um vial. O resultado foi posteriormente subtraído dos resultados obtidos para cada amostra.

$$
\mathrm{A}=\frac{\mathrm{A}_{\mathrm{p}}}{\varepsilon(\mathrm{E}) \cdot \mathrm{I} \gamma \cdot \mathrm{T}}
$$

Em que:

$\mathrm{A}=$ atividade $(\mathrm{Bq})$;

$A p=$ área do pico (já corrigida para o $B G$ );

$\varepsilon(E)=$ eficiência do detector;

IY = probabilidade de emissão da energia;

$\mathrm{T}=$ tempo de contagem (s).

\subsubsection{Radionuclídeos emissores alfa}

Para calcular as concentrações de atividades dos radionuclídeos emissores alfa nos filtros, por espectrometria alfa, aplicou-se a Equação (4). Para calcular o determinado e o coeficiente de recuperação química, aplicaram-se as equações (2) e (3), respectivamente.

O BG, foi preparado e analisado nas mesmas condições das amostras, ou seja, ao invés de utilizar uma alíquota de $20 \mathrm{~mL}$ da solução estoque para a separação radioquímica, utilizou-se uma alíquota de $20 \mathrm{~mL}$ de $\mathrm{HNO}_{3} 8 \mathrm{~mol}$. L-1. O resultado foi posteriormente subtraído dos resultados obtidos para cada amostra.

$$
\begin{gathered}
\text { Determinado }=\frac{\text { Área }}{\mathrm{T} \cdot \varepsilon} \\
\mathrm{RQ}=\frac{\text { Determinado }}{\text { Adicionado }}
\end{gathered}
$$




$$
\mathrm{C}_{1}=\frac{\mathrm{A}_{2}}{\mathrm{RQ} \cdot \varepsilon \cdot \mathrm{T} \cdot \mathrm{m}}
$$

Em que:

Determinado $=$ concentração de atividade determinada $\left(\mathrm{Bq} \cdot \mathrm{mL}^{-1}\right)$;

Área = área do traçador;

$\mathrm{T}=$ tempo de análise (s);

$\varepsilon=$ eficiência de contagem do equipamento;

$R Q$ = fator de recuperação química;

Adicionado $=$ concentração de atividade adicionada $\left(\mathrm{Bq} \cdot \mathrm{mL}^{-1}\right)$;

$\mathrm{C}_{1}=$ concentração de atividade $\left(\mathrm{Bq} \cdot \mathrm{g}^{-1}\right)$;

$\mathrm{A}_{2}$ = área do radionuclídeo a ser determinado (já corrigida para o $\mathrm{BG}$ );

$\mathrm{m}=$ massa de amostra $(\mathrm{g})$.

\subsubsection{Radionuclídeos emissores beta}

Para as análises de Sr e Ni por espectrometria de cintilação em meio líquido, as concentrações de atividades dos radionuclídeos foram calculadas aplicando-se a Equação (5).

O BG, foi preparado e analisado nas mesmas condições das amostras, ou seja, ao invés de utilizar uma alíquota de (20 mL para $\mathrm{Sr}$ e $15 \mathrm{~mL}$ para Ni) da solução estoque para a separação radioquímica, utilizou-se uma alíquota de $(20 \mathrm{~mL}$ para $\mathrm{Sr}$ e $15 \mathrm{~mL}$ para $\mathrm{Ni}$ ) de $\mathrm{HNO}_{3} 8 \mathrm{~mol}$. $\mathrm{L}^{-1}$. Os resultados foram posteriormente subtraídos dos resultados obtidos para cada amostra.

$$
\mathrm{C}_{\text {amostra }}=\frac{\mathrm{CPM}_{\mathrm{amostra}}-\mathrm{CPM}_{\mathrm{BG}}}{\mathrm{m} \cdot 60 \cdot \mathrm{RQ} \cdot \varepsilon}
$$

Em que:

$\mathrm{C}_{\text {amostra }}=$ Concentração de atividade $\left(\mathrm{Bq} \cdot \mathrm{g}^{-1}\right)$;

CPMamostra = Contagens por minuto da amostra;

$\mathrm{CPM}_{\mathrm{BG}}=$ Contagens por minuto do background;

$\mathrm{m}=$ massa de amostra $(\mathrm{g})$;

$R Q$ = fator de recuperação química;

$\varepsilon=$ eficiência da contagem.

Para a análise de ${ }^{241}$ Pu por espectrometria de cintilação em meio líquido, as concentrações de atividades foram calculadas aplicando-se a Equação (6). 
O BG, foi preparado e analisado nas mesmas condições das amostras, ou seja, ao invés de utilizar uma alíquota de $20 \mathrm{~mL}$ da solução estoque para a separação radioquímica, utilizou-se uma alíquota de $20 \mathrm{~mL}$ de $\mathrm{HNO}_{3} 8 \mathrm{~mol}$. L-1. O resultado foi posteriormente subtraído dos resultados obtidos para cada amostra.

$$
A_{1}=\frac{A_{2} \cdot R_{1} \cdot 100 \%}{\varepsilon \cdot R_{2} \cdot \alpha \cdot m \cdot 60}
$$

Na qual:

$\mathrm{A}_{1}=$ concentração de atividade de ${ }^{241} \mathrm{Pu}$ na amostra $\left(\mathrm{Bq} \cdot \mathrm{g}^{-1}\right)$;

$\mathrm{A}_{2}=$ atividade do traçador de ${ }^{242} \mathrm{Pu}$ adicionado (dpm);

$\mathrm{R}_{1}$ = taxa de contagem líquida $(\mathrm{cpm})$ de ${ }^{241} \mathrm{Pu}$ por cintilação em meio líquido (já corrigida para o BG);

$\varepsilon=$ eficiência de detecção das partículas beta emitidas pelo ${ }^{241} \mathrm{Pu}$;

$\mathrm{R}_{2}=$ taxa de contagem líquida total das partículas alfa (cpm) por cintilação em meio líquido (já corrigida para o BG);

$\alpha=$ razão entre a contagem de partículas alfa emitidas pelo ${ }^{242} \mathrm{Pu}$ e a contagem total de partículas alfa medida no espectrômetro alfa;

$\mathrm{m}=$ massa da amostra $(\mathrm{g})$.

Todos os resultados obtidos em concentração de atividade $\left(\mathrm{Bq} \cdot \mathrm{g}^{-1}\right)$ foram convertidos para atividade $(\mathrm{Bq})$, utilizando as massas totais dos filtros.

\subsubsection{Cálculo da Atividade Mínima Detectável (MDA)}

A MDA dos isótopos foi calculada aplicando-se a Equação (7) (FERNANDO, 2013):

$$
\operatorname{MDA}=\frac{\mathrm{k}^{2}+2 \sqrt{2} \cdot \mathrm{k} \cdot \sigma}{\mathrm{T} \cdot \varepsilon \cdot \mathrm{y}}
$$

Na qual:

$\mathrm{k}=$ constante $^{\star} 1,645$;

$\sigma=$ desvio padrão das contagens no pico de energia;

$\mathrm{T}=$ tempo de contagem para aquisição do espectro (s);

$\varepsilon=$ eficiência do detector no pico de energia;

$\mathrm{y}=$ yield para energia do radionuclídeo.

*Assumindo que os riscos de $5 \%$ são aceitáveis e que os erros aleatórios são distribuídos normalmente, a constante $\mathrm{k}$, assume o valor 1,645. 


\subsection{Cálculo do escore-Z}

O cálculo do escore-Z faz uma transformação dos valores reais em valores codificados. Esta transformação é feita a partir da razão entre a diferença do valor de atividade observada e a média obtida entre todas as fatias de filtro e o desvio padrão, conforme a Equação (8):

$$
\mathrm{Z}=\frac{\mathrm{x}-\overline{\mathrm{x}}}{\sigma}
$$

Em que:

$Z$ = valores codificados;

$x=$ variável aleatória;

$\bar{x}=$ média;

$\sigma=$ desvio padrão.

\subsection{Fator de escala}

A partir dos resultados obtidos para a concentração de atividade dos radionuclídeos selecionados para estudo, o Fator de Escala (FE) é definido a partir da Equação (9) (NIESE e BODEN, 1995; NIESE e GLEISBERG, 1995; NIESE e GLEISBERG, 1996; IAEA, 1997; EPRI, 1999; ISO, 2007; IAEA, 2007; REMEIKIS et al., 2009; IAEA, 2009; TADDEI, 2013):

$$
\mathrm{FE}=\frac{\mathrm{A}_{\mathrm{RDM}}}{\mathrm{A}_{\mathrm{RC}}}
$$

Na qual:

A RDM = atividade de um RDM;

$\mathrm{A}_{\mathrm{RC}}=$ atividade do $\mathrm{RC}$ correspondente.

Devido ao fato dos valores de FE poderem diferir até por ordens de grandeza, o valor médio FE do Fator de Escala é calculado pela média geométrica de acordo com a Equação (10) (EPRI, 1996; EPRI, 1999; IAEA, 2009; TADDEI, 2013):

$$
\overline{\mathrm{FE}}=\mathrm{e}^{\left(\frac{\sum_{\mathrm{i}=1}^{\mathrm{N}} \ln (\mathrm{FE})_{\mathrm{i}}}{\mathrm{N}}\right)}
$$

Em que:

$\mathrm{N}=$ número total de valores obtidos para o $\mathrm{FE}$. 
Por outro lado, o valor da dispersão $\sigma$ para o conjunto de dados constituído por essas medidas é calculado pela Equação (11) (EPRI, 1996; EPRI, 1999; IAEA, 2009; TADDEI, 2013):

$$
\mathrm{D}_{2 \sigma}=\mathrm{e}^{2 \cdot\left(\sqrt{\frac{\sum_{\mathrm{i}=1}^{\mathrm{N}}\left[\ln (\mathrm{FE})_{\mathrm{i}}-\ln (\overline{\mathrm{FE}})\right]^{2}}{\mathrm{~N}-1}}\right)}
$$

Convencionou-se que a existência de um Fator de Escala útil para caracterizar um conjunto de dados é definida somente se $D_{2 \sigma} \leq 10$, o que significa exigir que $95,5 \%$ dos valores do Fator de Escala obtidos a partir das medidas realizadas devam estar compreendidos dentro do intervalo apresentado na Equação (12) (U. S. NRC, 1983; EPRI, 1996; EPRI, 1999; IAEA, 2009; TADDEI, 2013):

$$
\frac{\overline{\mathrm{FE}}}{10} \leq(\mathrm{FE})_{\mathrm{i}} \leq \overline{\mathrm{FE}} \cdot 10
$$

Caso a condição definida pela Equação (12) não seja satisfeita, numa segunda tentativa busca-se estabelecer uma Função de Correlação (FC) entre o Radionuclídeo de Difícil Medição (RDM) e o Radionuclídeo Chave (RC) correspondente. 


\section{RESULTADOS E DISCUSSÃO}

\subsection{Homogeneidade dos filtros}

Os rejeitos radioativos são considerados homogêneos quando apresentam uma distribuição essencialmente uniforme de atividade e dos conteúdos físicos. Exemplos de rejeitos radioativos homogêneos são os concentrados, os líquidos solidificados e as resinas de troca iônica gastas. Em geral, são resíduos fluidos, nos quais pode ser assumido que a atividade está distribuída de maneira aproximadamente uniforme no volume, assim como nos fluxos de rejeitos misturados uniformemente em matriz sólida (ISO, 2007).

A matriz de rejeito radioativo estudada, o filtro cartucho, é considerada, de um modo geral, homogênea (ISO, 2007). Durante o período em que estes filtros estavam em uso (um conjunto com seis filtros), eles se encontravam na posição vertical, imersos em água que percorria toda sua extensão com a finalidade de ser filtrada, passada sob alta pressão. Entretanto, antes de serem removidos em definitivo do reator IEA-R1, eles ficaram estocados nas dependências do reator, armazenados dentro de baldes plásticos, na posição inclinada, com a finalidade de reduzir o excesso de água, a quantidade de radionuclídeos e as doses de radiação ocupacionais no processo de remoção e embalagem dos rejeitos radioativos. Em decorrência desse procedimento, pode acontecer um deslocamento dos radionuclídeos nas matrizes, em sentido da entrada para a saída dos fluxos, tornando-as não homogêneas devido à estratificação dos radionuclídeos.

Para avaliar o grau de homogeneidade dos rejeitos radioativos contidos em cada um dos cartuchos de filtro, aplicou-se o método para matrizes estáveis de rejeitos radioativos, segundo o qual a medida da distribuição de um ou mais radionuclídeos emissores de raios gama ou de elementos não radioativos é considerada suficiente para esse objetivo. Deste modo, os cartuchos de filtro podem ser declarados homogêneos se os resultados das atividades de ${ }^{60} \mathrm{Co}$ e/ou ${ }^{108 \mathrm{~m}} \mathrm{Ag}$ e/ou ${ }^{110 \mathrm{~m}} \mathrm{Ag}$ nas amostras retiradas em diferentes posições no comprimento do filtro estiverem dentro de um Intervalo Relativo (I.R.) de 30\% (TADDEI, 2013; IAEA, 2007). 
O ${ }^{60} \mathrm{Co}$ é um radionuclídeo representativo dos produtos de ativação, assim, por analogia torna-se possível supor que radionuclídeos não emissores de raios gama apresentam distribuição semelhante (TADDEI, 2013).

Na Figura 13 é apresentado um espectro dos raios gama, obtido como resultado de uma medida com duração de 35.000 segundos na amostra de filtro. É importante mencionar que dentre os únicos radionuclídeos emissores de raios gama presentes nos filtros $\left({ }^{60} \mathrm{Co},{ }^{108 \mathrm{~m}} \mathrm{Ag}\right.$ e ${ }^{110 \mathrm{~m}} \mathrm{Ag}$ ) com atividade elevada $\mathrm{O}$ suficiente para que fosse visível no espectro, apenas o primeiro havia sido previamente selecionado juntamente com o ${ }^{137} \mathrm{Cs}$ como RCs.

Figura 13-Espectro gama de Co e Ag obtido como resultado de medida, com duração de 35.000 segundos, em amostra de filtro

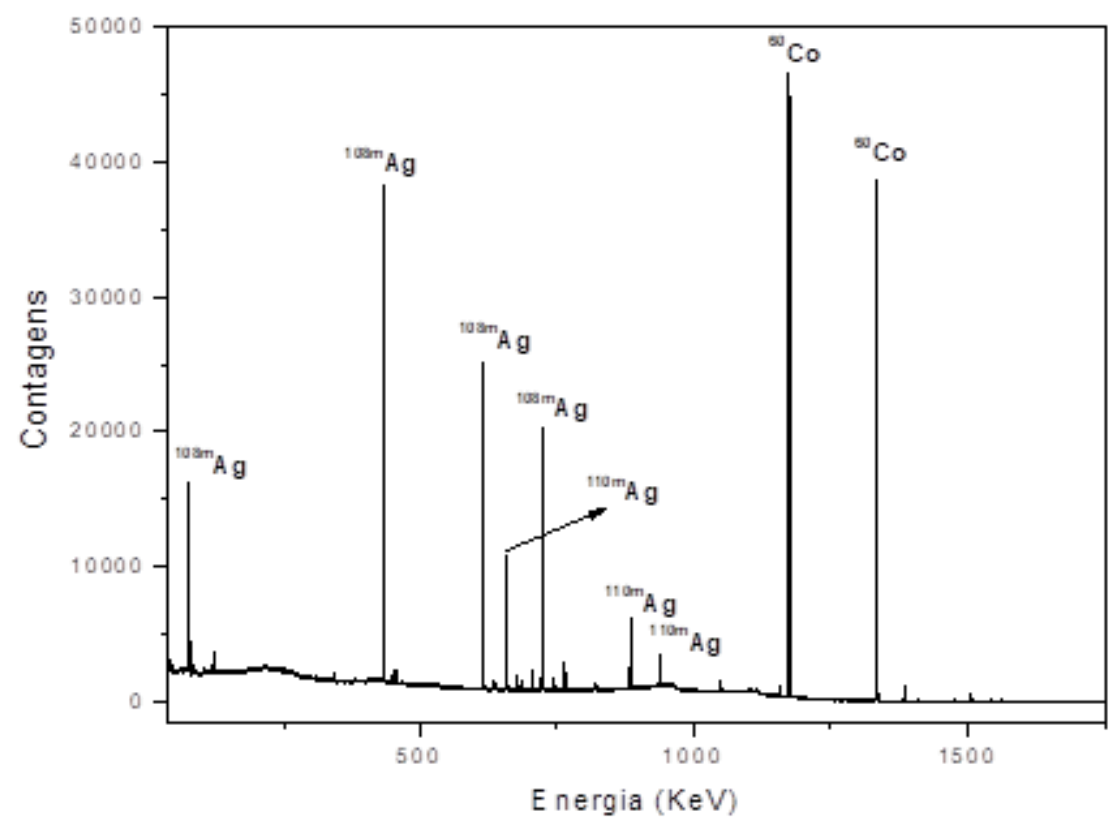

FONTE: autor da tese

Segundo TADDEI (2013), também merece destaque o fato dos picos correspondentes aos raios gama do ${ }^{60} \mathrm{Co}$ sempre aparecerem nesses espectros com nítida proeminência em relação aos picos de outros radionuclídeos, evidenciando que constituem ocorrências muito raras de falhas de combustível nuclear no longo histórico de operação do reator IEA-R1.

Diante do espectro de raios gama obtido de uma amostra de filtro, foi possível notar a ausência do ${ }^{137} \mathrm{Cs}$. Em um estudo realizado com amostras de carvão e resina de troca iônica também empregadas no tratamento da água do reator, TADDEI (2013) obteve concentrações de atividades médias para ${ }^{137} \mathrm{Cs}$ da 
ordem de $1,42 \times 10^{2} \mathrm{~Bq} \cdot \mathrm{g}^{-1}$ e $61,96 \times 10 \mathrm{~Bq} \cdot \mathrm{g}^{-1}$, respectivamente. Uma das propriedades físicas do césio é a temperatura de volatilização em $400^{\circ} \mathrm{C}$, deste modo a temperatura utilizada para a calcinação dos filtros foi de $350^{\circ} \mathrm{C}$, o que elimina a hipótese de o césio ter sido evaporado durante a calcinação. Outra propriedade relevante do césio é a alta solubilidade em água, que diante dos resultados obtidos por TADDEI (2013), foi possível confirmar que todo césio contido na água passou pelo filtro e ficou retido no carvão e na resina por adsorção e troca iônica, respectivamente, desta forma, não há ${ }^{137} \mathrm{Cs}$ nos filtros (OJOVAN e LEE, 2005).

Nas Figuras 14 a 21 são mostrados os resultados da avaliação da homogeneidade dos filtros. A representação gráfica foi elaborada com valores de escore-Z, em que a variável reduzida $Z$ faz uma transformação dos valores reais em valores codificados.

Figura 14-Avaliação da homogeneidade do filtro 5 , utilizando valores de escore-Z

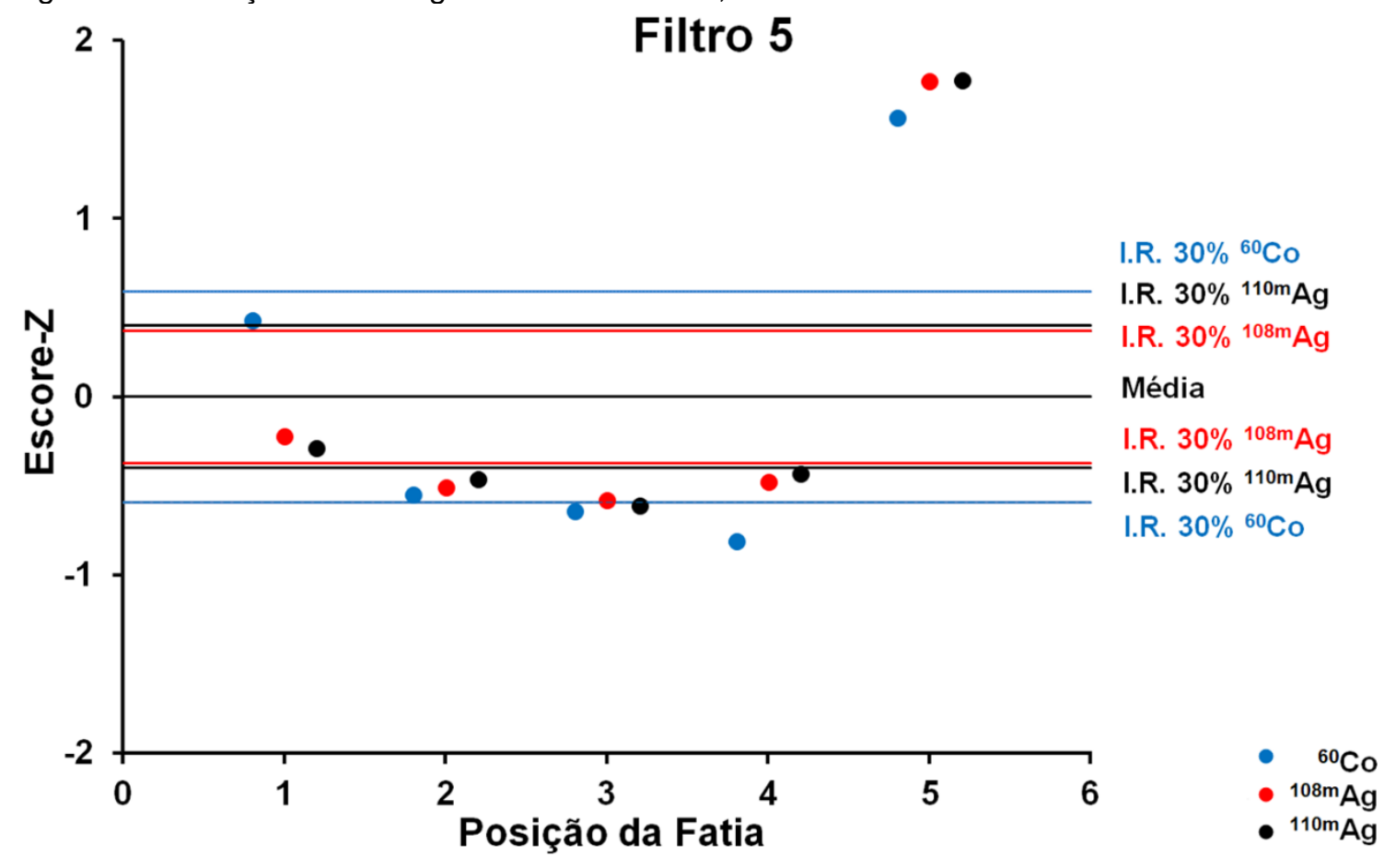

FONTE: autor da tese 
Figura 15-Avaliação da homogeneidade do filtro 6, utilizando valores de escore-Z

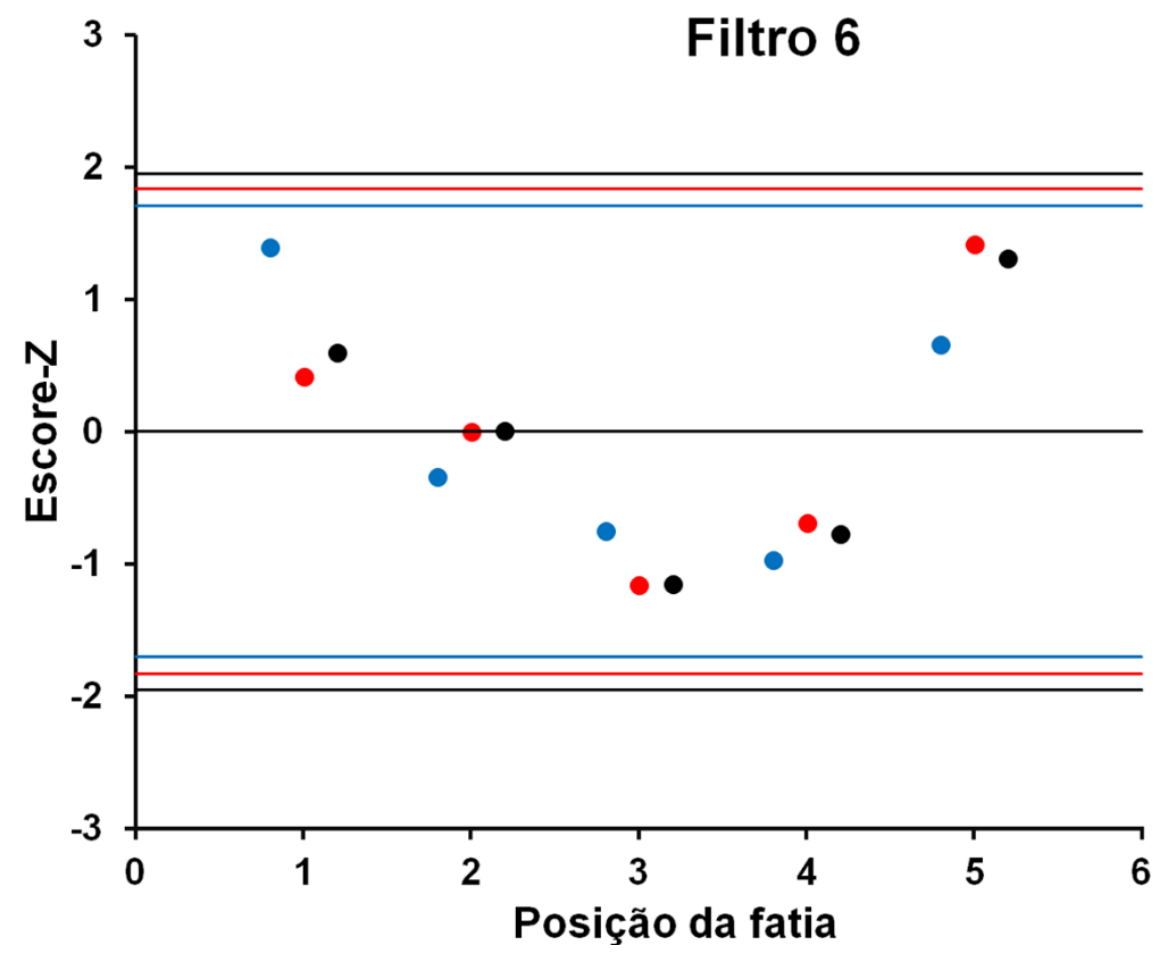

I.R. $30 \%{ }^{110 m} \mathrm{Ag}$

I.R. $30 \%{ }^{108 m} \mathrm{Ag}$

I.R. $30 \% \quad{ }^{60} \mathrm{Co}$

Média

I.R. $30 \% \quad{ }^{60} \mathrm{Co}$

I.R. $30 \%{ }^{108 m} \mathrm{Ag}$

I.R. $30 \%{ }^{110 \mathrm{~m} A g}$

FONTE: autor da tese

Figura 16-Avaliação da homogeneidade do filtro 7, utilizando valores de escore-Z

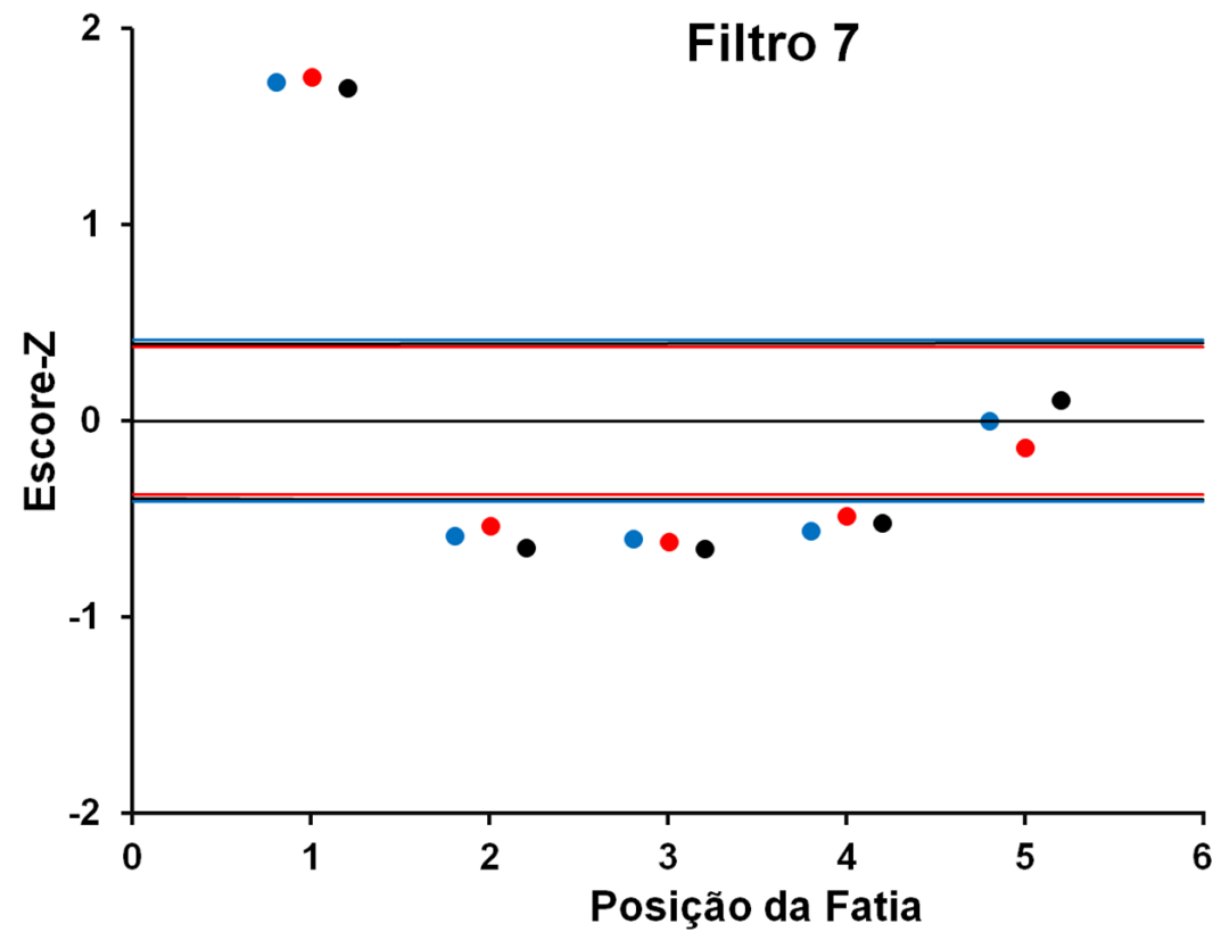

I.R. $30 \%{ }^{60} \mathrm{Co}$

I.R. $30 \%{ }^{110 \mathrm{~m}} \mathrm{Ag}$

I.R. $30 \%{ }^{108 \mathrm{~m}} \mathrm{Ag}$

Média

I.R. $30 \%{ }^{108 \mathrm{~m}} \mathrm{Ag}$

I.R. $30 \%{ }^{110 \mathrm{~m}} \mathrm{Ag}$

I.R. $30 \%{ }^{60} \mathrm{Co}$

FONTE: autor da tese

- ${ }^{60} \mathrm{Co}$

- $108 \mathrm{~m} \mathrm{Ag}$

- $110 \mathrm{~m} \mathrm{Ag}$ 
Figura 17-Avaliação da homogeneidade do filtro 8, utilizando valores de escore-Z

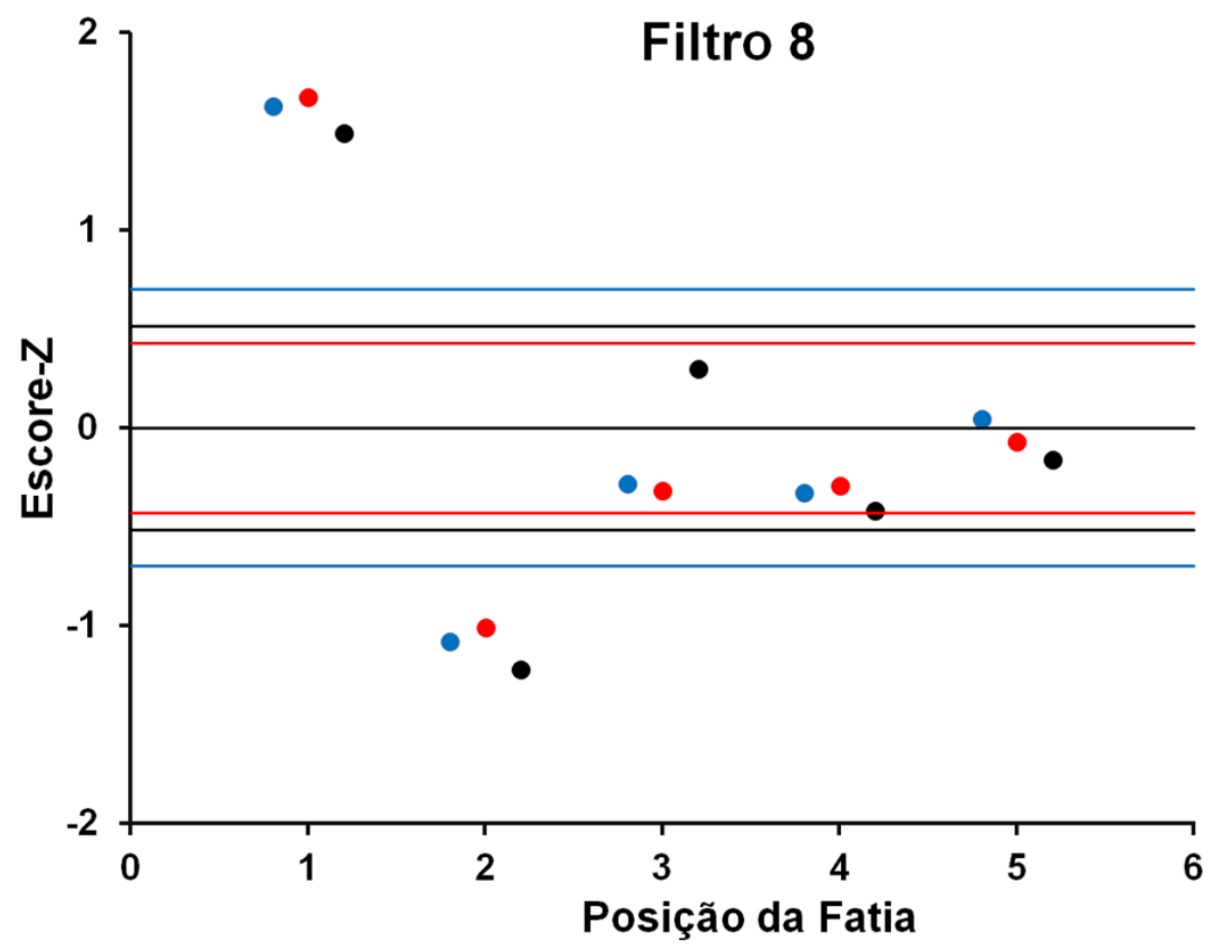

I.R. $30 \%{ }^{60} \mathrm{Co}$

I.R. $30 \%{ }^{110 \mathrm{~m}} \mathrm{Ag}$

I.R. $30 \%{ }^{108 \mathrm{~m}} \mathrm{Ag}$

Média

I.R. $30 \%{ }^{108 \mathrm{~m}} \mathrm{Ag}$

I.R. $30 \%{ }^{110 \mathrm{~m}} \mathrm{Ag}$

I.R. $30 \%{ }^{60} \mathrm{Co}$

- ${ }^{60} \mathrm{Co}$

- $108 \mathrm{~m} \mathrm{Ag}$

- $110 \mathrm{~m} \mathrm{Ag}$

FONTE: autor da tese

Figura 18-Avaliação da homogeneidade do filtro 9, utilizando valores de escore-Z



FONTE: autor da tese 
Figura 19-Avaliação da homogeneidade do filtro 10, utilizando valores de escore-Z

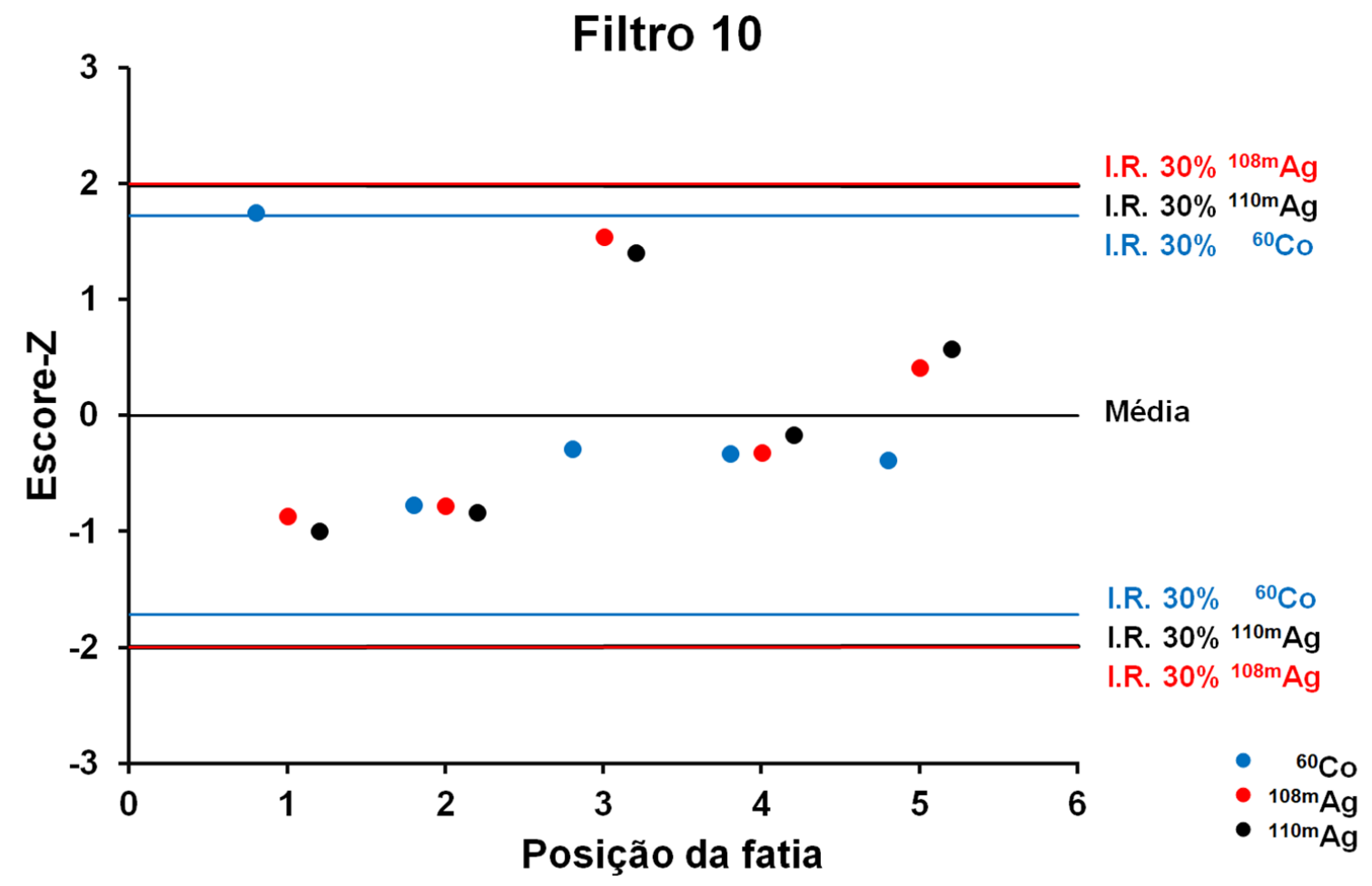

FONTE: autor da tese

Figura 20-Avaliação da homogeneidade do filtro 12, utilizando valores de escore-Z



I.R. $30 \%{ }^{108 \mathrm{~m}} \mathrm{Ag}$

I.R. $30 \%{ }^{110 \mathrm{~m} A g}$

I.R. $30 \% \quad{ }^{60} \mathrm{Co}$

Média

I.R. $30 \% \quad{ }^{60} \mathrm{Co}$

I.R. $30 \%{ }^{110 \mathrm{~m}} \mathrm{Ag}$

I.R. $30 \%{ }^{108 \mathrm{~m}} \mathrm{Ag}$

- ${ }^{60} \mathrm{Co}$

- $108 \mathrm{~m} \mathrm{Ag}$

- ${ }^{110 \mathrm{~m} A g}$

FONTE: autor da tese 
Figura 21-Avaliação da homogeneidade do filtro 15, utilizando valores de escore-Z

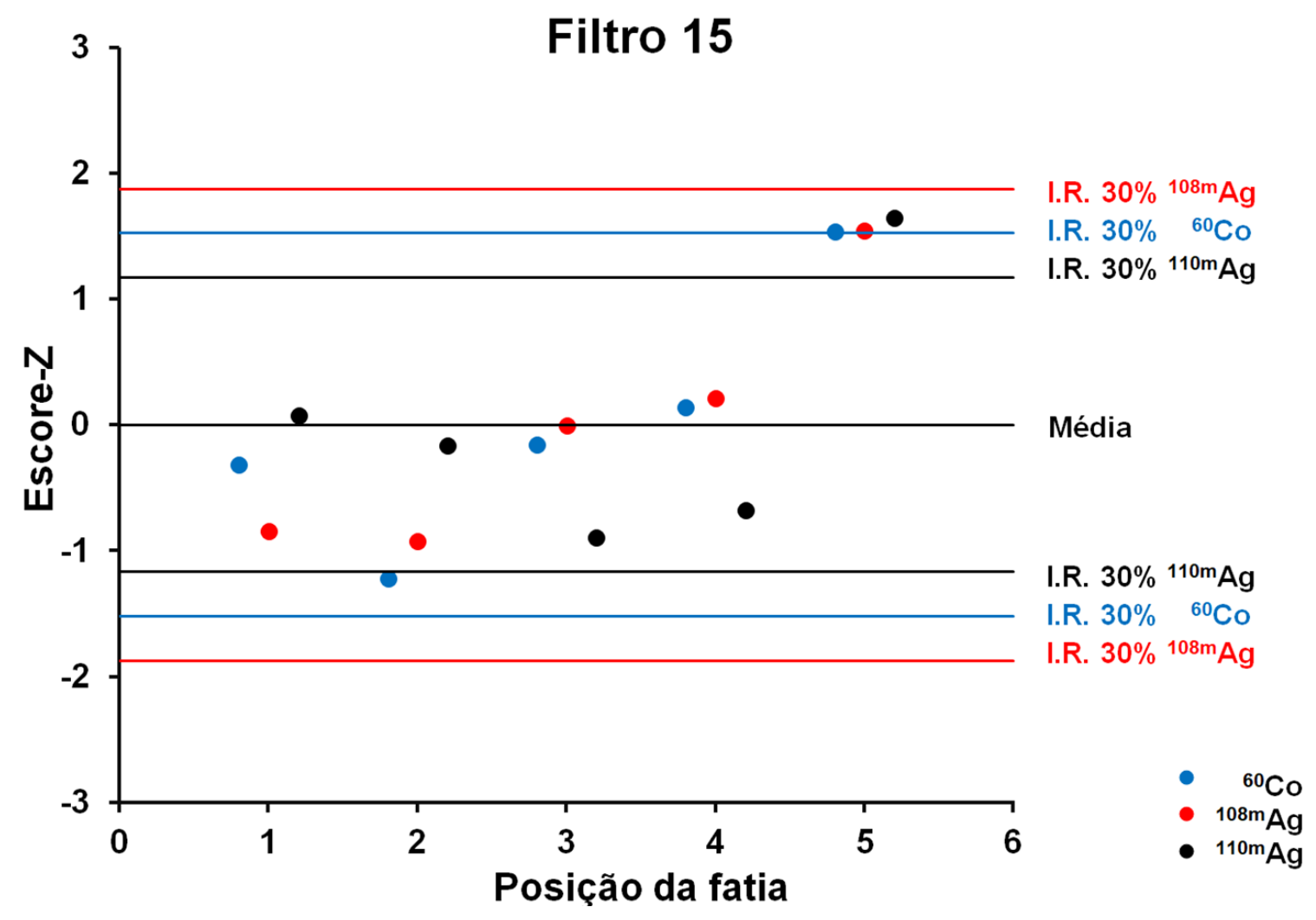

FONTE: autor da tese

Para cada radionuclídeo foi calculado um Intervalo Relativo (I.R.) a partir da média obtida com todas as fatias, calculou-se 30\% acima e 30\% abaixo da média, que estão identificados nos gráficos por linhas horizontais superiores e inferiores à linha horizontal da média, cada radionuclídeo está identificado por uma cor, o qual está identificando os pontos no gráfico e as linhas de limite superior e limite inferior.

De acordo com a IAEA (2007), um filtro é considerado homogêneo se os valores de escore- $Z$ estiverem distribuídos dentro do intervalo relativo de $30 \%$.

Por meio do escore-Z foi possível avaliar a homogeneidade dos filtros. Dos oito filtros analisados, um deles, o filtro número quinze, resultou em um único ponto fora do I.R, de um total de quinze pontos, referente a medida de ${ }^{110 \mathrm{~m}} \mathrm{Ag}$, o que pode ter sido ocasionado por perda de material durante o processo de solubilização do filtro.

Cinco filtros apresentaram valores de escore-Z dentro do I.R. podendo ser declarados homogêneos.

Três filtros não atenderam o critério estabelecido pela IAEA (2007), todos os cartuchos de filtro foram pesados antes da amostragem, três possuem uma 
massa aproximada de $240 \mathrm{~g}$, bem inferior a massa aproximada de $390 \mathrm{~g}$ dos outros doze filtros. O comportamento desses filtros poderia ser explicado por suas características físicas (massa, densidade e micragem) serem diferentes, e baixa qualidade do material, o que levaria a uma distribuição irregular dos radionuclídeos.

Diante desses fatos, uma investigação sobre a origem desses filtros foi realizada e pôde-se concluir que existem dois tipos de filtros, um com massa inicial de $350 \mathrm{~g}$ e outro com massa inicial de $200 \mathrm{~g}$, eles possuem a mesma altura e uma diferença no diâmetro, segundo informações obtidas em contato com o responsável pela fabricação dos filtros, ele afirma que os dois são produzidos da mesma forma, o que varia é o molde no qual eles são produzidos. Nas Figuras 22 (A) e 22 (B) são ilustradas fatias dos filtros homogêneo e heterogêneo.

Figura 22-(A) fatia do filtro homogêneo, (B) fatia do filtro heterogêneo
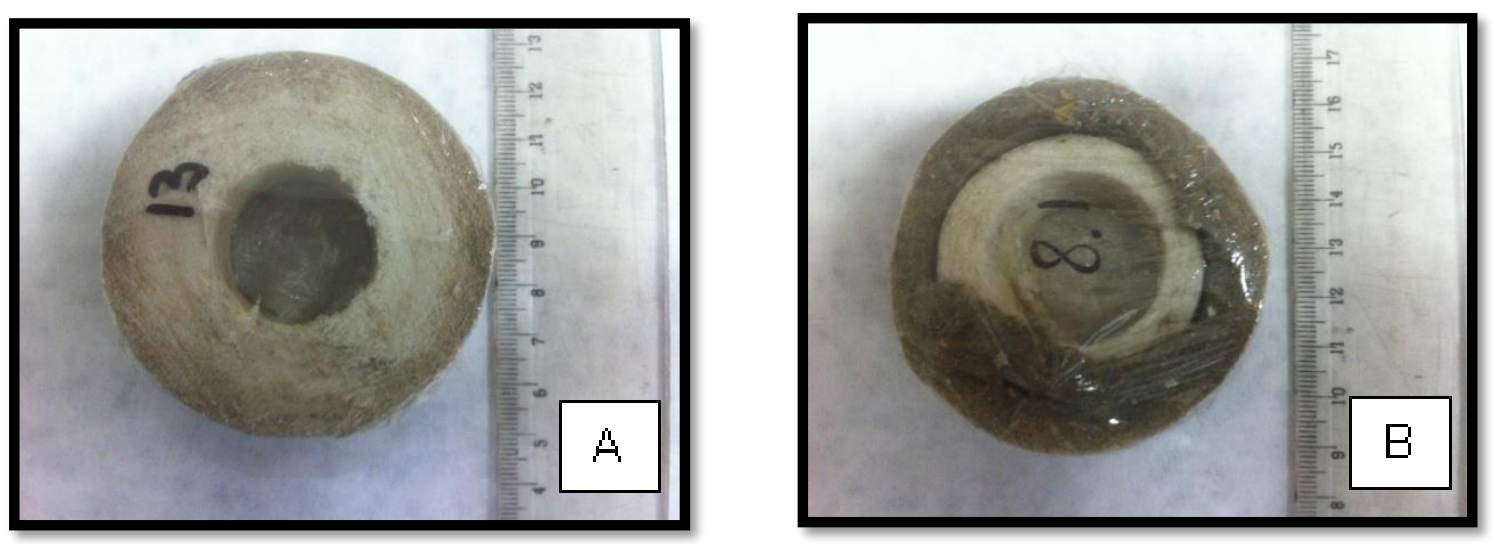

FONTE: autor da tese

\subsection{Separação radioquímica dos radionuclídeos emissores alfa}

As amostras de filtro foram analisadas conforme os procedimentos radioquímicos descritos anteriormente. Espectros resultantes dessas análises são apresentados a seguir, ilustrando, em termos qualitativos, os RDMs que foram detectados no rejeito radioativo estudado.

Após a separação sequencial dos isótopos de U, Pu, Am e Cm, foram obtidos espectros, os quais são mostrados na Figura 23 para os isótopos de $U$, na Figura 24 para os isótopos de Pu (emissores alfa), na Figura 25 para os isótopos de $\mathrm{Pu}$ (emissor beta) e na Figura 26 para os isótopos de Am e Cm. 
O procedimento de separação dos elementos $\mathrm{Sr}$ e Ni gerou espectros de ${ }^{90} \mathrm{Sr}$, cujo aspecto geral é semelhante ao mostrado na Figura 27, bem como espectros de ${ }^{63} \mathrm{Ni}$ similares ao apresentado na Figura 28.

Figura 23-Espectro alfa de U obtido como resultado de medida com duração de 200040 segundos em amostra de filtro

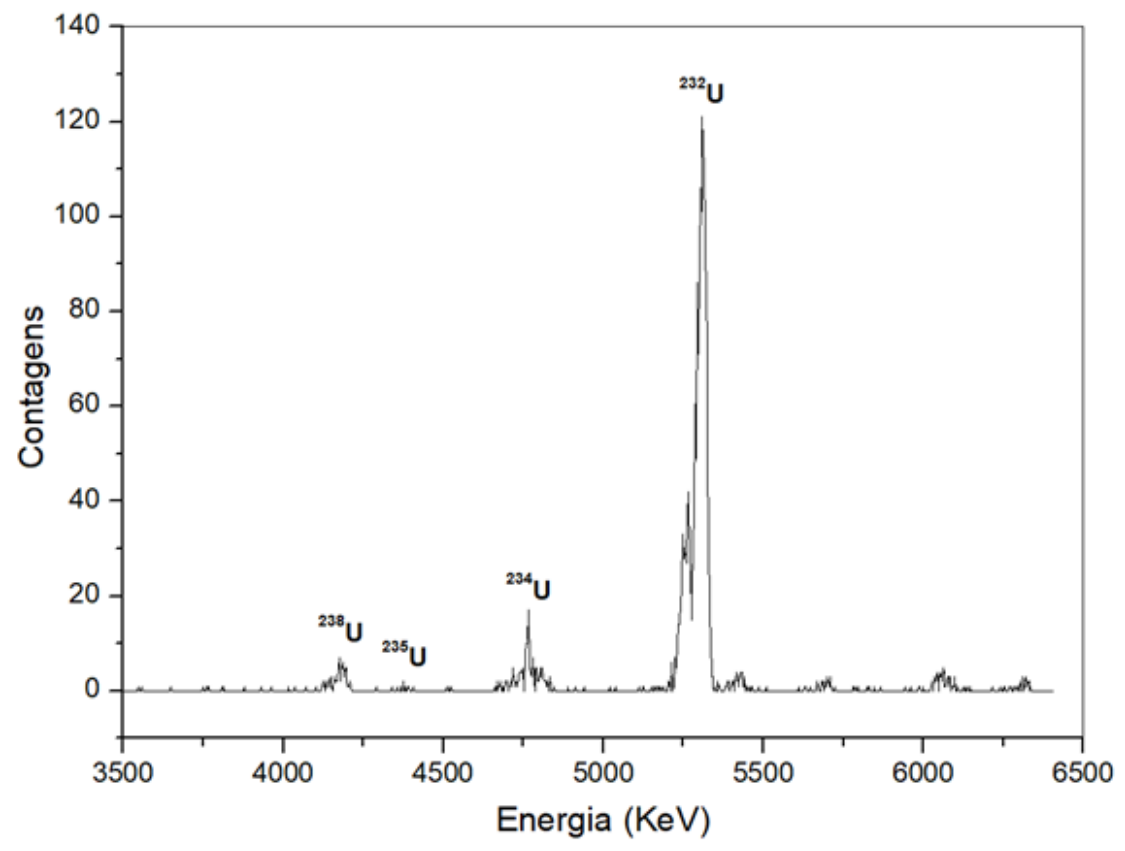

FONTE: autor da tese 
Figura 24-Espectro alfa de Pu obtido como resultado de medida com duração de 200040 segundos em amostra de filtro

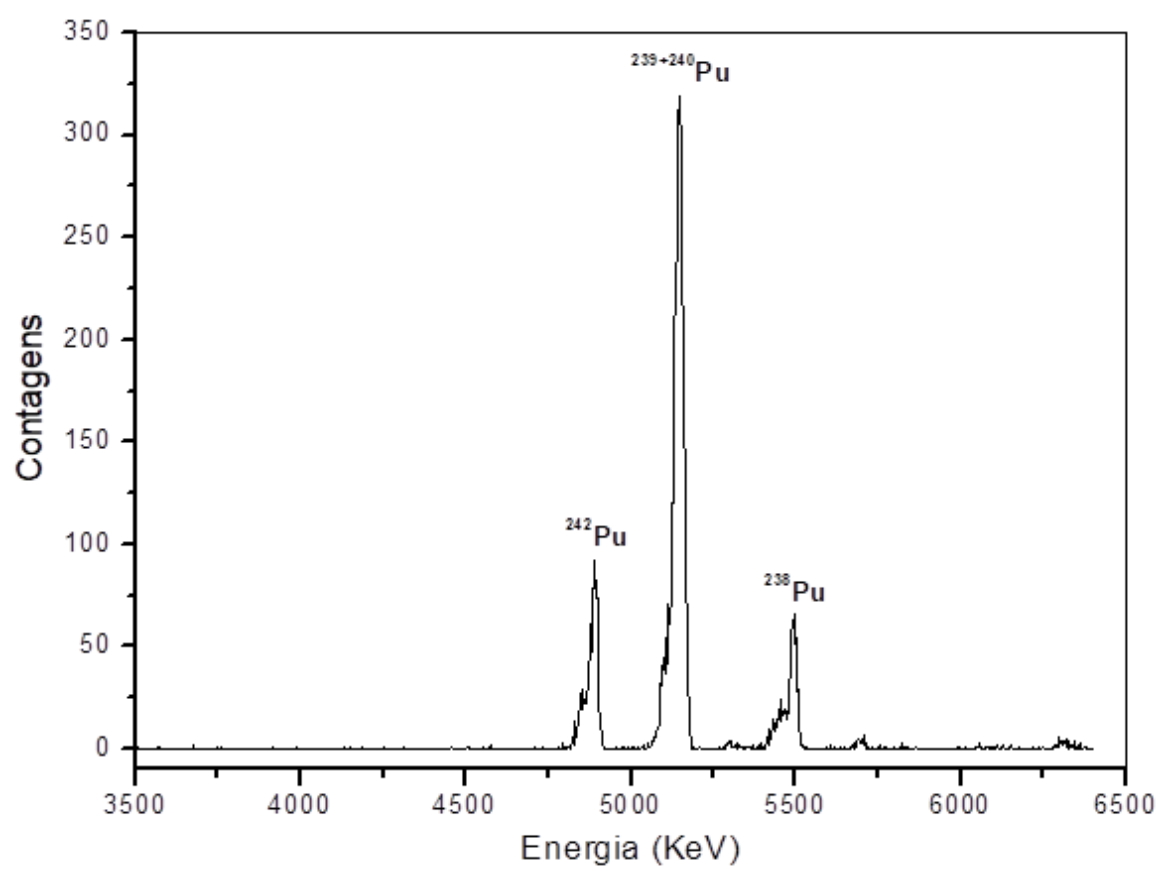

FONTE: autor da tese

Figura 25-Espectro alfa e beta de ${ }^{241} \mathrm{Pu}$ obtido como resultado de medida com duração de 18000 segundos em amostra de filtro

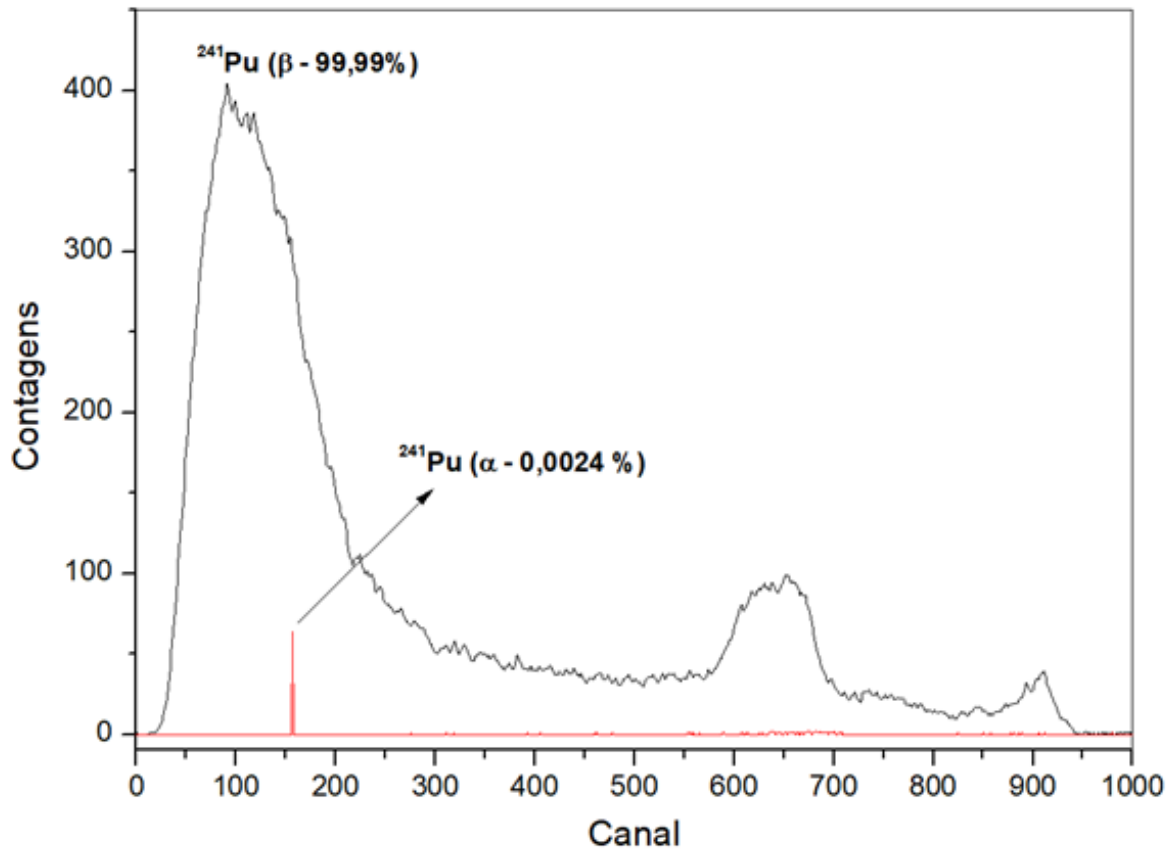

FONTE: autor da tese 
Figura 26-Espectro alfa de $\mathrm{Am}$ e $\mathrm{Cm}$ obtido como resultado de medida com duração de 200040 segundos em amostra de filtro

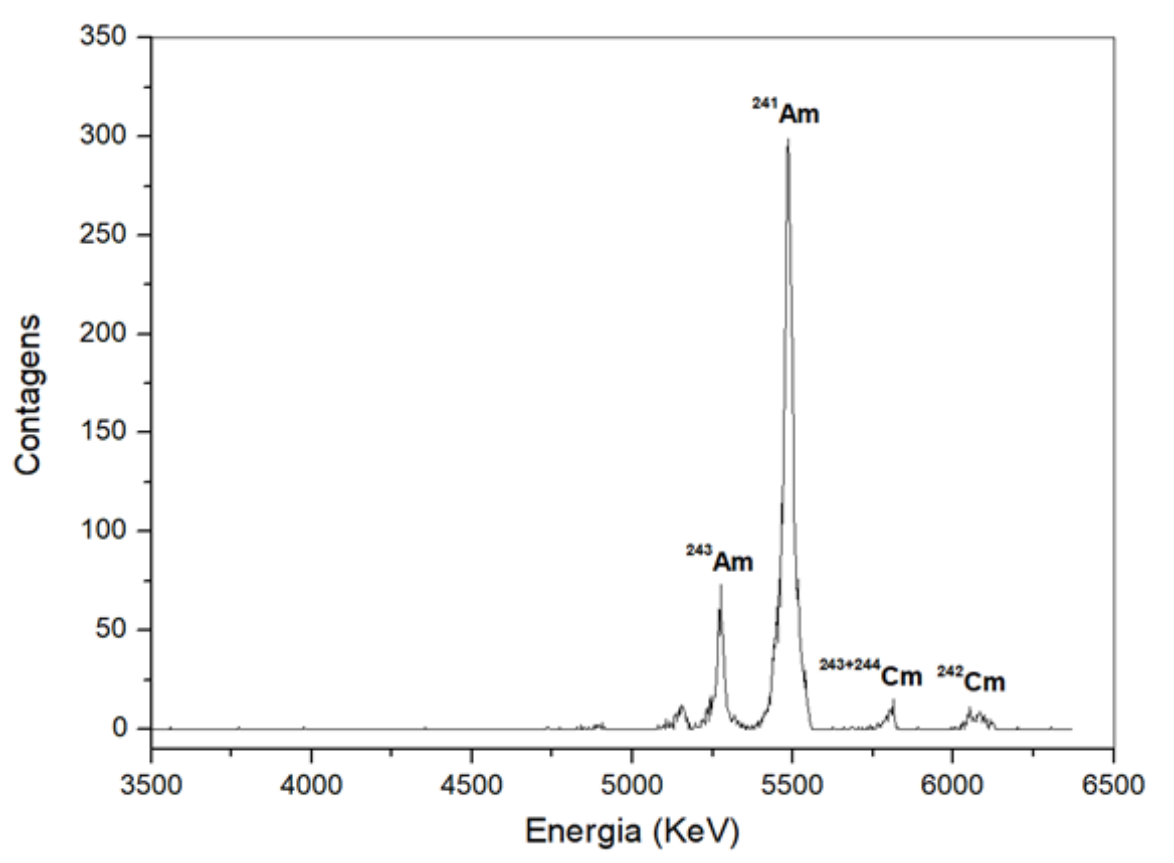

FONTE: autor da tese

Figura 27-Espectro beta de Sr obtido como resultado de medida com duração de 14400 segundos em amostra de filtro

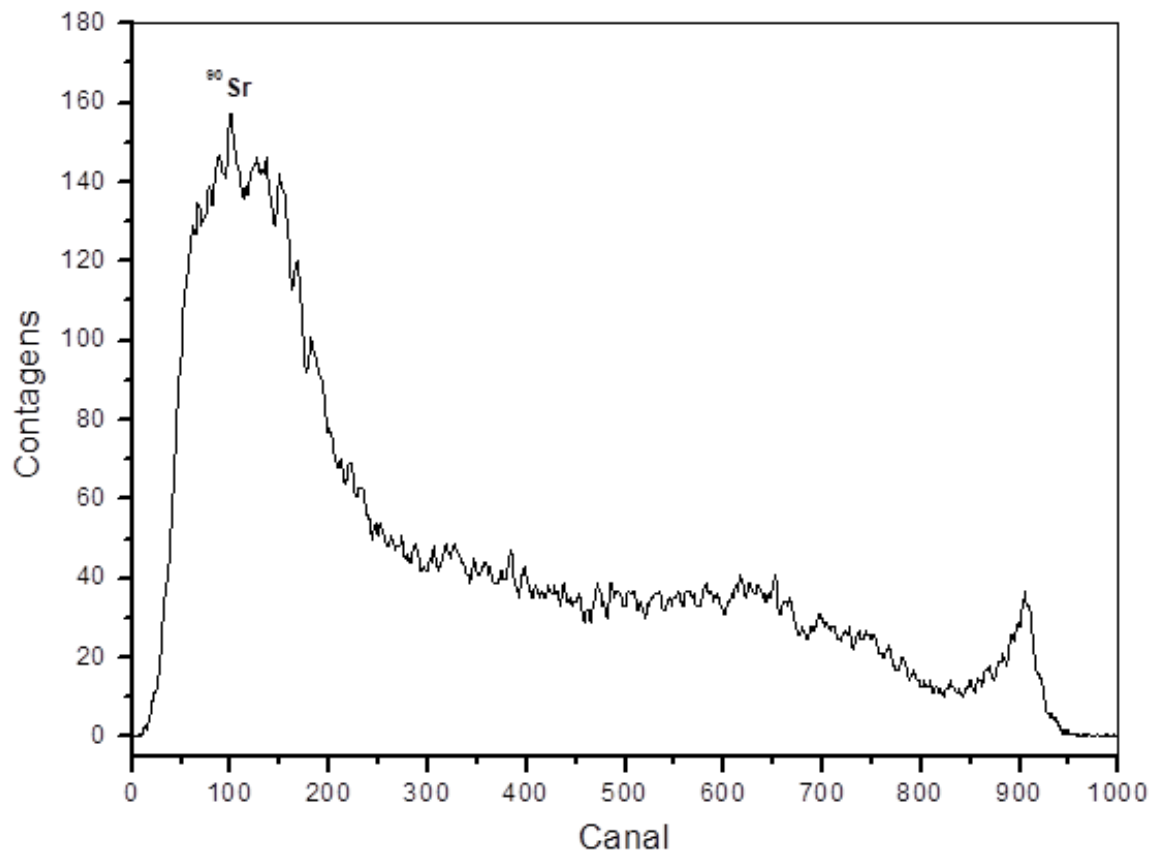

FONTE: autor da tese 
Figura 28-Espectro beta de Ni obtido como resultado de medida com duração de 3600 segundos em amostra de filtro

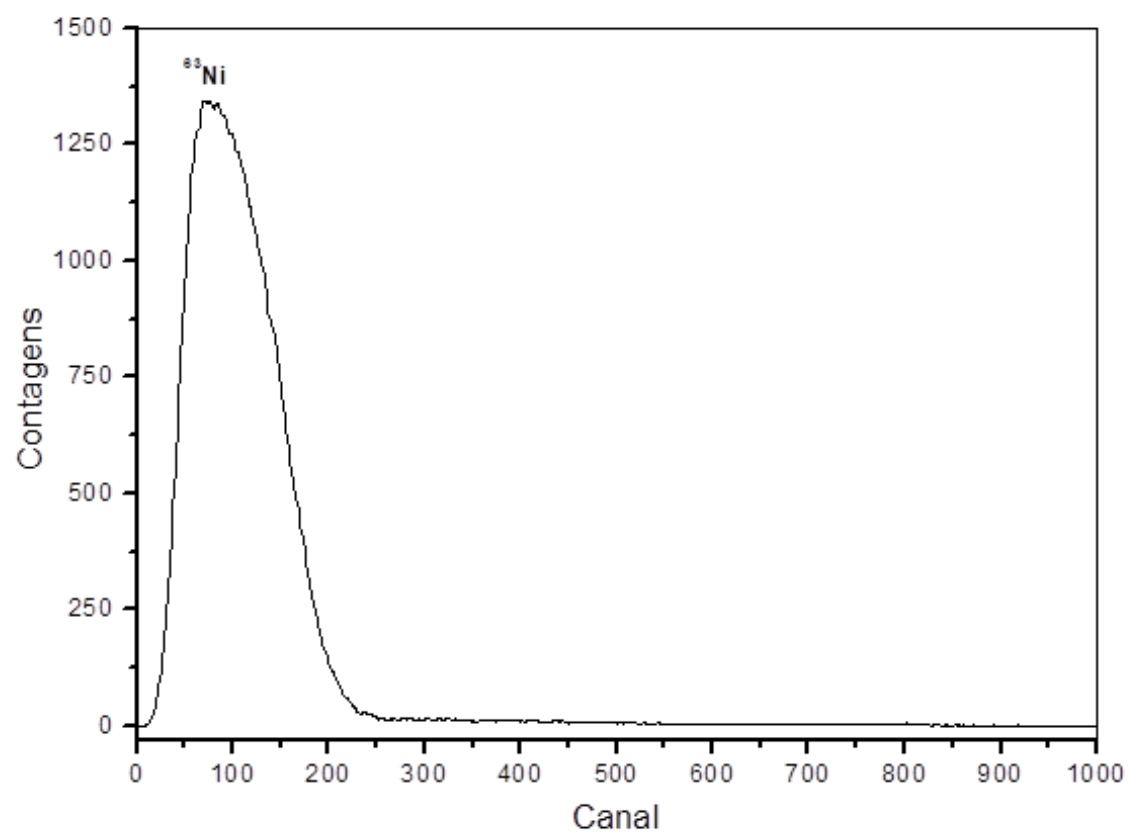

FONTE: autor da tese

Não foi possível analisar ${ }^{237} \mathrm{~Np}$ nas amostras de filtro, para isso seria necessário estabelecer um método sequencial para todos os radionuclídeos, pois a energia alfa do traçador ${ }^{242} \mathrm{Pu}(4860 \mathrm{KeV})$ é próxima da energia do ${ }^{237} \mathrm{~Np}$ (4771 $\mathrm{KeV})$ e a resolução do equipamento (20 KeV) não permite a distinção entre estes dois picos de energia. Além disso, ao se utilizar o ${ }^{236} \mathrm{Pu}(\mathrm{T} 1 / 2=2,87$ anos) devese considerar seu decaimento para ${ }^{232} \mathrm{U}$, o que inviabiliza a determinação dos isótopos de $U$; uma solução para este problema seria a purificação do traçador ${ }^{236} \mathrm{Pu}$, porém não foi possível a aquisição deste padrão.

A presença de ${ }^{3} \mathrm{H}$ é detectada em amostras no estado líquido ou sólida, desde que elas estejam imersas em solução aquosa ou úmida, pois $0{ }^{3} \mathrm{H}$ encontra-se na forma de água triciada. Com base nessas informações, $\mathrm{o}{ }^{3} \mathrm{H}$ não foi analisado nas amostras de filtro, uma vez que $0{ }^{3} \mathrm{H}$ evaporou durante o período de secagem dos filtros antes do acondicionamento.

A análise do ${ }^{14} \mathrm{C}$ utiliza um procedimento por combustão das amostras, no entanto, o equipamento que seria empregado neste trabalho, apresentou problemas desde sua instalação, não sendo possível sua utilização. 
A análise do ${ }^{55} \mathrm{Fe}$ foi desconsiderada neste estudo por dois motivos, tempo de meia-vida curto ( $\mathrm{t} 1 / 2=2,74$ anos) e o seu inventário no repositório tem baixa prioridade.

O ${ }^{59} \mathrm{Ni}$ não foi analisado nas amostras de filtro, a sua contribuição para o inventário radioativo é bem pequena, a sua atividade é bem menor comparada com a atividade do ${ }^{63} \mathrm{Ni}$, sendo menos relevante que o ${ }^{63} \mathrm{Ni}$, deste modo, o impacto nos resultados totais seria pequeno devido a sua baixa contribuição relativa ao inventário total. Para a análise dele é necessário um investimento alto para aquisição do espectrômetro gama de baixa energia, sendo que ele pode ser calculado por FE, não sendo necessário a realização da análise.

A contribuição do ${ }^{99} \mathrm{Tc}$ para o inventário é muito baixa e por este motivo ele também não foi analisado neste trabalho.

Para as análises do ${ }^{129}$ e e ${ }^{135} \mathrm{Cs}$ seria necessário o estudo e desenvolvimento de métodos de separação radioquímica e neste trabalho não estava prevista esta atividade.

\subsection{Atividades dos radionuclídeos nas amostras}

Nas Tabelas 2 a 5, são apresentadas as atividades (Bq) de cada radionuclídeo e as propagações de erros, para cada amostra de filtro. 
Tabela 2-Atividades de ${ }^{60} \mathrm{Co},{ }^{63} \mathrm{Ni},{ }^{90} \mathrm{Sr}$ e ${ }^{108 \mathrm{~m}} \mathrm{Ag}$ nas amostras de filtro

\begin{tabular}{|c|c|c|c|c|c|c|c|c|c|}
\hline \multirow{3}{*}{$\begin{array}{c}\text { Filtros } \\
1\end{array}$} & \multicolumn{9}{|c|}{ Atividades (Bq) por filtro } \\
\hline & \multicolumn{2}{|c|}{${ }^{60} \mathrm{Co}\left(\mathrm{x} \mathrm{10^{5 } )}\right.$} & \multicolumn{2}{|c|}{${ }^{63} \mathrm{Ni}\left(\times 10^{4}\right)$} & \multicolumn{2}{|c|}{${ }^{90} \mathrm{Sr}\left(\times 10^{2}\right)$} & \multicolumn{3}{|c|}{${ }^{108 m} \mathrm{Ag}\left(\times 1^{4}\right)$} \\
\hline & 4,68 & $\pm 0,06$ & 4,01 & $\pm 0,05$ & $1,80 \pm$ & $\pm 0,14$ & $7,57=$ & \pm & 0,12 \\
\hline 2 & 16,63 & $\pm 0,21$ & 11,82 & $\pm 0,12$ & $5,24 \pm$ & $\pm 0,43$ & $6,57=$ & \pm & 0,10 \\
\hline 3 & 5,30 & $\pm 0,07$ & 4,11 & $\pm 0,04$ & $5,31 \pm$ & $\pm 0,42$ & $10,36=$ & \pm & 0,16 \\
\hline 4 & 4,84 & $\pm 0,06$ & 3,14 & $\pm 0,03$ & $6,61 \pm$ & $\pm 0,51$ & $10,98=$ & \pm & 0,17 \\
\hline 5 & 6,53 & $\pm 0,08$ & 5,59 & $\pm 0,06$ & $5,49 \pm$ & $\pm 0,44$ & $3,28=$ & \pm & 0,05 \\
\hline 6 & 3,05 & $\pm 0,04$ & 2,17 & $\pm 0,02$ & $2,83 \pm$ & $\pm 0,22$ & 5,20 & \pm & 0,08 \\
\hline 7 & 4,19 & $\pm 0,05$ & 2,73 & $\pm 0,03$ & $4,93 \pm$ & $\pm 0,40$ & $3,18=$ & \pm & 0,05 \\
\hline 8 & 7,25 & $\pm 0,09$ & 3,83 & $\pm 0,04$ & $2,87 \pm$ & $\pm 0,22$ & $5,02=$ & \pm & 0,08 \\
\hline 9 & 3,11 & $\pm 0,04$ & 1,81 & $\pm 0,02$ & $10,91 \pm$ & $\pm 0,84$ & $5,29=$ & \pm & 0,08 \\
\hline 10 & 3,52 & $\pm 0,05$ & 2,63 & $\pm 0,03$ & $2,71 \pm$ & $\pm 0,21$ & $6,24=$ & \pm & 0,09 \\
\hline 11 & 4,34 & $\pm 0,06$ & 3,08 & $\pm 0,04$ & $42,11 \pm$ & $\pm \quad 3,51$ & $7,29=$ & \pm & 0,11 \\
\hline 12 & 3,90 & $\pm 0,05$ & 2,44 & $\pm 0,03$ & $3,12 \pm$ & $\pm 0,24$ & $5,03=$ & \pm & 0,08 \\
\hline 13 & 4,10 & $\pm 0,05$ & 3,38 & $\pm 0,04$ & $18,50 \pm$ & $\pm \quad 1,49$ & $7,36=$ & \pm & 0,11 \\
\hline 14 & 4,63 & $\pm 0,06$ & 3,94 & $\pm 0,04$ & $4,17 \pm$ & $\pm 0,33$ & $8,99=$ & \pm & 0,14 \\
\hline 15 & 4,14 & $\pm 0,05$ & 2,90 & $\pm 0,03$ & $11,98 \pm$ & $\pm 0,96$ & $8,46=$ & \pm & 0,13 \\
\hline
\end{tabular}

FONTE: autor da tese 
Tabela 3-Atividades de ${ }^{110 \mathrm{~m}} \mathrm{Ag},{ }^{234} \mathrm{U},{ }^{235} \mathrm{U}$ e ${ }^{238} \mathrm{U}$ nas amostras de filtro

\begin{tabular}{|c|c|c|c|c|c|c|}
\hline \multirow{3}{*}{$\begin{array}{c}\text { Filtros } \\
1\end{array}$} & \multicolumn{6}{|c|}{ Atividades $(\mathrm{Bq})$ por filtro } \\
\hline & ${ }^{110 m} \mathrm{Ag}\left(\times 10^{4}\right)$ & \multicolumn{2}{|c|}{${ }^{234} U\left(\times 10^{-1}\right)$} & \multicolumn{2}{|c|}{${ }^{235} \mathrm{U}\left(\mathrm{x} \mathrm{10^{-3 }}\right)$} & ${ }^{238} \mathrm{U}\left(\mathrm{x} 10^{-1}\right)$ \\
\hline & $4,33 \pm 0,06$ & 6,69 & $\pm 0,70$ & $36,14 \pm$ & $\pm 17,19$ & $2,73 \pm 0,41$ \\
\hline 2 & $22,88 \pm 0,27$ & 10,66 & $\pm 0,93$ & $47,54 \pm$ & $\pm 18,14$ & $4,16 \pm 0,50$ \\
\hline 3 & $5,58 \pm 0,07$ & 8,43 & $\pm 0,84$ & $51,13 \pm$ & $\pm 20,33$ & $4,94 \pm 0,60$ \\
\hline 4 & $5,82 \pm 0,07$ & 8,58 & $\pm 0,78$ & $61,32 \pm$ & $\pm 19,22$ & $3,32 \pm 0,43$ \\
\hline 5 & $10,82 \pm 0,13$ & 6,27 & $\pm 0,63$ & $45,71 \pm$ & $\pm 18,36$ & $3,86 \pm 0,46$ \\
\hline 6 & $2,45 \pm 0,03$ & 5,36 & $\pm 0,55$ & $21,11 \pm$ & $\pm 14,63$ & $1,84 \pm 0,29$ \\
\hline 7 & $8,54 \pm 0,10$ & 10,61 & $\pm 0,88$ & $39,55 \pm$ & $\pm 16,71$ & $3,48 \pm 0,42$ \\
\hline 8 & $18,49 \pm 0,21$ & 9,81 & $\pm 0,82$ & $28,72 \pm$ & $\pm 15,13$ & $3,13 \pm 0,39$ \\
\hline 9 & $2,42 \pm 0,03$ & 4,40 & $\pm 0,54$ & $<$ & 5,42 & $1,63 \pm 0,31$ \\
\hline 10 & $4,50 \pm 0,06$ & 5,13 & $\pm 0,51$ & $36,37 \pm$ & $\pm 11,67$ & $1,67 \pm 0,26$ \\
\hline 11 & $1,83 \pm 0,03$ & 4,22 & $\pm 0,48$ & $6,06 \pm$ & $\pm 12,20$ & $1,58 \pm 0,27$ \\
\hline 12 & $4,02 \pm 0,05$ & 4,71 & $\pm 0,49$ & $<$ & 5,42 & $2,21 \pm 0,31$ \\
\hline 13 & $3,95 \pm 0,05$ & 5,73 & $\pm 0,57$ & $<$ & 5,42 & $1,87 \pm 0,29$ \\
\hline 14 & $3,54 \pm 0,05$ & 7,01 & $\pm 0,65$ & $28,59 \pm$ & $\pm 14,84$ & $2,14 \pm 0,31$ \\
\hline 15 & $7,34 \pm 0,09$ & 4,96 & $\pm 0,52$ & $12,98 \pm$ & $\pm \quad 12,73$ & $1,61 \pm 0,27$ \\
\hline
\end{tabular}

FONTE: autor da tese 
Tabela 4-Atividades de ${ }^{238} \mathrm{Pu},{ }^{239+240} \mathrm{Pu}$ e ${ }^{241} \mathrm{Pu}$ nas amostras de filtro

\begin{tabular}{|c|c|c|c|c|c|c|c|c|c|}
\hline \multirow{3}{*}{$\begin{array}{c}\text { Filtros } \\
1\end{array}$} & \multicolumn{9}{|c|}{ Atividades $(\mathrm{Bq})$ por filtro } \\
\hline & \multicolumn{3}{|c|}{${ }^{238} \mathrm{Pu}\left(\times 10^{1}\right)$} & \multicolumn{3}{|c|}{${ }^{239+240} \mathrm{Pu}\left(\times 1^{2}\right)$} & \multicolumn{3}{|c|}{${ }^{241} \mathrm{Pu}\left(\mathrm{x} \mathrm{10^{3 } )}\right.$} \\
\hline & 2,25 & \pm & 0,13 & 0,98 & \pm & 0,05 & 16,05 & \pm & 0,22 \\
\hline 2 & 6,59 & \pm & 0,35 & 2,81 & \pm & 0,15 & 258,75 & \pm & 3,42 \\
\hline 3 & 2,29 & \pm & 0,13 & 1,14 & \pm & 0,06 & 25,78 & \pm & 0,35 \\
\hline 4 & 1,84 & \pm & 0,11 & 0,80 & \pm & 0,04 & 20,18 & \pm & 0,27 \\
\hline 5 & 4,87 & \pm & 0,27 & 1,64 & \pm & 0,09 & 83,82 & \pm & 1,13 \\
\hline 6 & 2,39 & \pm & 0,14 & 0,62 & \pm & 0,03 & 7,14 & \pm & 0,10 \\
\hline 7 & 5,07 & \pm & 0,31 & 1,02 & \pm & 0,06 & 23,09 & \pm & 0,38 \\
\hline 8 & 5,67 & \pm & 0,30 & 2,02 & \pm & 0,10 & 143,32 & \pm & 1,88 \\
\hline 9 & 3,57 & \pm & 0,21 & 0,52 & \pm & 0,03 & 0,18 & \pm & 0,003 \\
\hline 10 & 3,51 & \pm & 0,20 & 0,96 & \pm & 0,05 & 20,40 & \pm & 0,29 \\
\hline 11 & 3,57 & \pm & 0,20 & 0,96 & \pm & 0,05 & 19,73 & \pm & 0,28 \\
\hline 12 & 1,41 & \pm & 0,08 & 0,47 & \pm & 0,02 & 11,55 & \pm & 0,15 \\
\hline 13 & 1,58 & \pm & 0,10 & 0,73 & \pm & 0,04 & 4,53 & \pm & 0,07 \\
\hline 14 & 1,46 & \pm & 0,09 & 0,74 & \pm & 0,04 & 8,94 & \pm & 0,13 \\
\hline 15 & 2,25 & \pm & 0,13 & 0,80 & \pm & 0,04 & 10,44 & \pm & 0,15 \\
\hline
\end{tabular}

FONTE: autor da tese 
Tabela 5-Atividades de ${ }^{241} \mathrm{Am},{ }^{242} \mathrm{Cm}$ e ${ }^{243+244} \mathrm{Cm}$ nas amostras de filtro

\begin{tabular}{|c|c|c|c|c|c|c|c|c|c|}
\hline \multirow{3}{*}{$\begin{array}{c}\text { Filtros } \\
1\end{array}$} & \multicolumn{9}{|c|}{ Atividades $(\mathrm{Bq})$ por filtro } \\
\hline & \multicolumn{3}{|c|}{${ }^{241} \mathrm{Am}\left(\times 10^{2}\right)$} & \multicolumn{3}{|c|}{${ }^{242} \mathrm{Cm}\left(\times 10^{-1}\right)$} & \multicolumn{3}{|c|}{${ }^{243+244} \mathrm{Cm}\left(\times 1^{-1}\right)$} \\
\hline & 0,54 & \pm & 0,03 & 1,04 & \pm & 0,28 & 5,48 & \pm & 0,65 \\
\hline 2 & 1,13 & \pm & 0,06 & 3,64 & \pm & 0,54 & 20,21 & \pm & 1,58 \\
\hline 3 & 0,65 & \pm & 0,03 & 1,74 & \pm & 0,36 & 6,62 & \pm & 0,73 \\
\hline 4 & 0,55 & \pm & 0,03 & 1,18 & \pm & 0,29 & 5,17 & \pm & 0,62 \\
\hline 5 & 0,39 & \pm & 0,02 & 1,88 & \pm & 0,28 & 12,20 & \pm & 0,88 \\
\hline 6 & 0,65 & \pm & 0,04 & 2,13 & \pm & 0,42 & 6,58 & \pm & 0,85 \\
\hline 7 & 0,36 & \pm & 0,03 & 5,04 & \pm & 1,30 & 16,05 & \pm & 2,47 \\
\hline 8 & 1,19 & \pm & 0,06 & 5,13 & \pm & 0,60 & 27,06 & \pm & 1,92 \\
\hline 9 & 0,46 & \pm & 0,03 & 2,05 & \pm & 0,39 & 6,16 & \pm & 0,67 \\
\hline 10 & 0,54 & \pm & 0,03 & 1,18 & \pm & 0,31 & 9,15 & \pm & 0,93 \\
\hline 11 & 0,62 & \pm & 0,03 & 3,22 & \pm & 0,49 & 9,66 & \pm & 0,93 \\
\hline 12 & 0,43 & \pm & 0,02 & 2,80 & \pm & 0,39 & 7,21 & \pm & 0,68 \\
\hline 13 & 0,58 & \pm & 0,03 & 3,30 & \pm & 0,60 & 8,31 & \pm & 0,99 \\
\hline 14 & 0,66 & \pm & 0,04 & 3,16 & \pm & 0,42 & 12,51 & \pm & 1,00 \\
\hline 15 & 0,41 & \pm & 0,02 & 2,78 & \pm & 0,35 & 6,07 & \pm & 0,62 \\
\hline
\end{tabular}

FONTE: autor da tese.

As atividades calculadas para cada filtro não foram normalizadas para a data em que os filtros foram retirados do reator IEA-R1, pois para calcular as atividades corrigidas é necessário a data em que os rejeitos radioativos foram retirados definitivamente do sistema de purificação da água do circuito de refrigeração do reator, e não foi realizado nenhum tipo de registro desta informação.

Avaliando um estudo recente (TADDEI, 2013) e os dados obtidos neste estudo, de um modo geral, dentre os radionuclídeos cuja determinação demandou a utilização prévia de procedimentos radioquímicos e, portanto, constituem RDMs, o mais abundante nas três matrizes de rejeitos radioativos (filtro, carvão e resina) foi o ${ }^{63} \mathrm{Ni}$. 
O ${ }^{90} \mathrm{Sr}$ em geral encontra-se na forma insolúvel, o que explica os baixos valores de atividades encontrado nas amostras de filtro, e, portanto, foram retidos predominantemente por adsorção no carvão ativado (TADDEl, 2013).

As atividades do isótopo de ${ }^{241} \mathrm{Pu}$ são mais altas comparadas com as dos isótopos de $\mathrm{Pu}$ emissores alfa, devido ao tempo de meia-vida ( $\mathrm{T} 1 / 2=14,33$ anos). $\mathrm{O}{ }^{241} \mathrm{Am}$ é um dos produtos do seu decaimento, o que explica um leve aumento nas atividades de ${ }^{241} \mathrm{Am}$.

Foram obtidos resultados abaixo da atividade mínima detectável (MDA) para o ${ }^{235} \mathrm{U}$.

\subsection{Fator de escala}

A metodologia utilizada para o cálculo dos FEs, descrita anteriormente, foi aplicada aos resultados das atividades dos RDMs e dos RCs apresentados nas Tabelas 2 a 5.

Os valores médios dos Fatores de Escala obtidos para cada par $\mathrm{RDM} / \mathrm{RC}$, assim como das dispersões $2 \sigma$ correspondentes, são apresentados na Tabela 6. 
Tabela 6-Valores médios dos Fatores de Escala e valores da dispersão $2 \sigma$ obtidos para os filtros

\begin{tabular}{|c|c|c|}
\hline RDM / RC & $\overline{\mathrm{FE}}$ & $\mathrm{D} 2 \sigma$ \\
\hline${ }^{63} \mathrm{Ni} /{ }^{60} \mathrm{Co}$ & $7,12 \times 10^{-2}$ & 1,3 \\
\hline${ }^{63} \mathrm{Ni} /{ }^{108 \mathrm{~m}} \mathrm{Ag}$ & $5,42 \times 10^{-1}$ & 3,0 \\
\hline${ }^{90} \mathrm{Sr} /{ }^{60} \mathrm{Co}$ & $1,20 \times 10^{-3}$ & 6,9 \\
\hline${ }^{90} \mathrm{Sr} /{ }^{108 \mathrm{~m}} \mathrm{Ag}$ & $9,12 \times 10^{-3}$ & 5,4 \\
\hline${ }^{234} \mathrm{U} /{ }^{60} \mathrm{Co}$ & $1,35 \times 10^{-6}$ & 1,9 \\
\hline${ }^{234} \mathrm{U} /{ }^{108 \mathrm{~m}} \mathrm{Ag}$ & $1,03 \times 10^{-5}$ & 2,7 \\
\hline${ }^{235} \mathrm{U} /{ }^{60} \mathrm{Co}$ & $5,77 \times 10^{-8}$ & 3,7 \\
\hline${ }^{235} \mathrm{U} /{ }^{108 \mathrm{~m}} \mathrm{Ag}$ & $4,60 \times 10^{-7}$ & 4,9 \\
\hline${ }^{238} \mathrm{U} /{ }^{60} \mathrm{Co}$ & $5,17 \times 10^{-7}$ & 1,9 \\
\hline${ }^{238} \mathrm{U} /{ }^{108 m} \mathrm{Ag}$ & $3,94 \times 10^{-6}$ & 3,1 \\
\hline${ }^{238} \mathrm{Pu} /{ }^{60} \mathrm{Co}$ & $5,92 \times 10^{-5}$ & 2,5 \\
\hline${ }^{238} \mathrm{Pu} /{ }^{108 \mathrm{~m}} \mathrm{Ag}$ & $4,51 \times 10^{-4}$ & 4,7 \\
\hline${ }^{239+240} \mathrm{Pu} /{ }^{60} \mathrm{Co}$ & $1,99 \times 10^{-4}$ & 1,6 \\
\hline${ }^{239+240} \mathrm{Pu} /{ }^{108 m} \mathrm{Ag}$ & $1,51 \times 10^{-3}$ & 3,7 \\
\hline${ }^{241} \mathrm{Pu} /{ }^{60} \mathrm{Co}$ & $3,38 \times 10^{-2}$ & 15,6 \\
\hline${ }^{241} \mathrm{Pu} /{ }^{108 m} \mathrm{Ag}$ & $2,57 \times 10^{-1}$ & 32,5 \\
\hline${ }^{241} \mathrm{Am} /{ }^{60} \mathrm{Co}$ & $1,19 \times 10^{-4}$ & 2,0 \\
\hline${ }^{241} \mathrm{Am} /{ }^{108 m} \mathrm{Ag}$ & $9,09 \times 10^{-4}$ & 2,4 \\
\hline${ }^{242} \mathrm{Cm} /{ }^{60} \mathrm{Co}$ & $4,98 \times 10^{-7}$ & 3,0 \\
\hline${ }^{242} \mathrm{Cm} /{ }^{108 m} \mathrm{Ag}$ & $3,79 \times 10^{-6}$ & 4,3 \\
\hline${ }^{243+244} \mathrm{Cm} /{ }^{60} \mathrm{Co}$ & $1,93 \times 10^{-6}$ & 2,2 \\
\hline${ }^{243+244} \mathrm{Cm} /{ }^{108 m} \mathrm{Ag}$ & $1,47 \times 10^{-5}$ & 4,4 \\
\hline
\end{tabular}

FONTE: autor da tese

Os isótopos radioativos de $\mathrm{Ni}$ e de Co presentes nos rejeitos radioativos estudados têm origem predominantemente na ativação neutrônica da fina camada de Ni metálico que constitui o revestimento das barras de controle utilizadas no cerne do reator IEA-R1 (TADDEl et al., 2013c). Além dessa origem comum, ambos os elementos são relativamente insolúveis em meio aquoso neutro, de maneira que se esperava a existência de Fatores de Escala envolvendo esses radionuclídeos. 
Conforme previsto, de fato foi obtido Fator de Escala para ${ }^{63} \mathrm{Ni} \mathrm{com}{ }^{60} \mathrm{Co}$, obtevese também Fator de Escala com a ${ }^{108 \mathrm{~m}} \mathrm{Ag}$.

De acordo com TADDEl (2013), em meio aquoso, ${ }^{90} \mathrm{Sr}$ geralmente é encontrado na forma iônica. Porém, em soluções levemente alcalinas, este RDM pode estar na forma de carbonato insolúvel. Em qualquer uma dessas duas formas químicas, espera-se a existência de um Fator de Escala para ${ }^{90} \mathrm{Sr}$ com ${ }^{137} \mathrm{Cs}$, pois ambos são produtos de fissão. Esse comportamento geral envolvendo ${ }^{90} \mathrm{Sr}$ é semelhante ao observado em rejeitos radioativos de reatores nucleares de potência, nos quais Fatores de Escala para ${ }^{90} \mathrm{Sr}$ apresentam na maioria das vezes valores da dispersão $2 \sigma$ ligeiramente menores com ${ }^{137} \mathrm{Cs}$ do que com ${ }^{60} \mathrm{Co}$, mas não raramente ocorre o contrário, devido às duas características que ${ }^{90} \mathrm{Sr}$ e ${ }^{60} \mathrm{Co}$ têm em comum: formação majoritária em camadas superficiais de componentes presentes no cerne do reator e baixa solubilidade em água.

Segundo pesquisas internacionais, determina-se a concentração de atividade de ${ }^{239} \mathrm{Pu}$ em rejeitos radioativos mediante utilização de Fator de Escala desse RDM com o radionuclídeo emissor de raios gama ${ }^{144} \mathrm{Ce}$ (EPRI, 1996; EPRI, 1999) para em seguida estabelecer correlações entre as concentrações de atividade de cada um dos demais isótopos de elementos transurânicos e a concentração de atividade de ${ }^{239} \mathrm{Pu}$. Considera-se o Fator de Escala para ${ }^{239} \mathrm{Pu}$ com ${ }^{144} \mathrm{Ce}$, fundamento dessa sistemática, como a correlação entre radionuclídeos mais bem estudada (EPRI, 1996; TADDEI, 2013).

Entretanto, não foi possível utilizar essa sistemática nos trabalhos utilizando amostras de filtro, carvão ativado e resina de troca iônica, pois a meiavida relativamente curta do ${ }^{144} \mathrm{Ce}(\mathrm{T} 1 / 2=284,9$ dias $)$ tornou inviável empregá-lo como Radionuclídeo Chave (RC) alternativo para caracterizar os rejeitos radioativos armazenados há no mínimo 10 anos no IPEN/CNEN-SP (TADDEI, 2013).

Nos rejeitos radioativos estudados, não foram obtidos Fator de Escala, para ${ }^{241} \mathrm{Pu} /{ }^{60} \mathrm{Co}$ e ${ }^{241} \mathrm{Pu} /{ }^{108 \mathrm{~m}} \mathrm{Ag}$. 


\section{CONCLUSÕES}

Diante do estudo realizado, foi possível finalizar os experimentos e com os resultados obtidos, pode-se concluir que:

Após vários testes, foi possível estabelecer um método de solubilização para o filtro, ele possui características hidrofóbicas e não é solúvel em nenhum tipo de ácido, sendo ele submetido a aquecimento ou agitação. No entanto, ele é calcinável, o que tornou possível a solubilização, após dias em chapa aquecedora com adição de ácidos.

Em relação à avaliação do grau de homogeneidade dos filtros, de acordo com a IAEA (2007), pode-se afirmar que os filtros possuem distribuição homogênea somente se os valores de escore-Z estiverem dentro do intervalo relativo de $30 \%$. Diante dos resultados apresentados nos gráficos, ainda que 3 dos 8 filtros, sejam classificados como heterogêneos. Vale ressaltar que esses 3 filtros são aqueles que possuem massa inferior, não estejam dentro dos limites de aceitação, pode-se afirmar que os filtros apresentam distribuição homogênea de atividade.

Foi desenvolvida uma metodologia para a caracterização radioisotópica dos filtros utilizados no processo de purificação da água do circuito primário do reator IEA-R1, por meio de técnicas radioanalíticas de separação, que envolvem a separação dos radionuclídeos por troca iônica e extração cromatográfica.

Foram determinados, a partir de dados analíticos, a correlação existente entre os RDM e RCs selecionados, visando a avaliação do inventário radioisotópico do termo fonte para um repositório. Para determinação dos RDM, foram utilizados métodos de separação radioquímica com resinas cromatográficas específicas e posterior quantificação por espectrometria alfa e beta.

Foram obtidos FEs para os RDMs, com exceção do ${ }^{241} \mathrm{Pu}$, o que significa que nas próximas análises dos RDMs em amostras de filtro, não será necessário fazer a separação radioquímica, com o cálculo do FE será possível obter a atividade de cada amostra, o que reduzirá significativamente o tempo gasto com a parte experimental.

$\mathrm{O}{ }^{241} \mathrm{Pu}$ é o único radionuclídeo que não possui fator de escala com ${ }^{60} \mathrm{Co}$ e ${ }^{108 m} \mathrm{Ag}$ para as amostras de filtro.

Não foi encontrado ${ }^{137} \mathrm{Cs}$ nas amostras de filtro, o que corrobora com os resultados obtidos por TADDEI (2013), que confirmou que todo césio contido na 
água passou pelo filtro e ficou retido no carvão e na resina por adsorção e troca iônica, respectivamente, desta forma, não há ${ }^{137} \mathrm{Cs}$ nos filtros.

De acordo com as atividades obtidas, podemos concluir que 0 radionuclídeo com maior atividade média por filtro é o ${ }^{60} \mathrm{Co}$, da ordem de $0,53 \mathrm{MBq}$, na sequência o ${ }^{63} \mathrm{Ni},{ }^{108 \mathrm{~m}} \mathrm{Ag},{ }^{110 \mathrm{~m}} \mathrm{Ag}$ e ${ }^{241} \mathrm{Pu}$ da ordem de $3,84 \times 10^{4} ; 6,72 \times 10^{4}$; $7,10 \times 10^{4} ; 4,36 \times 10^{4} \mathrm{~Bq}$, respectivamente.

Os demais apresentaram atividades média de ${ }^{90} \mathrm{Sr},{ }^{239+240} \mathrm{Pu},{ }^{238} \mathrm{Pu}$ e ${ }^{241} \mathrm{Am}$ de $8,57 \times 10^{2} ; 1,08 \times 10^{2} ; 3,22 \times 10$ e 6,11 x $10 \mathrm{~Bq}$, respectivamente.

Os isótopos de $\mathrm{U}$ e $\mathrm{Cm}$ apresentaram valores de atividades baixos, alguns até mesmo menor que o MDA, ${ }^{234} \mathrm{U}\left(6,84 \times 10^{-1} \mathrm{~Bq}\right),{ }^{235} \mathrm{U}\left(3,46 \times 10^{-2} \mathrm{~Bq}\right)$, ${ }^{238} \mathrm{U}\left(2,68 \times 10^{-1} \mathrm{~Bq}\right),{ }^{242} \mathrm{Cm}\left(2,69 \times 10^{-1} \mathrm{~Bq}\right)$ e ${ }^{243+244} \mathrm{Cm}\left(0,11 \times 10^{-1} \mathrm{~Bq}\right)$. Os rendimentos químicos médio para cada radionuclídeo variaram de: ${ }^{63} \mathrm{Ni}(70$ a $97 \%)$, U (79 a 96\%), Pu (62 a 74\%) e Am e Cm (65 a 83\%). 


\section{REFERÊNCIAS BIBLIOGRÁFICAS}

ADYA, V. C.; SENGUPTA, A.; DHAWALE, B. A.; RAJESWARI, B.; THULASIDAS, S. K.; GODBOLE, S. V. Recovery of americium from analytical solid waste containing large amounts of uranium, plutonium and silver. J. Radioanal. Nucl. Chem., v. 291, p. 843-848, 2012.

AGEYEV, V. A.; ODINTSOV, O. O.; SAJENIOUK, A. D. Routine radiochemical method for the determination of ${ }^{90} \mathrm{Sr},{ }^{238} \mathrm{Pu},{ }^{239+240} \mathrm{Pu},{ }^{241} \mathrm{Am}$ and ${ }^{244} \mathrm{Cm}$ in environmental samples. J. Radioanal. Nucl. Chem., v. 264, n. 2, p. 337-342, 2005.

AMPHLETT, C. B. Treatment and disposal of radioactive wastes. International series of monographs on nuclear energy. Division V, v. 2, Pergamon Press, London, 1961.

BERG, J.F., FONNESBECK, J.E. Determination of ${ }^{14} \mathrm{C}$ in activated metal waste. Analytica Chimica Acta, v. 447, p. 191-197, 2001.

CANBERRA Industries. "espectrometria alfa." Disponível em: <http://www.canberra.com/products/696.asp> Acesso em: 04 nov. 2016.

CHEN, Q.; DAHLGAARD, H.; NIELSEN, S. P.; AARKROG, A. ${ }^{242} \mathrm{Pu}$ as tracer for radionuclides in soil samples. J. Radioanal. Nucl. Chem., v. 226, n. 1 e 2, p. 279-284, 1997.

CHEN, Q.; DAHLGAARD, H.; NIELSEN, S. P.; AARKROG, A. ${ }^{242} \mathrm{Pu}$ as tracer for simultaneous determination of ${ }^{237} \mathrm{~Np}$ and ${ }^{239,240} \mathrm{Pu}$ in environmental samples. J. Radioanal. Nucl. Chem., v. 253, n. 3, p. 451-458, 2002.

COMISSÃO NACIONAL DE ENERGIA NUCLEAR. Gerência de Rejeitos Radioativos de Baixo e Médio Níveis de radiação. Brasil, 2014a (CNEN- NN- 8.01).

COMISSÃO NACIONAL DE ENERGIA NUCLEAR. Licenciamento de depósitos de rejeitos radioativos de baixo e médio níveis de radiação. Brasil, 2014b (CNEN-NN-8.02).

COMISSÃO NACIONAL DE ENERGIA NUCLEAR. Glossário de Segurança Nuclear. Rio de Janeiro, Brasil, 2015.

COSTA, P. Desenvolvimento de uma metodologia para caracterização do filtro cuno do reator IEA-R1 utilizando o método de Monte Carlo. Dissertação de Mestrado - Instituto de Pesquisas Energéticas e Nucleares - IPEN/CNEN-SP, São Paulo, 2014.

DORFNER, K. Ion exchangers: Properties and applications. Ann Arbor: Ann Arbor Science Publishers, 1972.

DULANSKÁ, S.; REMENEC, B.; DURKOT, E.; GALANDA, D.; MÁTEL, L. Determination of ${ }^{239,240} \mathrm{Pu},{ }^{238} \mathrm{Pu}$ isotopes in soil samples using molecular 
recognition technology product AnaLig Pu-02 gel. J. Radioanal. Nucl. Chem., v. 293, p. $847-850,2012 a$.

DULANSKÁ, S.; REMENEC, B.; MÁTEL, L.; DURKOT, E. Rapid determination of ${ }^{239,240} \mathrm{Pu},{ }^{238} \mathrm{Pu},{ }^{241} \mathrm{Am}$ and ${ }^{90} \mathrm{Sr}$ in radioactive waste using combined SPE sorbents AnaLig Pu-02, AnaLig Sr-01 and TRU Resin. J. Radioanal. Nucl. Chem., v. 293, p. 81-85, 2012b.

EICHROM TECHNOLOGIES INC. Americium, neptunium, plutonium, thorium, curium, uranium and strontium in water (with vacuum box system). Analytical procedures ACW 17 VBS Rev. 1.0, p. 1-17, Lisle IL, 2006.

EICHROM TECHNOLOGIES INC. "Extração cromatográfica." Disponível em: <http://www.eichrom.com/products> Acesso em: 04 nov. 2017.

ELECTRIC POWER RESEARCH INSTITUTE - EPRI. Low Level Waste Characterization Guidelines. Palo Alto, CA. TR-107201, 1996.

ELECTRIC POWER RESEARCH INSTITUTE - EPRI. Utility Use of Constant Scaling Factors. Palo Alto, CA. TR-109448, 1999.

FERNANDO, K., WONG, R., TAYLOR, B. Validation of gamma spectroscopy systems for free release measurements. LABONET 2013 - Annual meeting of the international network of laboratories for nuclear waste characterization - Vienna, Áustria, December, 10 to 12, 2013.

GLEIZES, M., COTE, G., LARIVIÈRE, D. A rapid sequential separation of actinides and radiostrontium coupled to ICP-MS and gas proportional counting. Journal of Radioanalytical and Nuclear Chemistry, v. 310, p. 217-227, 2016.

GRAHEK, Z.; NODILO, M. Continuous separation of Sr, Y and some actinides by mixed solvent anion exchange and determination of ${ }^{89,90} \mathrm{Sr},{ }^{238,239} \mathrm{Pu}$ and ${ }^{241} \mathrm{Am}$ in soil and vegetation samples. J. Radioanal. Nucl. Chem., v. 293, n. 3, p. 815-827, 2012.

GASCÓN, J. L.; ACENA, M. L.; SUÁREZ, J. A.; RODRIGUÉZ, M. Radiochemical methods for the determination of plutonium, americium and curium in typical waste streams. J. Alloys and Compounds., v. 213 e 214, p. 557-559, 1994.

HABIBI, A.; VIVIEN, C.; BOULET, B.; COSSONNET, C.; GURRIARAN, R.; GLEIZES, M.; COTE, G.; LARIVIĖRE, D. A rapid sequential separation of actinides and radiostrontium coupled to ICP-MS and gas proportional counting. J Radioanal Nucl Chem., v. 310, p. 217-227, 2016.

HIROMOTO, G.; DELLAMANO, J. C.; MARUMO, J. T.; ENDO, L. S.; VICENTE, R.; HIRAYAMA, T. Introdução à gerência de rejeitos radioativos. São Paulo: Instituto de Pesquisas Energéticas e Nucleares, Departamento de Rejeitos Radioativos, 1999. 
HORWITZ, E. P.; CHIARIZIA, R. M.; DIETZ, M. L.; DIAMOND, H.; NELSON, D. Separation and pre-concentration of actinides by extraction chromatography using a supported liquid anion exchanger: Application to the characterization of high-level nuclear waste solutions. Analytica Chemica Acta, v. 281, p. 361-372, 1993.

HORWITZ, E. P.; DIETZ, M. L.; CHIARIZIA, R. M.; DIAMOND, H.; MAXWELL, S. L.; NELSON, M. R. Separation and pre-concentration of actinides by extraction chromatography using a supported liquid anion exchanger: Application to the characterization of high-level nuclear waste solutions. Analytica Chimica Acta, v. 310, p. 63-78, 1995.

HORWITZ, E.P. Extraction Chromatography of Actinides and Selected Fission Products: Principles and Achievement of Selectivity. International Workshop on the Application of Extraction Chromatography in Radionuclide Measurement (IRMM 1996), Geel, Belgium, 9-10 November/1996.

HOU, X., OSTERGAARD, L.F., NIELSEN, S.P. Determination of ${ }^{63} \mathrm{Ni}$ and ${ }^{55} \mathrm{Fe}$ in nuclear wastes samples using radiochemical separation and liquid scintillation counting. Analytica Chimica Acta, v. 535, p. 297- 307, 2005.

$\mathrm{HOU}, \mathrm{X}$. Rapid analysis of ${ }^{14} \mathrm{C}$ and ${ }^{3} \mathrm{H}$ in graphite and concrete for decommissioning of nuclear reactor. Applied Radiation and Isotopes, v. 62, p. 871-882, 2005.

IKÄHEIMONEN, T.K. Measurement of ${ }^{241} \mathrm{Pu}$ in environmental samples. Journal of Radioanalytical and Nuclear Chemistry, v. 243, p. 535-541, 2000.

INSTITUTO DE PESQUISAS ENERGÉTICAS E NUCLEARES. (Folheto fornecido aos visitantes para visitas técnicas). Reator IEA-R1. Divisão de Comunicação Social, IPEN. São Paulo, 2002.

INSTITUTO DE PESQUISAS ENERGÉTICAS E NUCLEARES. Reator IEA-R1. Disponível em: https://www.ipen.br/portal_por/portal/interna.php?secao_id=729 Acesso em: 13 mar. 2012.

INTERNATIONAL ATOMIC ENERGY AGENCY - IAEA. Conditioning of low-and intermediate-level radioactive wastes. Vienna, 1983a (TECDOC, 222).

INTERNATIONAL ATOMIC ENERGY AGENCY - IAEA. Handling and storage of conditioned high-level wastes. Vienna, 1983b (TECDOC, 229).

INTERNATIONAL ATOMIC ENERGY AGENCY - IAEA. Treatment of low-and intermediate-level liquid radioactive wastes. Vienna, 1984 (TECDOC, 236).

INTERNATIONAL ATOMIC ENERGY AGENCY - IAEA. Radioactive waste management - An IAEA source book. Vienna, 1992.

INTERNATIONAL ATOMIC ENERGY AGENCY - IAEA. Characterization of Radioactive Waste Forms and Packages. IAEA Technical Reports Series No 383, Vienna, 1997. 
INTERNATIONAL ATOMIC ENERGY AGENCY - IAEA. Predisposal Management of Low and Intermediate Level Radioactive Waste, IAEA Safety Standards Series No. WS-G-2.5, IAEA, Vienna (2003).

INTERNATIONAL ATOMIC ENERGY AGENCY - IAEA. Strategy and Methodology for Radioactive Waste Characterization. IAEA - TECDOC-1537, Vienna, 2007.

INTERNATIONAL ATOMIC ENERGY AGENCY - IAEA. Determination and Use of Scaling Factors for Waste Characterization in Nuclear Power Plants. IAEA Nuclear Energy Series No. NW-T-1.18, Vienna, 2009.

INTERNATIONAL ORGANIZATION FOR STANDARDIZATION - ISO. Nuclear energy - Nuclear fuel technology - Scaling factor method to determine the radioactivity of low - and intermediate - level radioactive waste packages generated at nuclear power plants. ISO 21238:2007(E), 2007.

ISIKI, V. L. K. Avaliação do cimento Portland como matriz de imobilização de carvão ativo proveniente do reator de pesquisas do IPEN-CNEN/SP. Dissertação (Acadêmica) - Faculdades Oswaldo Cruz, São Paulo, 2003.

KASTNER, G. F.; FERREIRA, A. V.; MIRAGLIA, F. G.; SILVA, A. J. A.; MONTEIRO, R. P. G. Determinação de ${ }^{235} \mathrm{U}$ e ${ }^{238} \mathrm{U}$ em rejeitos de atividades baixas e médias provenientes de centrais nucleares de potência. Revista Brasileira de Ciências Ambientais, n. 16, p. 1-5, 2010.

$\mathrm{KEKKI}, \mathrm{T}$.; TIITTA, A. Evaluation of the radioactive waste characterization at the Olkiluoto nuclear power plant. STUK-YTO-TR 162. Radiation and Nuclear Safety Authority - Helsinki, FI, March, 2000.

$\mathrm{KORKISCH}$, J. Modern methods for the separation of rarer metals. New York: Pergamon Press, 1969.

$\mathrm{KORKISCH}$, J. Handbook of Ion exchange resins: Their applicability to inorganic analytical chemistry. Florida: CRC Press. v. I and II, 1989.

LA ROSA, J. J.; COOPER, E. L.; GHODS-ESPHAHANI, A.; JANSTA, V.; MAKAREWICZ, M.; SHAWKY, S.; VAJDA, N. Radiochemical methods used by the IAEA's laboratories at Seibersdorf for the determination of ${ }^{90} \mathrm{Sr},{ }^{144} \mathrm{Ce}$ and $\mathrm{Pu}$ radionuclides in environmental samples collected for the international Chernobyl project. Journal of Environmental Radioactivity., v. 17, p. 183-209, 1992.

LEE, M. H.; JUNG, E. C.; KIM, W. H.; JEE, K. Y. Sequential separation of the actinides in environmental and radioactive waste samples. J. Alloys and Compounds., v. 444 e 445, p. 544-549, 2007.

LEE, S. H.; LA ROSA, J.; GASTAUD, J.; POVINEC, P. P. The development of sequential separation methods for the analysis of actinides in sediments and biological materials using anion-exchange resins and extraction chromatography. J. Radioanal. Nucl. Chem., v. 263, n. 2, p. 419-425, 2005. 
Longo, E. Comunicação pessoal, 2014.

MAGNUSSON, Å., STENSTRÖM, K., ARONSSON, P.-O. ${ }^{14} \mathrm{C}$ in spent ionexchange resins and process water from nuclear reactors: a method for quantitative determination of organic and inorganic fractions. Journal of Radioanalytical and Nuclear Chemistry, v. 275, p. 261-273, 2008.

MAXWELL, S. L. Rapid method for determination of plutonium, americium and curium in large soil samples. J. Radioanal. Nucl. Chem., v. 275, n. 2, p. 395-402, 2008.

MAXWELL, S. L.; CULLIGAN, B. K.; KELSEY-WALL, A.; SHAW, P. J. Rapid determination of actinides in emergency food samples. J. Radioanal. Nucl. Chem., v. 292, p. 339-347, 2012.

MELLADO, J.; LLAURADÓ, M.; RAURET, G. Determination of Pu, Am, U, Th and $\mathrm{Sr}$ in marine sediment by extraction chromatography. Anal. Chim. Acta., v. 443, p. 81-90, 2001.

MICHEL, H.; BARCI-FUNEL, G.; DALMASSO, J.; ARDISSON, G. One step ion exchange process for the radiochemical separation of americium, plutonium and neptunium in sediments. J. Radioanal. Nucl. Chem., v. 240, n. 2, p. 467-470, 1999.

MORENO, J.; VAJDA, N.; DANESI, P. R.; LAROSA, J. J.; ZEILLER, E.; SINOJMERI, M. Combined procedure for the determination of ${ }^{90} \mathrm{Sr},{ }^{241} \mathrm{Am}$ and $\mathrm{Pu}$ radionuclides in soil samples. J. Radioanal. Nucl. Chem., v. 226, n. 1 e 2, p. 279- 284, 1997.

MURALI, M. S.; BHATTACHARAYYA, A.; RAUT, D. R.; KAR, A. S.; TOMAR, B. S.; MANCHANDA, V. K. Characterization of high level waste for minor actinides by chemical separation and alpha spectrometry. J. Radioanal. Nucl. Chem., v. 294, n. 1, p. 149-153, 2011.

NIESE, S., BODEN, W. Scaling Factors for activated corrosion products in lowlevel-wastes from power reactors. Journal of Radioanalytical and Nuclear Chemistry, v. 198, p. 161-167, 1995.

NIESE, S., GLEISBERG, B. Determination of radioisotopes of $\mathrm{Ce}, \mathrm{Eu}, \mathrm{Pu}, \mathrm{Am}$ and $\mathrm{Cm}$ in low-level wastes from power reactors. Journal of Radioanalytical and Nuclear Chemistry, v. 200, p. 31-41, 1995.

NIESE, S., GLEISBERG, B. Determination of radioisotopes of $\mathrm{Ce}, \mathrm{Eu}, \mathrm{Pu}, \mathrm{Am}$ and $\mathrm{Cm}$ in low-level wastes from power reactors using low-level measuring techniques. Applied Radiation and Isotopes, v. 47, p. 1113-1114, 1996.

OJOVAN, M.; LEE, W. An Introduction to nuclear waste immobilization. Elsevier Science, 1st Edition, 2005. 
PAYNE, R. F.; CLARK, S. B.; ELLISTON, J. T. Radioanalytical approach to determine ${ }^{238} \mathrm{Pu},{ }^{239+240} \mathrm{Pu},{ }^{241} \mathrm{Pu}$ and ${ }^{241} \mathrm{Am}$ in soils. J. Radioanal. Nucl. Chem., v. 277 , n. 1, p. 269-274, 2008.

PERKIN-ELMER INC. Sample Oxidizer Model 307 - Operation Manual. Manual Reorder No. 1694057. Shelton CT, 2003.

PULHANI, V. A.; DAFAUTI, S.; HEGDE, A. G. Separation of uranium from iron in ground water samples using ion exchange resins. J. Radioanal. Nucl. Chem., DOI 10.1007/s10967-011-1582-0, 2011.

RADCHEM. Nordic Nuclear Safety Research. Radiochemical procedures for the determination of $\mathrm{Sr}, \mathrm{U}, \mathrm{Pu}, \mathrm{Am}$ and $\mathrm{Cm}$. NKS-124. ISBN 87-7893-185-1. Roskilde, 2006.

REIS JR., A. S.; TEMBA, E. S. C.; KASTNER, G. F.; MONTEIRO, R. P. G. Combined procedure using radiochemical separation of plutonium, americium and uranium radionuclides for alpha-spectrometry. J. Radioanal. Nucl. Chem., v. 287, p. 567-572, 2010.

REMEIKIS, V., PLUKIS, A., JUODIS, L., GUDELIS, A., LUKAUSKAS, D., DRUTEIKIENĖ, R., LUJANIENĖ, G., LUKŠIENĖ, B., PLUKIENĖ, R.,DUŠKESAS, G. Study of the nuclide inventory of operational radioactive waste for the RBMK- 1500 reactor. Nuclear Engineering and Design, v. 239, p. 813-818, 2009.

RODRÍGUEZ, M.; GASCÓN, J. L.; SUÁREZ, J. A. Study of the interferences in the determination of $\mathrm{Pu}, \mathrm{Am}$ and $\mathrm{Cm}$ in radioactive waste by extraction chromatography. Talanta., v. 45, p. 181-187, 1997.

ROSSKOPFOVÁ, O., GALAMBOŠ, M., RAJEC, P. Determination of ${ }^{63} \mathrm{Ni}$ in low level solid radioactive waste. Journal of Radioanalytical and Nuclear Chemistry, v. 289, p. 251-256, 2011.

SALMINEN, S. Development of analytical methods for the separation of plutonium, americium, curium and neptunium from environmental samples. Dissertação (Mestrado) - University of Helsinki, Finland, 2009.

SAMUELSON, $O$. Ion exchange separations in analytical chemistry. Stockholm: Almquist and Wiksell, v. 96, 5ª ed. New York, 1963.

SEABORG, T.G., LOVELAND, W.D. The Elements Beyond Uranium. John Wiley \& Sons Inc., New York, 1990.

SILVA, R. E.; ISIKI, V. L. K.; GOES, M. M.; POTIENS JR, A.; DELLAMANO, J. C.; VICENTE, $R$. Characterization of radioactive wastes-spent ion-exchange resins and charcoal filter beds. International Nuclear Atlantic Conference - INAC 2009. Rio de Janeiro, September, 27 to October 2, 2009. 
TADDEI, M. H. T.; MARUMO, J. T.; TERREMOTO, L. A. A.; VICENTE, R. Characterization of radioactive spent ion-exchange resins. WM 2011 Conference - Phoenix, AZ, February, 27 to March 3, 2011.

TADDEI, M. H. T.; VICENTE, R.; MARUMO, J. T.; SAKATA, S. K.; TERREMOTO, L. A. A. Determination of long-lived radionuclides in radioactive waste from the IEA-R1 nuclear research reactor. Journal of Radioanalytical and Nuclear Chemistry, v. 295, Issue 2, p. 951- 957, 2013a.

TADDEI, M. H. T. Determinação de Fatores de Escala para Estimativa do Inventário de Radionuclídeos em Rejeitos de Média e Baixa Atividades do Reator IEA-R1. Tese de Doutoramento - Instituto de Pesquisas Energéticas e Nucleares - IPEN/CNEN-SP, São Paulo, 2013b.

TADDEI, M.H.T., MACACINI, J.F., VICENTE, R., MARUMO, J.T., SAKATA, S.K., TERREMOTO, L.A.A. Determination of ${ }^{63} \mathrm{Ni}$ and ${ }^{59} \mathrm{Ni}$ in spent ion-exchange resin and activated charcoal from the IEA-R1 nuclear research reactor. Applied Radiation and Isotopes, v. 77, p. 50-55, $2013 \mathrm{c}$.

TADDEI, M.H.T.; MACACINI, J.F.; VICENTE, R.; MARUMO, J.T.; TERREMOTO; L.A.A. Determination of scaling factors to estimate the radionuclide inventory of wastes from the IEA-R1 research reactor. Journal of Radioanalytical and Nuclear Chemistry, v. 303, Issue 3, p. 2467-2481, 2015.

TAVCAR, P.; BENEDIK, L. Determination of actinides and ${ }^{90} \mathrm{Sr}$ in spent ion exchange resins. Radiochim. Acta., v. 93, p. 623-625, 2005.

TAVCAR, P.; SMODIS, B.; BENEDIK, L. Radiological characterization of low- and intermediate - level radioactive wastes. J. Radioanal. Nucl. Chem., v. 273, n. 3, p. 593-596, 2007.

TEMBA, C.S.E.; REIS Jr., S.A.; AMARAL, M.A., MONTEIRO, G.P.R. Separation and determination of ${ }^{90} \mathrm{Sr}$ in low and intermediate level radioactive wastes using extraction chromatography and LSC. Journal of Radioanalytical and Nuclear Chemistry, v. 290, p. 631-635, 2011.

TESSARO, A. P. G. Desenvolvimento de Métodos Radiométricos para a Caracterização de Rejeitos Radioativos. Dissertação de Mestrado - Instituto de Pesquisas Energéticas e Nucleares - IPEN/CNEN-SP, São Paulo, 2015.

TOLGYESI, S.; GRESITS, I.; PAST, T.; SZABÓ, L.; VOLENT, G.; PINTÉR, T. Determination of alpha-emitting isotopes in radioactive wastes of nuclear power plant paks. J. Radioanal. Nucl. Chem. v. 254, n. 2, p. 357-361, 2002.

US NUCLEAR REGULATORY COMMISSION. Licensing Requirements for Land Disposal of Radioactive Waste. Code of Federal Regulations, Title 10, Part 61, Federal Register, 47, p. 57446, December, 1982.

VAJDA, N.; KIM, C. K. Determination of ${ }^{241} \mathrm{Am}$ isotope: A review of analytical methodology. J. Radioanal. Nucl. Chem., v. 284, p. 341-366, 2010. 
INSTITUTO DE PESQUISAS ENERGÉTICAS E NUCLEARES

Diretoria de Pesquisa, Desenvolvimento e Ensino

Av. Prof. Lineu Prestes, 2242 - Cidade Universitária CEP: 05508-000

Fone/Fax(0XX11) 3133-8908

SÃO PAULO - São Paulo - Brasil

http://www.ipen.br

O IPEN é uma Autarquia vinculada à Secretaria de Desenvolvimento, associada à Universidade de São Paulo e gerida técnica e administrativamente pela

Comissão Nacional de Energia Nuclear, órgão do

Ministério da Ciência, Tecnologia, Inovações e Comunicações. 